Original article

\title{
Synthesis and biological evaluation of unsaturated keto and exomethylene D-arabinopyranonucleoside analogs: Novel 5-fluorouracil analogs that target thymidylate synthase
}

\author{
Niki Tzioumaki ${ }^{a}$, Stella Manta ${ }^{a}$, Evangelia Tsoukala ${ }^{a}$, Johan Vande Voorde ${ }^{b}$, Sandra Liekens ${ }^{b}$, \\ Dimitri Komiotis $^{\mathrm{a}, * *}$, Jan Balzarini ${ }^{\mathrm{b}, *}$ \\ ${ }^{a}$ Department of Biochemistry and Biotechnology, Laboratory of Organic Chemistry, University of Thessaly, 26 Ploutonos Str., 41221 Larissa, Greece \\ ${ }^{\mathrm{b}}$ Rega Institute for Medical Research, Katholieke Universiteit Leuven, Minderbroedersstraat 10, 3000 Leuven, Belgium
}

\section{A R T I C L E I N F O}

\section{Article history:}

Received 30 June 2010

Received in revised form

6 October 2010

Accepted 6 January 2011

Available online 22 January 2011

\section{Keywords:}

Unsaturated nucleosides

Chemotherapy

5-Fluorouracil prodrugs

Ketonucleosides

Antiviral

Cytotoxicity

\begin{abstract}
A B S T R A C T
The synthesis of pyrimidine unsaturated keto and exomethylene arabinopyranonucleoside analogs as potential antitumor and antiviral agents is described. Commercially available 1,2,3,4-tetra-O-acetylD-arabinopyranose (1) was condensed with silylated thymine, uracil, 5-fluorouracil, $N^{4}$-benzoyl cytosine and 5-(trifluoromethyl)uracil, respectively, deacetylated and acetylated to afford 1-(3,4-O-isopropylidene$\alpha$-D-arabinopyranosyl)pyrimidine analogs 4 . Two different synthetic routes were investigated for the conversion of compounds 4 into the new 1-(2,3,4-trideoxy-2-methylene- $\alpha$-pent-3-enopyranosyl)nucleoside derivatives of thymine (10a), uracil (10b), 5 -fluorouracil (10c) and $N^{4}$-benzoyl cytosine (10d). Only the first approach could afford derivative 10d. Debenzoylation of 10d afforded 1-(2,3,4-trideoxy-2-methylene$\alpha$-pent-3-enopyranosyl)cytosine (10f). The first approach resulted also to the 2-keto-3,4-unsaturated analogs 9. The new analogs did not show inhibition of DNA and RNA virus replication in cell culture. The 2 '-ketonucleoside derivatives 9 were found to be more cytostatic than the corresponding 2 '-exomethylene nucleosides 10. The 5-fluorouracil unsaturated keto derivative $\mathbf{9 c}$ and the exomethylene derivatives $\mathbf{1 0 c}$ and 13c showed antiproliferative activity in the lower micromolar range. Experimental evidence revealed that 9c, 10c and 13c may act as novel types of 5-fluorouracil releasing prodrugs, and points to thymidylate synthase as target for their cytostatic action.
\end{abstract}

(c) 2011 Elsevier Masson SAS. All rights reserved.

\section{Introduction}

Nucleosides and their analogs are considered as the cornerstone for the development of effective, selective and non-toxic antiviral and antitumor agents [1-6]. Extensive work has been conducted to search for new types of nucleosides with high biological activity, limited toxicity and less likely to develop drug resistance [7]. Over the past two decades, nucleoside/nucleotide chemistry has evolved to facilitate efficient routes to effective agents for the treatment of AIDS [3], herpes [2] and viral hepatitis [8].

Lately, nucleosides bearing a six-membered carbohydrate moiety have been evaluated for their potential antiviral [9-11],

\footnotetext{
* Corresponding author. Katholieke Universiteit Leuven, Department of Microbiology and Immunology, Rega Institute for Medical Research, Minderbroedersstraat 10, 3000 Leuven, Belgium. Tel.: +32 16 337341; fax: +32 16 337340.

** Corresponding author. Tel.: +30 2410 565285; fax: +30 2410565290 .

E-mail addresses: dkom@bio.uth.gr (D. Komiotis), jan.balzarini@rega.kuleuven. be (J. Balzarini).
}

antioxidant [12] and antibiotic [13] properties and mimic of natural building blocks in nucleic acid synthesis $[14,15]$. Modifications in the sugar residue of the aforementioned nucleosides furnished enzymatically stable nucleic acid analogs [16], which can be considered as bioisosteres of natural nucleosides and nucleotides, and can play a major role in different domains like therapy, diagnosis and biotechnology. The unsaturated keto and exocyclic methylene nucleosides are a series of sugar modified pyranonucleosides, whose biological importance has been extensively emphasized. These agents were found to exhibit interesting antitumor and antiviral properties [17-22], while a number of them proved to be key intermediates in synthetic and biosynthetic processes. In addition, their activity is clearly independent of the anomeric configuration, the axial or equatorial position of the heterocyclic base, and the L or D configuration of the sugar [19,23].

As part of our program to search for new antitumor and antiviral agents, we have previously synthesized a series of unsaturated keto [24-28] as well as exomethylene pyranonucleoside analogs [29,30], which proved to be efficient as tumor cell growth inhibitors. Our 
findings suggest that the presence of a primary hydroxyl and hydroxymethyl function does not seem to be critical for biological activity. This was clearly evident since early synthesized 6'-protected and hydroxymethyl-lacking analogs [31] were very effective cytotoxic agents.

Taking into consideration these interesting results, the aim of the present study is to synthesize a series of new hydroxymethyl-lacking pyrimidine nucleoside analogs in order to further investigate the structural features of the sugar and base moieties. Therefore, we report herein an efficient synthesis of $3^{\prime}, 4^{\prime}$-unsaturated $2^{\prime}$-keto and -exomethylene arabinonucleoside analogs, containing thymine, uracil, 5-fluorouracil, $N^{4}$-benzoyl cytosine, 5-(trifluoromethyl)uracil and cytosine as base moiety and the evaluation of their biological properties. Given the fact that for each series of compounds, the 5-fluorouracil nucleoside analogs were most cytostatic, thymidylate synthase (TS) could be considered as a potential target enzyme. TS converts $2^{\prime}$-deoxyuridylate (dUMP) to thymidylate (dTMP) and represents the only de novo pathway for the tumor cell to generate thymine nucleotide building blocks for DNA synthesis. It is well known that 5-fluorouracil (5-FU), after metabolic conversion by several enzymes of the pyrimidine nucleotide metabolism pathways is a potent inhibitor of TS as its 5-fluoro-2'-dUMP derivative. It can also be incorporated into DNA [through its 5-fluoro-2'-deoxyuridine-5'-triphosphate (FdUTP) derivative] and may also disrupt RNA synthesis [through its 5-fluoro-uridine-5'-triphosphate (FUTP) derivative] (Scheme 1) [32]. We could demonstrate that the unsaturated keto and exomethylene D-arabinopyranonucleoside analogs of 5-fluorouracil likely represent novel prodrugs of 5-FU and target (at least partially) TS to exert their cytostatic action.

\section{Results and discussion}

\subsection{Synthesis}

The starting materials, 1-(2,3,4-tri-O-acetyl- $\alpha$-D-arabinopyranosyl)nucleosides of thymine (2a), uracil (2b), 5-fluorouracil (2c), $N^{4}$-benzoyl cytosine (2d) and 5-(trifluoromethyl)uracil (2e) were obtained by condensing commercially available 1,2,3,4-tetra$O$-acetyl-D-arabinopyranose (1) with silylated thymine, uracil, 5fluorouracil, $N^{4}$-benzoyl cytosine and 5-(trifluoromethyl)uracil, respectively, in the presence of trimethylsilyl trifluoromethane-

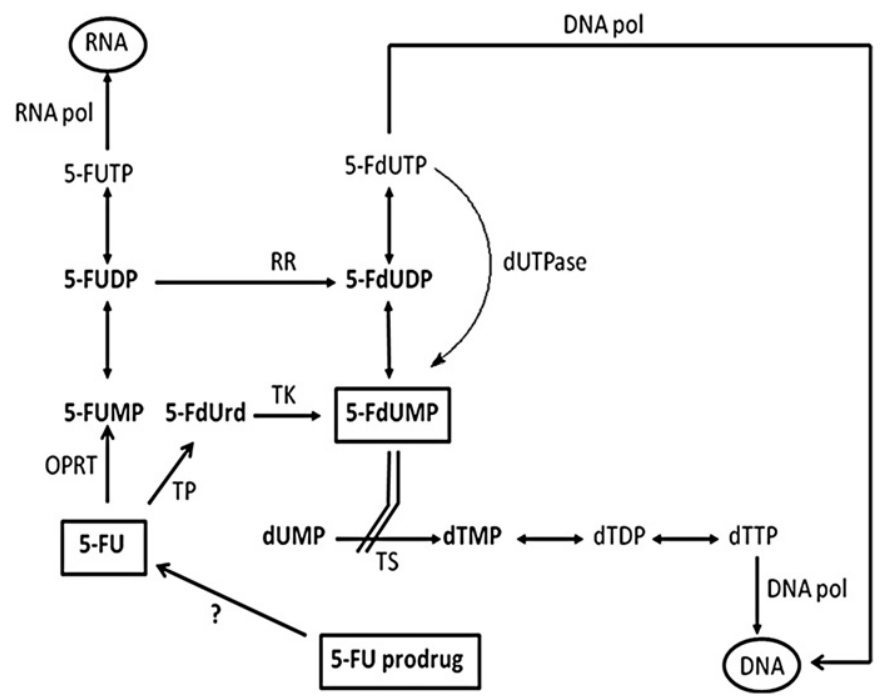

Scheme 1. Metabolic pathways to convert 5-FU to its active metabolites. OPRT: Orotate phosphoribosyltransferase, TK: thymidine kinase, TS: thymidylate synthase, TP: thymidine phosphorylase, RR: ribonucleotide reductase, dUTPase: $2^{\prime}$-deoxyuridine-5'triphosphate hydrolase, RNA pol: RNA polymerase, DNA pol: DNA polymerase. sulfonate $\left(\mathrm{Me}_{3} \mathrm{SiOSO}_{2} \mathrm{CF}_{3}\right)$ or $\mathrm{SnCl}_{4}$, in refluxing 1,2-dichloroethane (1,2- $\mathrm{EtCl}_{2}$ ) or acetonitrile (Scheme 2) [33]. Removal of all $O$-acetyl protecting groups of $\mathbf{2}(\mathbf{a}-\mathbf{c}, \mathbf{e})$ with saturated methanolic ammonia [34], gave compounds $\mathbf{3}(\mathbf{a}-\mathbf{c}, \mathbf{e})$, in excellent yields. Selective deprotection of $\mathbf{2 d}$ using sodium hydroxide/ethanol/pyridine gave benzoylated derivative 3d, in quantitative yield [35]. However, when compound $\mathbf{2 d}$ was treated with methanolic ammonia the fully unprotected nucleoside was obtained. Specific acetylation of 3 (a-e) using 2,2-dimethoxypropane [34] in acetone led to the $3^{\prime}, 4^{\prime}$ $O$-isopropylidene derivatives $\mathbf{4}(\mathbf{a}-\mathbf{e})$, respectively.

In order to elucidate the influence of keto and exomethylene moiety on the biological activity of the target molecules, two different synthetic routes were investigated for the conversion of compounds $\mathbf{4}$ into the desired olefinic derivatives $\mathbf{1 0}$. Only the first approach resulted to keto unsaturated derivatives $\mathbf{9}$ and afforded cytosine nucleoside 10d, while the second one led to saturated exomethylene analogs 13 . Therefore, in the first approach, acetylation of $\mathbf{4}(\mathbf{a}-\mathbf{e})$ using acetic anhydride $\left(\mathrm{Ac}_{2} \mathrm{O}\right)$ in pyridine followed by deisopropylidenation of the resulted derivatives $\mathbf{5}(\mathbf{a}-\mathbf{e})$, in $\mathrm{CH}_{2} \mathrm{Cl}_{2} / \mathrm{HCOOH}, 1: 1$, led to the vicinal diol derivatives $\mathbf{6}(\mathbf{a}-\mathbf{e})$, in high yields (79-95\%). Olefination of $\mathbf{6}(\mathbf{a}-\mathbf{e})$ with iodoform- $\mathrm{Ph}_{3} \mathrm{P}-$ imidazole [36-38] afforded 1-(2-O-acetyl-3,4-dideoxy- $\alpha$-D-glycero-pent-3-enopyranosyl)nucleosides of thymine (7a) in $65 \%$ yield, uracil (7b) in $66 \%$ yield, 5 -fluorouracil (7c) in 56\% yield, $N^{4}$-benzoyl cytosine (7d) in 61\% yield and 5-(trifluoromethyl)uracil (7e) in 65\% yield. Deacetylation of $\mathbf{7}(\mathbf{a}-\mathbf{c}, \mathbf{e})$ with saturated methanolic ammonia [34] and of 7d with sodium hydroxide/ethanol/pyridine [35], gave $\mathbf{8}(\mathbf{a}-\mathbf{c}, \mathbf{e})$ and $\mathbf{8 d}$, respectively, which after oxidation of the free hydroxyl group in the 2 -position of the sugar moiety with pyridinium dichromate (PDC)/ $\mathrm{Ac}_{2} \mathrm{O}$ [39], were converted to the desired unsaturated 2'-ketonucleosides $\mathbf{9}(\mathbf{a}-\mathbf{e})$. Wittig condensation of the keto intermediates $\mathbf{9}(\mathbf{a}-\mathbf{d})$, with $\mathrm{NaH}$ and methyl triphenylphosphonium bromide $\left(\mathrm{Ph}_{3} \mathrm{PCH}_{3} \mathrm{Br}\right)$ in the presence of $t$-amyl alcohol [40] in tetrahydrofuran (THF), afforded the exomethylene derivatives 10(a-d), respectively. Debenzoylation of 10d was performed with saturated methanolic ammonia to afford the desired unsaturated 2'-exomethylene cytosine derivative $\mathbf{1 0 f}$.

In the second approach, oxidation of the free hydroxyl group with $\mathrm{PDC} / \mathrm{Ac}_{2} \mathrm{O}$ [39] led to the formation of the desired 2 '-ketonucleosides $\mathbf{1 1}(\mathbf{a}-\mathbf{d})$. Wittig reaction of the obtained ketonucleosides $11(\mathbf{a}-\mathbf{d})$ resulted in $\mathbf{1 2}(\mathbf{a}-\mathbf{d})$, respectively. Deisopropylidenation of the resulted exomethylene compounds $\mathbf{1 2}(\mathbf{a}-\mathbf{c})$ in $\mathrm{CH}_{2} \mathrm{Cl}_{2} / \mathrm{HCOOH}, 1: 1$, led to the vicinal diol nucleosides $\mathbf{1 3}(\mathbf{a}-\mathbf{c})$, respectively. It is noteworthy that treatment of the isopropylidene derivative 12d with a mixture of $\mathrm{CH}_{2} \mathrm{Cl}_{2}$ and $\mathrm{HCOOH}, 1: 1$, or $90 \%$ trifluoroacetic acid (TFA) in $\mathrm{MeOH}$, or pyridinium p-toluenesulfonate (PPTS) in $\mathrm{MeOH}$ [41], or Amberlite IR $120 \mathrm{H}^{+}$resin in $\mathrm{MeOH}$ [42], or $50 \% \mathrm{CH}_{3} \mathrm{COOH}$ in $\mathrm{H}_{2} \mathrm{O}$ [34], unfortunately did not afford the desired 1-(2-deoxy-2-methylene- $\alpha$-D-erythro-pentopyranosyl)- $N^{4}$-benzoyl cytosine, but it led instead to intractable materials. Olefination of $13(\mathbf{a}-\mathbf{c})$ with iodine$\mathrm{Ph}_{3} \mathrm{P}$-imidazole [43-46] afforded 1-(2,3,4-trideoxy-2-methylene$\alpha$-pent-3-enopyranosyl)nucleosides of thymine (10a) in 57\% yield, uracil (10b) in 53\% yield, and 5-fluorouracil (10c) in 53\% yield.

Compounds $\mathbf{9}(\mathbf{a}-\mathbf{e}), \mathbf{1 0}(\mathbf{a}-\mathbf{d}, \mathbf{f})$ and $13(\mathbf{a}-\mathbf{c})$ were evaluated for their antiviral and cytostatic properties.

\subsection{Biological activity}

Whereas none of the compounds showed appreciable antiviral activity at subtoxic concentrations against a broad variety of DNA and RNA viruses (data not shown), there were striking differences in their cytostatic potential. In general, the unsaturated 2 '-ketonucleosides $\mathbf{9}$ showed a more pronounced cytostatic activity than the 2'-exomethylene nucleosides 10 and 13 (Table 1 ). In all structural groups of compounds, the nucleosides carrying the 5-fluorouracil 


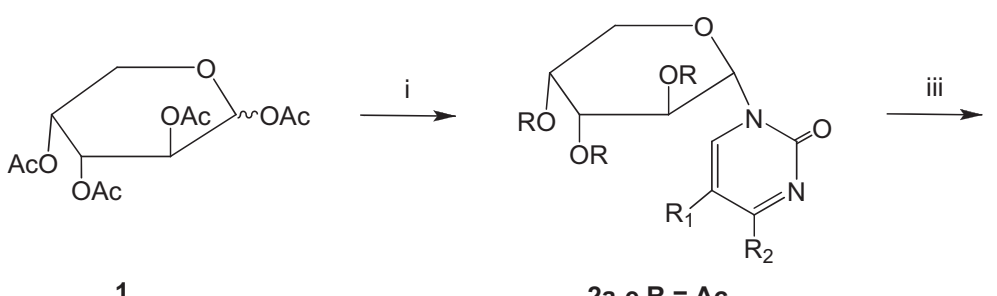<smiles>[R]c1cn(C2OCC3OC(C)(C)OC2C3O)c(=O)nc1[R]</smiles><smiles>[R]c1cn(C2OCC3CC(CC(C)O3)C2O)c(=O)nc1[R2]</smiles>

6a-e<smiles>[Y][V]</smiles><smiles>[R]OC1C=CCOC1n1cc([R])c([R2])nc1=O</smiles><smiles>[R][R][Ba][Ba][Ba][Ca]</smiles>

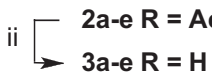<smiles>[R]c1cn(C2OCC3OC(C)(C)OC2C3O[CH])c(=O)nc1[R]</smiles>

5a-e<smiles>[R]c1cn(C2OCC=CC2=O)c(=O)nc1[R]</smiles>

9a-e

viii<smiles>[R]c1cn(C2OCC=CC2=C)c(=O)nc1[R]</smiles>

10a-c, $\left.\begin{array}{r}10 \mathrm{~d} \\ 10 \mathrm{f}<\end{array}\right]$ ii 4a-e

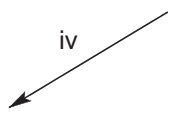

vii<smiles>[R]c1cn(C2OCC3OC(C)(C)OC2C3=O)c(=O)nc1[R]</smiles>

$11 a-d$<smiles>[R]c1cn(C2OCC3OC(C)(C)OC2C3=C)c(=O)nc1[R]</smiles>

12a-d

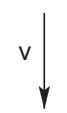

ix<smiles></smiles>

13a-c a: $\mathbf{R}_{1}=\mathrm{CH}_{3}, \mathrm{R}_{2}=\mathrm{OH}(\mathrm{Thy})$
b: $\mathbf{R}_{1}=\mathrm{H}, \mathrm{R}_{2}=\mathrm{OH}(\mathrm{U})$

c: $R_{1}=F, R_{2}=O H(5-F U)$

d: $R_{1}=H, R_{2}=\operatorname{NHCOPh}\left(N^{4}-B z C y t\right)$

e: $R_{1}=C_{3}, R_{2}=\mathrm{OH}\left(5-C_{3} \mathrm{U}\right)$

f: $R_{1}=H, R_{2}=N_{2}$ (Cyt)

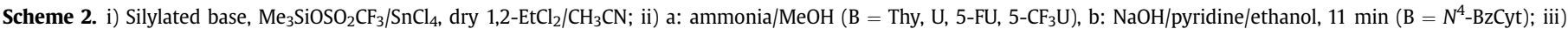

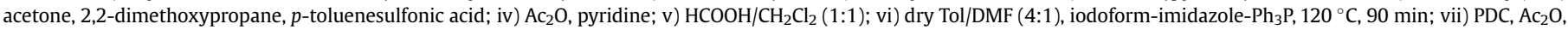
dry $\mathrm{CH}_{2} \mathrm{Cl}_{2}$; viii) $\mathrm{Ph}_{3} \mathrm{PCH}_{3} \mathrm{Br}$, NaH, $t$-amyl alcohol in THF, $0-25^{\circ} \mathrm{C}$; ix) dry Tol/DMF (4:1), iodine-imidazole- $\mathrm{Ph}_{3} \mathrm{P}, 80{ }^{\circ} \mathrm{C}, 15 \mathrm{~min}$.

base were far more cytostatic against the tumor cell lines than the corresponding thymine-, uracil-, cytosine-, $N^{4}$-benzoyl cytosineand 5-(trifluoromethyl)uracil-carrying derivatives. With the exception of the human T-lymphocyte CEM cells that were inhibited by the 5 -fluorouracil derivatives at higher micromolar concentrations, the murine leukemia L1210, the murine mammary carcinoma FM3A, and the human cervix carcinoma HeLa cells were inhibited in their proliferation by compounds $9 \mathbf{c}, \mathbf{1 0 c}$ and $\mathbf{1 3 c}$ at concentrations that were in the lower micromolar range. The reference compound 5 -FU was only $\sim 1.5$ - to 2.5 -fold more cytostatic than compound $\mathbf{9 c}$.
Interestingly, there was a strong correlation between the cytostatic activity of the individual compounds against the different tumor cell lines. The correlation coefficient $\left(\mathrm{R}^{2}\right)$ values for the $\mathrm{IC}_{50}$ values were 0.942 between L1210 and FM3A (both murine cell lines, 2-day assay), 0.833 between CEM and HeLa (both human cell lines, 3-day assay), 0.976 between murine leukemia L1210 (2-day assay) and human lymphocyte CEM (3-day assay), 0.878 between murine L1210 (2-day assay) and human HeLa (3-day assay) and 0.845 between murine carcinoma FM3A (2-day assay) and human carcinoma HeLa (3-day assay) cells. Thus, irrespective of the time period of incubation, 
Table 1

Cytostatic activity of test compounds.

\begin{tabular}{lllll}
\hline Compound & $\mathrm{IC}_{50}{ }^{\mathrm{a}}(\mu \mathrm{M})$ & & & \\
\cline { 2 - 5 } & $\mathrm{L} 1210$ & $\mathrm{FM} 3 \mathrm{~A}$ & $\mathrm{CEM}$ & HeLa \\
\hline 9a & $34 \pm 23$ & $77 \pm 32$ & $104 \pm 104$ & $34 \pm 37$ \\
$\mathbf{9 b}$ & $92 \pm 5$ & $121 \pm 44$ & $82 \pm 14$ & $42 \pm 29$ \\
$\mathbf{9 c}$ & $1.3 \pm 1.2$ & $0.23 \pm 0.07$ & $17 \pm 2$ & $1.4 \pm 0.6$ \\
$\mathbf{9 d}$ & $28 \pm 20$ & $62 \pm 34$ & $46 \pm 41$ & $72 \pm 5$ \\
9e & $23 \pm 12$ & $46 \pm 2$ & $39 \pm 6$ & $34 \pm 3$ \\
$\mathbf{1 0 a}$ & $486 \pm 60$ & $\geq 900$ & $504 \pm 5$ & $339 \pm 46$ \\
$\mathbf{1 0 b}$ & $549 \pm 83$ & $>1000$ & $450 \pm 39$ & $760 \pm 122$ \\
$\mathbf{1 0 c}$ & $8.6 \pm 3.1$ & $2.4 \pm 0.1$ & $85 \pm 4$ & $3.5 \pm 0.7$ \\
$\mathbf{1 0 d}$ & $368 \pm 68$ & $379 \pm 5$ & $432 \pm 0$ & $296 \pm 58$ \\
$\mathbf{1 0 f}$ & $1386 \pm 594$ & $\geq 1800$ & $1550 \pm 351$ & $990 \pm 117$ \\
$\mathbf{1 3 a}$ & $610 \pm 251$ & $775 \pm 16$ & $\geq 800$ & $\geq 800$ \\
$\mathbf{1 3 b}$ & $>800$ & $>800$ & $>800$ & $\geq 800$ \\
13c & $21 \pm 4$ & $1.9 \pm 0.4$ & $97 \pm 4$ & $18 \pm 4$ \\
5 -FU & $0.56 \pm 0.31$ & $0.18 \pm 0.02$ & $14 \pm 2$ & $0.57 \pm 0.23$ \\
\hline 5. & &
\end{tabular}

a $50 \%$ Inhibitory concentration required to inhibit tumor cell proliferation by $50 \%$. Data are the mean ( \pm S.D.) of at least 2 to 3 independent experiments. The murine leukemia L1210 and mammary carcinoma FM3A cells were grown for 2 days, and the human lymphocyte CEM and cervix carcinoma HeLa cells were grown for 3 days before the cytostatic activity of the test compounds was determined by tumor cell counting.

species origin or tissue origin, the cytostatic data correlated very well.

Since compounds $\mathbf{9}$ and $\mathbf{1 0}$ lack a free hydroxyl group for potential phosphorylation, it was tempting to assume, that these molecules may act as prodrugs of the free base, and that the 2 '-ketonucleoside derivative releases higher amounts of 5-FU, than the corresponding $2^{\prime}$-exomethylene nucleoside derivatives. When the compounds 9c, 10c and 13c were solubilized in phosphate buffered saline (PBS), 13c and 10c were fully stable up to 3 days after bringing the compounds into solution. Compound $9 \mathbf{c}$ was not stable and spontaneously and progressively released the free base 5-fluorouracil (data not shown). This may explain the higher cytostatic activity of $9 \mathrm{c}$ versus $10 \mathrm{c}$ and $\mathbf{1 3 c}$. When $9 \mathrm{c}, \mathbf{1 0 c}$ and $13 \mathrm{c}$ were exposed to phosphate buffer at $\mathrm{pH} 3.2$ for $60 \mathrm{~min}$, the compounds 10c and 13c were fully stable as attested by HPLC analysis, whereas the spontaneous release of 5-FU from $\mathbf{9 c}$ was not higher than in neutral solution.

One may assume, that for those compounds that owe their inhibitory effect on cell growth to inhibition of TS, the inhibitory action would be more readily reversed by co-administration of thymidine (dThd) than by 2 '-deoxyuridine (dUrd) (Scheme 1) [47]. Also, it has been demonstrated that compounds which inhibit the incorporation of (radiolabeled) dUrd into DNA and which do not inhibit the incorporation of (radiolabeled) dThd into DNA (or inhibit the latter to a significantly smaller extent than dUrd incorporation), selectively block TS [47]. To reveal whether the 5-fluorouracil derivatives $\mathbf{9 c}, \mathbf{1 0 c}$ and $\mathbf{1 3 c}$ behave mechanistically similar to the parent TS inhibitor 5-FU, we investigated whether their cytostatic activity can be reversed in the presence of uracil and the natural nucleosides such as dThd, dUrd and uridine. One murine (L1210) and one human (HeLa) cell line were chosen to perform the antimetabolic experiments since the cytostatic activity of the compounds against these cell lines were highly comparable. 5-FU, 5-fluoro-2'-deoxyuridine (5-FdUrd) and 5-fluorouridine (5-FUrd) were included as controls (Table 2). In L1210 cell cultures, addition of dThd $(20 \mu \mathrm{M})$ markedly reversed the cytostatic activity of $\mathbf{9 c}, \mathbf{1 0 c}$ and 13c (25- - 40-fold) and also 5-FU ( $\sim 40$-fold), 5-FUrd ( $\sim 100$ fold) and 5-FdUrd ( 100,000-fold). In contrast, $20 \mu \mathrm{M}$ dUrd only moderately reversed the cytostatic activity of the compounds (2- to 5 -fold). These data indicate that the mechanism of cytostatic activity may be due to inhibition of TS. Indeed, addition of dThd circumvents the inhibition of TS (and thus, efficiently reverses the cytostatic activity of 9c, 10c and 13c, 5-FU, 5-FUrd and 5-FdUrd), whereas dUrd does not efficiently reverse the cytostatic activity of TS inhibitors, because it needs to be converted to dTMP first by TS and for this reason TS has to remain active. Addition of uracil $(500 \mu \mathrm{M})$ had no significant effect on the antiproliferative activity of 9c, 10c and 13c, 5-FU, 5-FUrd and 5-FdUrd, whereas uridine (Urd) $(500 \mu \mathrm{M})$ only reversed the cytostatic effect of 5-FUrd, but not of the other compounds. Obviously, uridine competes with 5-FUrd for its conversion (phosphorylation) by uridine kinase, which is not the case for 9c, 10c and 13c, and 5-FU and 5-FdUrd.

We also examined whether 9c, 10c, 13c and 5-FU differentially inhibit the incorporation of radiolabeled dThd and dUrd into DNA of L1210 cell cultures (Table 3). Whereas the compounds inhibited $\left[{ }^{3} \mathrm{H}\right] \mathrm{dUrd}$ incorporation into DNA, they did not significantly inhibit $\left[{ }^{3} \mathrm{H}\right] \mathrm{dTh}$ incorporation into DNA [ $\mathrm{IC}_{50}$ (50\% inhibitory concentration): 349 to $>500 \mu \mathrm{M}$. Interestingly, a $24 \mathrm{~h}$ preincubation of the cells with 9c, 10c and 13c made the inhibitory effect of the test compounds against $\left[{ }^{3} \mathrm{H}\right] \mathrm{dUrd}$ but not $\left[{ }^{3} \mathrm{H}\right] \mathrm{dTh}$ incorporation even more pronounced (Table 3 ). These data again point to TS as the main target for cytostatic action of $\mathbf{9 c}, \mathbf{1 0 c}$ and $\mathbf{1 3 c}$, and 5-FU, they indicate that the compounds need some time for conversion to their active metabolite(s), and they are in full agreement with the reversal studies of the cytostatic activity in the presence of dThd and dUrd.

The activity of TS in intact tumor cells can also be directly monitored by measuring the tritium release by intact L1210 cell cultures that were exposed to $\left[5-{ }^{3} \mathrm{H}\right]$ deoxyuridine $\left(\left[5-{ }^{3} \mathrm{H}\right] \mathrm{dUrd}\right)$ and

Table 2

Effect of natural nucleosides and nucleobases on the cytostatic activity of 9c, 10c and 13c in murine L1210 and human HeLa cell cultures.

\begin{tabular}{|c|c|c|c|c|c|}
\hline & \multicolumn{5}{|l|}{$\mathrm{IC}_{50} \mathrm{a}(\mu \mathrm{M})$} \\
\hline & As such & dThd $(20 \mu \mathrm{M})$ & dUrd $(20 \mu \mathrm{M})$ & Urd $(500 \mu \mathrm{M})$ & Uracil $(500 \mu \mathrm{M})$ \\
\hline \multicolumn{6}{|l|}{ L1210 } \\
\hline 9c & $1.9 \pm 0.4$ & $75 \pm 57$ & $3.5 \pm 0.2$ & $2.0 \pm 0.2$ & $1.0 \pm 0.3$ \\
\hline $10 \mathrm{c}$ & $8.0 \pm 0.2$ & $182 \pm 23$ & $18 \pm 3$ & $5.7 \pm 2.0$ & $5.8 \pm 0.9$ \\
\hline $13 c$ & $21 \pm 4$ & $>500$ & $66 \pm 0.0$ & $18 \pm 3$ & $18 \pm 3$ \\
\hline 5-FU & $0.56 \pm 0.10$ & $21 \pm 1$ & $1.3 \pm 0.1$ & $0.62 \pm 0.02$ & $0.47 \pm 0.17$ \\
\hline 5-FUrd & $0.014 \pm 0.000$ & $1.2 \pm 1.1$ & $0.026 \pm 0.001$ & $0.72 \pm 0.01$ & $0.0075 \pm 0.0003$ \\
\hline 5-FdUrd & $0.0011 \pm 0.0005$ & $>100$ & $0.0051 \pm 0.0008$ & $0.0023 \pm 0.0006$ & $0.00063 \pm 0.00012$ \\
\hline \multicolumn{6}{|l|}{ HeLa } \\
\hline $9 c$ & $0.97 \pm 0.71$ & $7.1 \pm 2.2$ & $0.62 \pm 0.13$ & $5.3 \pm 2.2$ & $8.0 \pm 0.9$ \\
\hline $10 \mathrm{c}$ & $3.5 \pm 2.3$ & $34 \pm 1$ & $1.4 \pm 0.9$ & $8.0 \pm 1.4$ & $18 \pm 4$ \\
\hline $13 c$ & $18 \pm 4$ & $146 \pm 3$ & $12 \pm 12$ & $79 \pm 51$ & $58 \pm 4$ \\
\hline 5-FU & $0.45 \pm 0.07$ & $1.5 \pm 0.4$ & $0.18 \pm 0.06$ & $1.1 \pm 0.4$ & $1.0 \pm 0.8$ \\
\hline 5-FUrd & $0.014 \pm 0.002$ & $0.017 \pm 0.000$ & $0.022 \pm 0.007$ & $1.6 \pm 0.4$ & $0.016 \pm 0.000$ \\
\hline 5-FdUrd & $0.0094 \pm 0.0094$ & $8.5 \pm 4.7$ & $0.021 \pm 0.003$ & $0.061 \pm 0.069$ & $0.11 \pm 0.04$ \\
\hline
\end{tabular}

a $50 \%$ Inhibitory concentration required to inhibit tumor cell proliferation by $50 \%$. Data are the mean ( \pm S.D.) of at least 2 to 3 independent experiments. 
Table 3

Inhibitory activity of compounds $\mathbf{9 c}, \mathbf{1 0 c}$ and $\mathbf{1 3 c}$ and 5-FU against incorporation of radiolabeled precursors of DNA and RNA synthesis in murine leukemia L1210 cells.

\begin{tabular}{|c|c|c|c|}
\hline \multirow[t]{2}{*}{ Compound } & \multicolumn{3}{|l|}{$\mathrm{IC}_{50}^{\mathrm{a}}(\mu \mathrm{M})$} \\
\hline & [methyl- $\left.{ }^{3} \mathrm{H}\right] \mathrm{dThd}$ & {$\left[6-{ }^{3} \mathrm{H}\right] \mathrm{dUrd}$} & {$\left[5-{ }^{3} \mathrm{H}\right] \mathrm{Urd}$} \\
\hline & \multicolumn{3}{|c|}{ Without preincubation } \\
\hline 9c & $349 \pm 82$ & $3.1 \pm 0.1$ & $63 \pm 31$ \\
\hline 10c & $>500$ & $37 \pm 9$ & $>100$ \\
\hline $13 c$ & $>500$ & $85 \pm 22$ & $>100$ \\
\hline \multirow[t]{2}{*}{$5-F U$} & $>500$ & $0.97 \pm 0.61$ & $51 \pm 33$ \\
\hline & \multicolumn{3}{|c|}{ Upon $24 \mathrm{~h}$ preincubation } \\
\hline 9c & $294 \pm 15$ & $2.5 \pm 0.6$ & $16 \pm 5$ \\
\hline $10 c$ & $>500$ & $7.9 \pm 1.0$ & $84 \pm 6$ \\
\hline $13 c$ & $>500$ & $18 \pm 2$ & $282 \pm 15$ \\
\hline 5-FU & $>500$ & $0.37 \pm 0.05$ & $4.9 \pm 1.3$ \\
\hline
\end{tabular}

a $50 \%$ Inhibitory concentration, or compound concentration required to inhibit incorporation of radiolabel into DNA or RNA by $50 \%$.

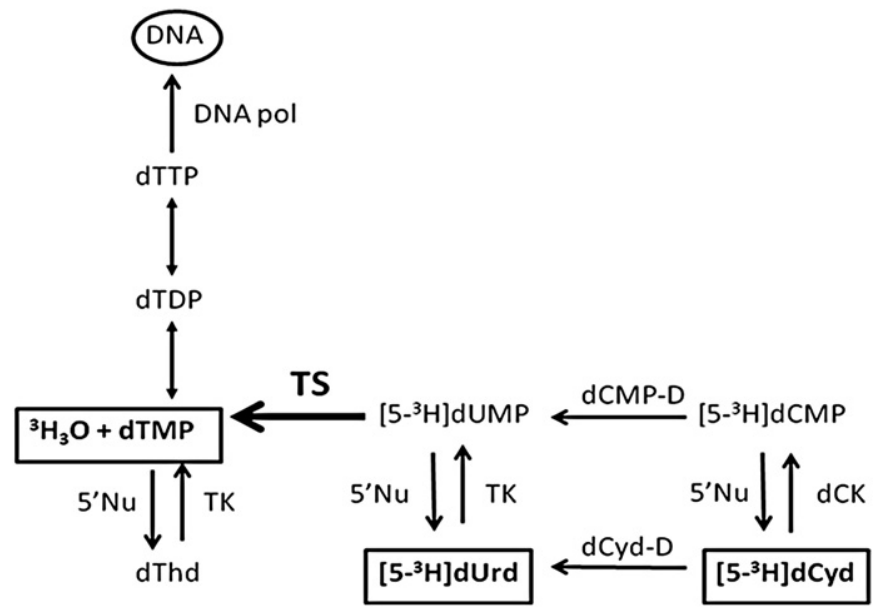

Scheme 3. In situ determination of TS activity by measurement of the tritium release from $\left[5-{ }^{3} \mathrm{H}\right] \mathrm{dUrd}$ or $\left[5^{3} \mathrm{H}\right] \mathrm{dCyd}$ added to the tumor cell cultures. dCK: $2^{\prime}$-Deoxycytidine kinase, dCyd-D: 2'-deoxycytidine deaminase, dCMP-D: 2'-deoxycytidylate deaminase, 5' Nu: 5'-nucleotidase, DNA pol: DNA polymerase, TK: thymidine kinase.

$\left[5-{ }^{3} \mathrm{H}\right]$ deoxycytidine $\left(\left[5-{ }^{3} \mathrm{H}\right] \mathrm{dCyd}\right)$ (Scheme 3) [48]. Indeed, after $\left[5-{ }^{3} \mathrm{H}\right] \mathrm{dUrd}$ or $\left[5-{ }^{3} \mathrm{H}\right] \mathrm{dCyd}$ have been converted to $\left[5-{ }^{3} \mathrm{H}\right] \mathrm{dUMP}$, the $\mathrm{C}-5$ tritium atom on the pyrimidine base is released during the TScatalyzed reductive methylation of the $\mathrm{C}-5$ of the uracil ring (Scheme 3). The ability of 9c, 10c and 13c, 5-FU and 5-FdUrd to inhibit tritium release from $\left[5-{ }^{3} \mathrm{H}\right] \mathrm{dUrd}$ and $\left[5-{ }^{3} \mathrm{H}\right] \mathrm{dCyd}$ was therefore evaluated in L1210 cell cultures at a variety of compound concentrations. 5-FdUrd proved to be a potent inhibitor of TS in situ. Its $\mathrm{IC}_{50}$ 's for tritium release from $\left[5-{ }^{3} \mathrm{H}\right] \mathrm{dUrd}$ and $\left[5-{ }^{3} \mathrm{H}\right] \mathrm{dCyd}$ ranked between 0.0004 and $0.0007 \mu \mathrm{M}$, irrespective of the time period of preincubation of the cells with 5-FdUrd (Table 4). The inhibitory activities of 5-FU and 9c, 10c and 13c were much less pronounced than 5-FdUrd, especially after only 15 min preincubation of the drugs. However, a longer preincubation time of the cells (for $4 \mathrm{~h}$ and, even more, for $24 \mathrm{~h}$ ) with 5-FU and the 5-fluorouracil derivatives before measuring TS activity in the intact cells revealed a much more pronounced inhibitory activity of the drugs against TS in situ. Taken all data together, our observations indicate that 5-FU and 9c, 10c and 13c indeed need several metabolic conversion steps before reaching TS as the target enzyme for inhibition, and support the view that 9c, 10c and $\mathbf{1 3 c}$ most likely act as prodrugs of 5-FU to exert their eventual cytostatic activity (Scheme 3).

The first predominant activation step for 5-FU to exert its cytostatic activity is catalyzed by orotic acid phosphoribosyltransferase (OPRT) converting it to 5-FUMP. This enzyme is selectively inhibited by K-oxonate [49]. Interestingly, when 5-FU and $\mathbf{9 c}$ are combined with the K-oxonate inhibitor at 200, 100 and $50 \mu \mathrm{M}$ in L1210 cell cultures, the cytostatic activity of both 5-FU and $\mathbf{1 3 c}$ are markedly decreased (>90\%). Instead, the cytostatic activity of 5-FdUrd (that does not need metabolic activation by OPRT) is unaffected by the addition of K-oxonate (data not shown). These findings are strongly suggestive for the obligatory release of 5-FU from $\mathbf{9 c}$ to eventually display a pronounced cytostatic activity, and therefore point to 9c acting as a prodrug of 5-FU. Finally, if 9c would act as a direct inhibitor of TS, it would be expected that the 5-(trifluoromethyl) uracil derivative 9e would also similarly act as a direct TS inhibitor and shows a similar cytostatic profile as $\mathbf{9 c}$. However, $\mathbf{9 e}$ is equally and moderately cytostatic against all four cell lines $\left(\mathrm{IC}_{50}: 23-46 \mu \mathrm{M}\right)$. This points to the release of 5-(trifluoromethyl)uracil, a base that is virtually inactive as a cytostatic agent.

The effect of the test compounds on TS was less pronounced in HeLa cell cultures than in L1210 cell cultures (esp. for $\mathbf{9 c}, \mathbf{1 0 c}$ and 13c, 5-FU and 5-FUrd) since co-administration of dThd with the compounds resulted in a much lesser degree of cytostatic reversal in HeLa than in L1210 cell cultures (Table 2). These observations are in agreement with our findings that addition of uracil and uridine had a more pronounced effect on the cytostatic activity of the compounds in HeLa cell than in L1210 cell cultures. Thus, the contribution of TS inhibition (and thus inhibition of DNA synthesis) in the eventual cytostatic activity of the compounds may be less pronounced, while the inhibitory effect of the compounds on uridine metabolism (and thus inhibition of RNA synthesis) may be more pronounced in HeLa cell cultures than in L1210 cell cultures. Indeed, addition of uracil or uridine markedly decreased the cytostatic activity of 13c (5- to 10-fold) and 5-FdUrd (6- to 11-fold) in HeLa cells, a phenomenon not being observed in L1210 cells (Table 2).

Compounds 9c, 10c and 13c have also been examined for their potential to act as substrate of purified recombinant human thymidine phosphorylase (TP) [50] and uridine phosphorylase type 1 (UP-1) [51] (which may release 5-FU from the prodrug). UP-1 represents an isoform of uridine phosphorylase (UP), that is more widely distributed and more abundantly expressed than UP-2 [51]. UP-1 plays an important role in the activation of 5-FU and its prodrug capecitabine. The prodrugs were found not to be

Table 4

Inhibitory activity of $\mathbf{9 c}, \mathbf{1 0 c}$ and $\mathbf{1 3 c}, 5$-FU and 5-FdUrd against tritium release from $\left[5-{ }^{3} \mathrm{H}\right] \mathrm{dUrd}$ and $\left[5-{ }^{3} \mathrm{H}\right] \mathrm{dCyd}$ in L1210 cell cultures.

\begin{tabular}{|c|c|c|c|c|c|c|}
\hline \multirow[t]{4}{*}{ Compound } & \multicolumn{6}{|c|}{$\left[{ }^{3} \mathrm{H}\right]$ release $\left(\mathrm{IC}_{50}{ }^{\mathrm{a}}\right)$ from } \\
\hline & \multicolumn{3}{|l|}{$\left[5-{ }^{3} \mathrm{H}\right] \mathrm{dUrd}$} & \multicolumn{3}{|l|}{$\left[5-{ }^{3} \mathrm{H}\right] \mathrm{dCyd}$} \\
\hline & \multicolumn{6}{|c|}{ Upon preincubation of L1210 cells with drug for following time period: } \\
\hline & $15 \mathrm{~min}$ & $4 \mathrm{~h}$ & $24 \mathrm{~h}$ & $15 \min$ & $4 \mathrm{~h}$ & $24 \mathrm{~h}$ \\
\hline 9c & $8.1 \pm 2.8$ & $0.83 \pm 0.085$ & $0.063 \pm 0.003$ & $>10$ & $0.95 \pm 0.007$ & $0.071 \pm 0.001$ \\
\hline $10 \mathrm{c}$ & $>10$ & $8.7 \pm 1.9$ & $0.43 \pm 0.18$ & $>10$ & $9.3 \pm 1.1$ & $2.2 \pm 2.0$ \\
\hline $13 c$ & $\geq 10$ & $3.6 \pm 5.6$ & $0.57 \pm 0.43$ & $8.2 \pm 0.35$ & $5.5 \pm 4.7$ & $5.4 \pm 1.8$ \\
\hline 5-FU & $\overline{7} .0 \pm 1.7$ & $0.22 \pm 0.18$ & $0.020 \pm 0.013$ & $\geq 10$ & $0.60 \pm 0.035$ & $0.06 \pm 0.016$ \\
\hline 5-FdUrd & $0.0006 \pm 0.0001$ & $0.0004 \pm 0.0003$ & $0.0004 \pm 0.0$ & $\overline{0} .0006 \pm 0.0001$ & $0.0007 \pm 0.0004$ & $0.0007 \pm 0.0001$ \\
\hline
\end{tabular}

a $50 \%$ Inhibitory concentration, or compound concentration required to inhibit tritium release from $\left[5-{ }^{3} \mathrm{H}\right] \mathrm{dUrd}$ or $\left[5-{ }^{3} \mathrm{H}\right] \mathrm{dCyd}$ by $50 \%$. 
substrates for these enzymes under conditions where dThd (for TP) and Urd (for UP) were very efficiently converted to thymine or uracil, respectively (data not shown). Moreover, the cytostatic activity of the 5-FU prodrugs was not decreased in the presence of benzyl acyclic uridine (BAU), a potent inhibitor of UP. Also, the cytostatic activity of 9c (and 5-FU) in L1210 cell cultures was not influenced by superinfection of the tumor cell cultures by Mycoplasma hyorhinis that induce pronounced levels of TP [52]. In contrast, 5'-deoxy-5-fluorouridine ( $5^{\prime}$-dFUrd), a prodrug of 5-FU that obligatorily needs TP activity to release 5-FU, is poorly cytostatic against L1210 cells, but becomes highly cytostatic in the presence of the Mycoplasma-infected tumor cells (data not shown). Therefore, TP and UP-1 are clearly not the enzymes responsible for efficient release of 5-FU from the 5-FU analogs. Other enzymes should be investigated for their potential to recognize the 5-FU analogs as a substrate for hydrolysis. Additional studies on 9c, 10c and $\mathbf{1 3 c}$ are currently ongoing to further reveal their (anti)-metabolic properties. It also remains to be determined whether the 5-FU analogues have a superior pharmacokinetic profile as compared to the free parent compound, and thus have a potential advantage over 5-FU in terms of clinical application.

\section{Conclusion}

In conclusion, the synthesis of unsaturated keto and exomethylene arabinopyranonucleoside analogues bearing thymine, uracil, 5-fluorouracil, $N^{4}$-benzoyl cytosine and 5-(trifluoromethyl) uracil was undertaken. The target unsaturated ketonucleoside $\mathbf{9}$ and their exomethylene $\mathbf{1 0}$ and $\mathbf{1 3}$ intermediates were found not to inhibit the replication of a broad variety of viruses. However, the 5-fluorouracil derivatives showed an interesting cytostatic potential in various cell culture assays. Antimetabolic experiments revealed that TS is the principal target for the cytostatic activity of 9c, 10c and 13c, which may act as novel type of prodrugs of 5-FU.

\section{Experimental}

\subsection{General procedure}

Melting points were recorded in a Mel-Temp apparatus and are uncorrected. Thin-layer chromatography (TLC) was performed on Merck precoated $60 \mathrm{~F}_{254}$ plates. Reactions were monitored by TLC on silica gel, with detection by UV light $(254 \mathrm{~nm}$ ) or by charring with sulfuric acid. Flash chromatography was performed using silica gel (240-400 mesh, Merck). ${ }^{1} \mathrm{H}$ NMR spectra were recorded at room temperature with a Bruker $400 \mathrm{MHz}$ spectrometer using chloroform-d $\left(\mathrm{CDCl}_{3}\right)$ and methanol- $\mathrm{d}_{4}\left(\mathrm{CD}_{3} \mathrm{OD}\right)$. Chemical shifts are reported in parts per million $(\delta)$ downfield from tetramethylsilane (TMS) as internal standard. Mass spectra were obtained with a Micromass Platform LC (ESI-MS). Optical rotations were measured using Autopol I polarimeter.

All reactions were carried out in dry solvents. $\mathrm{CH}_{2} \mathrm{Cl}_{2}$ and 1,2$\mathrm{EtCl}_{2}$ were distilled from phosphorous pentoxide and stored over $4 \mathrm{E}$ molecular sieves. Acetonitrile, toluene (Tol) and N,N-dimethylformamide (DMF) were distilled from calcium hydride and stored over 3E molecular sieves. THF was freshly distilled under nitrogen from sodium/benzophenone before use and pyridine stored over pellets of potassium hydroxide.

4.2. Synthesis of 1-(2,3,4-tri-O-acetyl- $\alpha$-D-arabinopyranosyl) nucleosides 2(a-e)

4.2.1. 1-(2,3,4-Tri-O-acetyl- $\alpha$-D-arabinopyranosyl)thymine (2a)

A mixture of thymine $(2.77 \mathrm{~g}, 21.99 \mathrm{mmol})$, hexamethyldisilazane (HMDS) (5.75 mL, $27.27 \mathrm{mmol})$ and saccharin $(185.29 \mathrm{mg}$,
$1.01 \mathrm{mmol})$ in dry $1,2-\mathrm{EtCl}_{2}(65 \mathrm{~mL})$ was refluxed for 30 min under nitrogen. To this were added 1,2,3,4-tetra-O-acetyl-D-arabinopyranose (1) $(5.0 \mathrm{~g}, 15.71 \mathrm{mmol})$ and $\mathrm{SnCl}_{4}(2.6 \mathrm{~mL}, 21.99 \mathrm{mmol})$. The reaction mixture was refluxed for $3 \mathrm{~h}$, neutralized with saturated sodium bicarbonate and then extracted with $\mathrm{CH}_{2} \mathrm{Cl}_{2}$. The organic extract was dried over anhydrous sodium sulfate, filtered and evaporated to dryness. The residue was purified by flash chromatography (EtOAc/hexane, 6:4) to give compound 2a (4.53 g, 75\%, $\left.R_{\mathrm{f}}=0.38\right)$ as a white solid, m.p. $122-124^{\circ} \mathrm{C}$. $[\alpha]_{\mathrm{D}}^{22}-12.0$ (c 0.500 , $\left.\mathrm{CHCl}_{3}\right)$; UV $\left(\mathrm{CHCl}_{3}\right): \lambda_{\max } 262 \mathrm{~nm}(\epsilon 6557) ;{ }^{1} \mathrm{H} \mathrm{NMR}\left(\mathrm{CDCl}_{3}\right): \delta 8.25$ (br s, $1 \mathrm{H}, \mathrm{NH}), 7.19$ (s, 1H, H-6), $5.72\left(\mathrm{~d}, 1 \mathrm{H}, J_{1^{\prime}, 2^{\prime}}=9.3 \mathrm{~Hz}, \mathrm{H}-1^{\prime}\right)$, 5.40-5.33 (m, 2H, H-2', H-4' $), 5.20\left(\mathrm{dd}, 1 \mathrm{H}, J_{2^{\prime}, 3^{\prime}}=10.1 \mathrm{~Hz}\right.$, $\left.J_{3^{\prime}, 4^{\prime}}=3.5 \mathrm{~Hz}, \mathrm{H}-3^{\prime}\right), 4.10\left(\mathrm{dd}, 1 \mathrm{H}, J_{4^{\prime}, 5 \mathrm{~b}^{\prime}}=3.9 \mathrm{~Hz}, J_{5 \mathrm{a}^{\prime}, 5 \mathrm{~b}^{\prime}}=13.5 \mathrm{~Hz}, \mathrm{H}-\right.$ $5 b^{\prime}$ ), 3.87 (d, 1H, H-5a'), 2.22, 2.02, 2.01 (3s, 9H, 3OAc), 1.97 (s, 3H, 5$\left.\mathrm{CH}_{3}\right)$; ESI-MS $(m / z) 385.34\left[\mathrm{M}+\mathrm{H}^{+}\right]$; Anal. Calcd for $\mathrm{C}_{16} \mathrm{H}_{20} \mathrm{~N}_{2} \mathrm{O}_{9}: \mathrm{C}$ 50.00, H 5.25, N 7.29. Found: C 50.11, H 5.49, N 7.51.

\subsubsection{1-(2,3,4-Tri-O-acetyl- $\alpha$-D-arabinopyranosyl)uracil ( $2 \boldsymbol{b})$}

A mixture of uracil $(2.46 \mathrm{~g}, 21.99 \mathrm{mmol})$, HMDS $(5.75 \mathrm{~mL}$, $27.26 \mathrm{mmol}$ ) and saccharin $(185.29 \mathrm{mg}, 1.01 \mathrm{mmol})$ in dry $\mathrm{CH}_{3} \mathrm{CN}$ $(68 \mathrm{~mL})$ was refluxed for $30 \mathrm{~min}$ under nitrogen. To this were added 1,2,3,4-tetra-O-acetyl-D-arabinopyranose (1) (5.0 g, $15.71 \mathrm{mmol}$ ) and $\mathrm{SnCl}_{4}(2.6 \mathrm{~mL}, 21.99 \mathrm{mmol})$. The reaction mixture was refluxed for $2 \mathrm{~h}$, neutralized with saturated sodium bicarbonate and then extracted with $\mathrm{CH}_{2} \mathrm{Cl}_{2}$. The organic extract was dried over anhydrous sodium sulfate, filtered and evaporated to dryness. The residue was purified by flash chromatography (EtOAc/hexane, 7:3) to give compound $\mathbf{2 b}\left(4.42 \mathrm{~g}, 76 \%, R_{\mathrm{f}}=0.42\right)$ as a white foam. $[\alpha]_{\mathrm{D}}^{22}$ -24.0 (c $\left.0.500, \mathrm{CHCl}_{3}\right) ; \mathrm{UV}\left(\mathrm{CHCl}_{3}\right): \lambda_{\max } 256 \mathrm{~nm}(\epsilon 7632) ;{ }^{1} \mathrm{H}$ NMR $\left(\mathrm{CDCl}_{3}\right): \delta 8.29(\mathrm{br} \mathrm{s}, 1 \mathrm{H}, \mathrm{NH}), 7.40\left(\mathrm{~d}, 1 \mathrm{H}, J_{5,6}=8.2 \mathrm{~Hz}, \mathrm{H}-6\right), 5.82$ $\left(\mathrm{dd}, 1 \mathrm{H}, J_{1^{\prime}, 5}=1.3 \mathrm{~Hz}, \mathrm{H}-5\right), 5.73\left(\mathrm{~d}, 1 \mathrm{H}, J_{1^{\prime}, 2^{\prime}}=9.2 \mathrm{~Hz}, \mathrm{H}-1^{\prime}\right), 5.40$ (m, $\left.1 \mathrm{H}, J_{4^{\prime}, 5 \mathrm{~b}^{\prime}}=2.0 \mathrm{~Hz}, \mathrm{H}-4^{\prime}\right), 5.33\left(\mathrm{~m}, 1 \mathrm{H}, \mathrm{H}-2^{\prime}\right), 5.20(\mathrm{dd}, 1 \mathrm{H}$, $\left.J_{3^{\prime}, 4^{\prime}}=3.4 \mathrm{~Hz}, \mathrm{H}-3^{\prime}\right), 4.11\left(\mathrm{dd}, 1 \mathrm{H}, J_{5 \mathrm{a}^{\prime}, 5 \mathrm{~b}^{\prime}}=13.5 \mathrm{~Hz}, \mathrm{H}-5 \mathrm{~b}^{\prime}\right), 3.86(\mathrm{~d}$, $\left.1 \mathrm{H}, \mathrm{H}-5 \mathrm{a}^{\prime}\right), 2.20,2.03,2.02$ (3s, 9H, 3OAc); ESI-MS $(\mathrm{m} / \mathrm{z}) 371.33$ $\left[\mathrm{M}+\mathrm{H}^{+}\right]$; Anal. Calcd for $\mathrm{C}_{15} \mathrm{H}_{18} \mathrm{~N}_{2} \mathrm{O}_{9}$ : C 48.65, $\mathrm{H} 4.90, \mathrm{~N} 7.56$. Found: C 49.04, H 5.24, N 7.41.

\subsubsection{1-(2,3,4-Tri-O-acetyl- $\alpha$-D-arabinopyranosyl)5-fluorouracil} (2c)

A mixture of 5-fluorouracil (2.54 g, $19.55 \mathrm{mmol})$, HMDS (5.75 mL, $27.26 \mathrm{mmol})$ and saccharin $(164.73 \mathrm{mg}, 0.90 \mathrm{mmol})$ in dry $\mathrm{CH}_{3} \mathrm{CN}(80 \mathrm{~mL})$ was refluxed for $30 \mathrm{~min}$ under nitrogen. To this were added 1,2,3,4-tetra-O-acetyl-D-arabinopyranose (1) (4.8 g, $15.04 \mathrm{mmol}$ ) and $\mathrm{Me}_{3} \mathrm{SiOSO}_{2} \mathrm{CF}_{3}(3.8 \mathrm{~mL}, 21.06 \mathrm{mmol})$. The reaction mixture was refluxed for $2 \mathrm{~h}$, neutralized with saturated sodium bicarbonate and then extracted with $\mathrm{CH}_{2} \mathrm{Cl}_{2}$. The organic extract was dried over anhydrous sodium sulfate, filtered and evaporated to dryness. The residue was purified by flash chromatography (EtOAc/hexane, $6: 4)$ to give compound $2 \mathrm{c}\left(5.0 \mathrm{~g}, 85 \%, R_{\mathrm{f}}=0.44\right)$ as a white foam. $[\alpha]_{\mathrm{D}}^{22}-24.0\left(\mathrm{c} 0.500, \mathrm{CHCl}_{3}\right) ; \mathrm{UV}\left(\mathrm{CHCl}_{3}\right): \lambda_{\max } 263 \mathrm{~nm}$ $(\epsilon 7878) ;{ }^{1} \mathrm{H}$ NMR $\left(\mathrm{CDCl}_{3}\right): \delta 8.99($ br s, $1 \mathrm{H}, \mathrm{NH}), 7.48(\mathrm{~d}, 1 \mathrm{H}$, $\left.J_{\mathrm{F} 5,6}=5.6 \mathrm{~Hz}, \mathrm{H}-6\right), 5.75\left(\mathrm{~d}, 1 \mathrm{H}, J_{1^{\prime}, 2^{\prime}}=8.5 \mathrm{~Hz}, \mathrm{H}-1^{\prime}\right), 5.45-5.23(\mathrm{~m}$, $\left.3 \mathrm{H}, \mathrm{H}-2^{\prime}, \mathrm{H}-3^{\prime}, \mathrm{H}-4^{\prime}\right), 4.13,3.91$ (q, AB-system, $2 \mathrm{H}, J=13.3 \mathrm{~Hz}, \mathrm{H}-5^{\prime}$ ), 2.24, 2.05, 2.04 (3s, 9H, 3OAc); ESI-MS $(\mathrm{m} / \mathrm{z}) 389.32$ [ $\left.\mathrm{M}+\mathrm{H}^{+}\right]$; Anal. Calcd for $\mathrm{C}_{15} \mathrm{H}_{17} \mathrm{FN}_{2} \mathrm{O}_{9}$ : C 46.40, H 4.41, N 7.21. Found: C 46.14, H 4.64, N 7.49.

\subsubsection{1-(2,3,4-Tri-O-acetyl- $\alpha$-D-arabinopyranosyl)- $N^{4}$-benzoyl cytosine (2d)}

A mixture of $N^{4}$-benzoyl cytosine (4.40 g, $20.42 \mathrm{mmol}$ ), HMDS (5.34 mL, $25.32 \mathrm{mmol}$ ) and saccharin (172.09 $\mathrm{mg}, 0.94 \mathrm{mmol})$ in dry $\mathrm{CH}_{3} \mathrm{CN}(80 \mathrm{~mL})$ was refluxed for $30 \mathrm{~min}$ under nitrogen. To this were added 1,2,3,4-tetra-O-acetyl-D-arabinopyranose (1) (5.0 g, $15.71 \mathrm{mmol}$ ) and $\mathrm{Me}_{3} \mathrm{SiOSO}_{2} \mathrm{CF}_{3}(4.0 \mathrm{~mL}, 21.99 \mathrm{mmol})$. The reaction mixture was refluxed for $1 \mathrm{~h}$, neutralized with saturated sodium 
bicarbonate and then extracted with $\mathrm{CH}_{2} \mathrm{Cl}_{2}$. The organic extract was dried over anhydrous sodium sulfate, filtered and evaporated to dryness. The residue was purified by flash chromatography (EtOAc/hexane, 7:3) to give compound $\mathbf{2 d}\left(5.8 \mathrm{~g}, 78 \%, R_{\mathrm{f}}=0.32\right)$ as a white solid, m.p. $159-161{ }^{\circ} \mathrm{C}$. $[\alpha]_{\mathrm{D}}^{22}-22.0$ (c $\left.0.500, \mathrm{CHCl}_{3}\right)$; UV $\left(\mathrm{CHCl}_{3}\right): \lambda_{\max } 262 \mathrm{~nm}\left(\epsilon\right.$ 17413); ${ }^{1} \mathrm{H} \mathrm{NMR}\left(\mathrm{CDCl}_{3}\right): \delta 7.62(\mathrm{~d}, 1 \mathrm{H}$, $\left.J_{5,6}=7.3 \mathrm{~Hz}, \mathrm{H}-6\right), 7.90-7.50(\mathrm{~m}, 6 \mathrm{H}, \mathrm{Bz}$ and $\mathrm{H}-5), 6.01(\mathrm{~d}, 1 \mathrm{H}$, $\left.J_{1^{\prime}, 2^{\prime}}=8.9 \mathrm{~Hz}, \mathrm{H}-1^{\prime}\right), 5.43\left(\mathrm{~m}, 1 \mathrm{H}, J_{4^{\prime}, 5 \mathrm{~b}^{\prime}}=1.9 \mathrm{~Hz}, \mathrm{H}-4^{\prime}\right), 5.35(\mathrm{~m}, 1 \mathrm{H}$, $\mathrm{H}-2^{\prime}$ ), 5.24 (dd, $1 \mathrm{H}, J_{2^{\prime}, 3^{\prime}}=10.1 \mathrm{~Hz}, J_{3^{\prime}, 4^{\prime}}=3.4 \mathrm{~Hz}, \mathrm{H}-3^{\prime}$ ), 4.15 (dd, $1 \mathrm{H}$, $\left.J_{5 \mathrm{a}^{\prime}, 5 \mathrm{~b}^{\prime}}=13.2 \mathrm{~Hz}, \mathrm{H}-5 \mathrm{~b}^{\prime}\right), 3.90\left(\mathrm{~d}, 1 \mathrm{H}, \mathrm{H}-5 \mathrm{a}^{\prime}\right), 2.22,2.03,2.00(3 \mathrm{~s}, 9 \mathrm{H}$, 3OAc); ESI-MS (m/z) $474.44\left[\mathrm{M}+\mathrm{H}^{+}\right]$; Anal. Calcd for $\mathrm{C}_{22} \mathrm{H}_{23} \mathrm{~N}_{3} \mathrm{O}_{9}$ : C 55.81, H 4.90 N 8.88. Found: C 55.44, H 4.64, N 8.61.

\subsubsection{1-(2,3,4-Tri-O-acetyl- $\alpha$-D-arabinopyranosyl)5-(trifluoromethyl) uracil (2e)}

A mixture of 5-(trifluoromethyl)uracil ( $0.99 \mathrm{~g}, 5.5 \mathrm{mmol}$ ), HMDS (1.45 mL, $6.82 \mathrm{mmol})$ and saccharin $(46.3 \mathrm{mg}, 0.25 \mathrm{mmol})$ in dry $\mathrm{CH}_{3} \mathrm{CN}(21 \mathrm{~mL})$ was refluxed for 30 min under nitrogen. To this were added 1,2,3,4-tetra-O-acetyl-D-arabinopyranose (1) (1.6 g, $5.0 \mathrm{mmol})$ and $\mathrm{Me}_{3} \mathrm{SiOSO}_{2} \mathrm{CF}_{3}(1.26 \mathrm{~mL}, 7.0 \mathrm{mmol})$. The reaction mixture was refluxed for $1 \mathrm{~h}$, neutralized with saturated sodium bicarbonate and then extracted with $\mathrm{CH}_{2} \mathrm{Cl}_{2}$. The organic extract was dried over anhydrous sodium sulfate, filtered and evaporated to dryness. The residue was purified by flash chromatography (EtOAc/hexane, 4:6) to give compound $2 \mathbf{e}\left(1.93 \mathrm{~g}, 88 \%, R_{\mathrm{f}}=0.3\right)$ as a white foam. $[\alpha]_{D}^{22}-12.0\left(\mathrm{c} 0.500, \mathrm{CHCl}_{3}\right) ; \mathrm{UV}\left(\mathrm{CHCl}_{3}\right): \lambda_{\max } 260 \mathrm{~nm}$ $(\epsilon 6689) ;{ }^{1} \mathrm{H} \mathrm{NMR}\left(\mathrm{CDCl}_{3}\right): \delta 8.32(\mathrm{br} \mathrm{s}, 1 \mathrm{H}, \mathrm{NH}), 7.86(\mathrm{~s}, 1 \mathrm{H}, \mathrm{H}-6)$, $5.73\left(\mathrm{~d}, 1 \mathrm{H}, J_{1^{\prime}, 2^{\prime}}=8.9 \mathrm{~Hz}, \mathrm{H}-1^{\prime}\right), 5.43-5.21\left(\mathrm{~m}, 3 \mathrm{H}, \mathrm{H}-2^{\prime}, \mathrm{H}-3^{\prime}, \mathrm{H}-4^{\prime}\right)$, 4.17-3.86 (m, 2H, H-5'), 2.19, 2.14, 2.10 (3s, 9H, 3OAc); ESI-MS ( $m / z)$ 439.31 [M $\left.+\mathrm{H}^{+}\right]$; Anal. Calcd for $\mathrm{C}_{16} \mathrm{H}_{17} \mathrm{~F}_{3} \mathrm{~N}_{2} \mathrm{O}_{9}$ : C 43.84, H 3.91, N 6.39. Found: C 43.92, H 3.98, N 6.42.

\subsection{Synthesis of 1-( $\alpha$-D-arabinopyranosyl)nucleosides $3(\boldsymbol{a}-\boldsymbol{e})$}

\subsubsection{1-( $\alpha$-D-Arabinopyranosyl)thymine (3a)}

Compound $2 \mathrm{a}$ ( $4.53 \mathrm{~g}, 11.78 \mathrm{mmol})$ was treated with ammonia/ $\mathrm{MeOH}$ (saturated at $0{ }^{\circ} \mathrm{C}, 0.66 \mathrm{~L}$ ). The solution was stirred overnight at room temperature and then was concentrated under reduced pressure to give compound $\mathbf{3 a}\left(2.95 \mathrm{~g}, 97 \%, R_{\mathrm{f}}=0.30\right.$ in EtOAc/ $\mathrm{MeOH}, 8: 2)$ as a white solid, m.p. $249-251{ }^{\circ} \mathrm{C}$. $[\alpha]_{\mathrm{D}}^{22}-18.0$ (c 0.570 , $\mathrm{MeOH})$; UV (MeOH): $\lambda_{\max } 262 \mathrm{~nm}(\epsilon$ 7201); ESI-MS $(m / z) 259.25$ $\left[\mathrm{M}+\mathrm{H}^{+}\right]$; Anal. Calcd for $\mathrm{C}_{10} \mathrm{H}_{14} \mathrm{~N}_{2} \mathrm{O}_{6}$ : C 46.51, H 5.46, N 10.85 . Found: C 46.83, H 5.32, N 10.46 .

\subsubsection{1-( $\alpha$-D-Arabinopyranosyl)uracil (3b), 5-fluorouracil (3c), 5- (trifluoromethyl)uracil (3e)}

Uracil, 5-fluorouracil and 5-(trifluoromethyl)uracil derivatives $\mathbf{3 b}, \mathbf{3 c}$ and $3 \mathbf{e}$ were synthesized by similar procedure as described for $3 a$.

3b:(2.86 g, 98\%, $R_{\mathrm{f}}=0.39$ in EtOAc/MeOH, 8:2). [ $\left.\alpha\right]_{\mathrm{D}}^{22}-12.0(\mathrm{c}$ $0.500, \mathrm{MeOH}) ; \mathrm{UV}(\mathrm{MeOH}): \lambda_{\max } 258 \mathrm{~nm}(\epsilon$ 6869); ESI-MS $(m / z)$ 245.22 [M $\left.+\mathrm{H}^{+}\right]$; Anal. Calcd for $\mathrm{C}_{9} \mathrm{H}_{12} \mathrm{~N}_{2} \mathrm{O}_{6}$ : C 44.27, $\mathrm{H} 4.95, \mathrm{~N}$ 11.47. Found: C 44.56, H 5.12, N 11.78.

3c: $\left(3.1 \mathrm{~g}, 92 \%, R_{\mathrm{f}}=0.44\right.$ in EtOAc/MeOH, 8:2), m.p. $257-259{ }^{\circ} \mathrm{C}$. $[\alpha]_{\mathrm{D}}^{22}-48.0$ (c 0.500, MeOH); UV (MeOH): $\lambda_{\max } 266 \mathrm{~nm}(\epsilon 7158)$; ESI-MS $(m / z) 263.17\left[\mathrm{M}+\mathrm{H}^{+}\right]$; Anal. Calcd for $\mathrm{C}_{9} \mathrm{H}_{11} \mathrm{FN}_{2} \mathrm{O}_{6}$ : C 41.23, H 4.23, N 10.68. Found: C 41.62, H 4.09, N 10.71.

3e: $\left(1.3 \mathrm{~g}, 97 \%, R_{\mathrm{f}}=0.14 \text { in EtOAc). [ } \alpha\right]_{\mathrm{D}}^{22}-34.0$ (c 0.605, $\left.\mathrm{MeOH}\right)$; UV (MeOH): $\lambda_{\max } 260 \mathrm{~nm}(\epsilon 6156)$; ESI-MS $(m / z) 313.21\left[\mathrm{M}+\mathrm{H}^{+}\right]$; Anal. Calcd for $\mathrm{C}_{10} \mathrm{H}_{11} \mathrm{~F}_{3} \mathrm{~N}_{2} \mathrm{O}_{6}$ : C 38.47, H 3.55, N 8.97. Found: C 38.57, H 3.71, N 8.86.

\subsubsection{1-( $\alpha$-D-Arabinopyranosyl)- $N^{4}$-benzoyl cytosine (3d)}

$N^{4}$-Benzoyl cytosine derivative $2 \mathbf{2 d}(5.8 \mathrm{~g}, 12.25 \mathrm{mmol})$ was dissolved in ethanol-pyridine $(122.5 \mathrm{~mL}+36.7 \mathrm{~mL}), 2 \mathrm{M} \mathrm{NaOH}$
$(12.2 \mathrm{~mL})$ was added and the mixture stirred for $11 \mathrm{~min}$ at room temperature. Amberlite IR-120 $\left(\mathrm{H}^{+}\right)$was added to neutralize the base. The suspension was filtered, the resin was washed with EtOH and pyridine $(100 \mathrm{~mL}+100 \mathrm{~mL})$ and the filtrate was evaporated. The solid residue was triturated with diethyl ether $(2 \times 30 \mathrm{~mL})$ and $\mathrm{CH}_{2} \mathrm{Cl}_{2}(2 \times 30 \mathrm{~mL})$ and filtered. 3d was obtained $(3.36 \mathrm{~g}, 79 \%$, $R_{\mathrm{f}}=0.4$ in EtOAc/MeOH, 8:2) as a white foam, and it was used without further purification. $[\alpha]_{\mathrm{D}}^{22}-12.0$ (c $\left.0.500, \mathrm{MeOH}\right)$; UV (MeOH): $\lambda_{\max } 261 \mathrm{~nm}\left(\epsilon\right.$ 15313); ESI-MS $(\mathrm{m} / z) 348.33\left[\mathrm{M}+\mathrm{H}^{+}\right.$]; Anal. Calcd for $\mathrm{C}_{16} \mathrm{H}_{17} \mathrm{~N}_{3} \mathrm{O}_{6}$ : C 55.33, H 4.93, N 12.10. Found: C 55.56, H 5.02, N 12.47 .

\subsection{Synthesis of 1-(3,4-O-isopropylidene- $\alpha$-D-arabinopyranosyl) nucleosides $\mathbf{4}(\boldsymbol{a}-\boldsymbol{e})$}

\subsubsection{1-(3,4-O-Isopropylidene- $\alpha$-D-arabinopyranosyl)thymine (4a)}

To a stirred suspension of $\mathbf{3 a}(2.95 \mathrm{~g}, 11.43 \mathrm{mmol})$ in anhydrous acetone $(197 \mathrm{~mL})$ and 2,2-dimethoxypropane $(10 \mathrm{~mL})$ was added p-toluenesulfonic acid monohydrate $(0.37 \mathrm{~g}, 1.94 \mathrm{mmol})$. After $6 \mathrm{~h}$ the resulting solution was neutralized with triethylamine so that $\mathrm{pH}$ did not exceed 7. The solution was concentrated and the residue was purified by flash chromatography (EtOAc) to give $\mathbf{4 a}$ (2.86 g, $\left.84 \%, R_{\mathrm{f}}=0.39\right)$ as a white foam. $[\alpha]_{\mathrm{D}}^{22}-48.0$ (c $\left.0.500, \mathrm{MeOH}\right)$; UV $(\mathrm{MeOH}): \lambda_{\max } 262 \mathrm{~nm}(\epsilon 11760) ;{ }^{1} \mathrm{H} \mathrm{NMR}\left(\mathrm{CDCl}_{3}\right): \delta 7.26(\mathrm{~s}, 1 \mathrm{H}, \mathrm{H}-6)$, $5.51\left(\mathrm{~d}, 1 \mathrm{H}, J_{1^{\prime}, 2^{\prime}}=8.8 \mathrm{~Hz}, \mathrm{H}-1^{\prime}\right), 4.37-4.28\left(\mathrm{~m}, 3 \mathrm{H}, \mathrm{H}-3^{\prime}, \mathrm{H}-4^{\prime}, \mathrm{H}-5 \mathrm{a}^{\prime}\right)$, $4.02\left(\mathrm{dd}, 1 \mathrm{H}, J_{4^{\prime}, 5 \mathrm{~b}^{\prime}}=1.7 \mathrm{~Hz}, J_{5 \mathrm{a}^{\prime}, 5 \mathrm{~b}^{\prime}}=13.9 \mathrm{~Hz}, \mathrm{H}-5 \mathrm{~b}^{\prime}\right), 3.77(\mathrm{dd}, 1 \mathrm{H}$, $\left.J_{2^{\prime}, 3^{\prime}}=8.5 \mathrm{~Hz}, \mathrm{H}-2^{\prime}\right), 1.89\left(\mathrm{~s}, 3 \mathrm{H}, 5-\mathrm{CH}_{3}\right), 1.62,1.42\left(2 \mathrm{~s}, 6 \mathrm{H}, 2 \mathrm{CH}_{3}\right)$; ESIMS $(m / z) 299.29\left[\mathrm{M}+\mathrm{H}^{+}\right]$; Anal. Calcd for $\mathrm{C}_{13} \mathrm{H}_{18} \mathrm{~N}_{2} \mathrm{O}_{6}$ : C 52.34, $\mathrm{H}$ 6.08, N 9.39. Found: C 52.65, H 5.97, N 9.63.

\subsubsection{1-(3,4-0-Isopropylidene- $\alpha$-D-arabinopyranosyl)uracil (4b), 5-fluorouracil (4c), $N^{4}$-benzoyl cytosine (4d), 5-(trifluoromethyl) uracil (4e)}

Uracil, 5-fluorouracil, $N^{4}$-benzoyl cytosine and 5-(trifluoromethyl)uracil derivatives $\mathbf{4 b}, \mathbf{4 c}, \mathbf{4 d}$ and $\mathbf{4 e}$ were synthesized by similar procedure as described for $\mathbf{4 a}$.

4b: $\left(2.76 \mathrm{~g}, 83 \%, R_{\mathrm{f}}=0.46 \text { in EtOAc). [ } \alpha\right]_{\mathrm{D}}^{22} 6.0$ (c 0.485, MeOH); $\mathrm{UV}(\mathrm{MeOH}): \lambda_{\max } 259 \mathrm{~nm}(\epsilon 6836) ;{ }^{1} \mathrm{H} \mathrm{NMR}\left(\mathrm{CD}_{3} \mathrm{OD}\right): \delta 7.61(\mathrm{~d}, 1 \mathrm{H}$, $\left.J_{5,6}=8.1 \mathrm{~Hz}, \mathrm{H}-6\right), 5.72(\mathrm{~d}, 1 \mathrm{H}, \mathrm{H}-5), 5.37\left(\mathrm{~d}, 1 \mathrm{H}, J_{1^{\prime}, 2^{\prime}}=9.5 \mathrm{~Hz}, \mathrm{H}-1^{\prime}\right)$, $4.24-4.28$ ( $\left.\mathrm{m}, 2 \mathrm{H}, \mathrm{H}-4^{\prime}, \mathrm{H}-5 \mathrm{a}^{\prime}\right), 4.16\left(\mathrm{t}, 1 \mathrm{H}, J_{3^{\prime}, 4^{\prime}}=6.0 \mathrm{~Hz}, \mathrm{H}-3^{\prime}\right), 3.99$ $\left(\mathrm{dd}, 1 \mathrm{H}, J_{4^{\prime}, 5 \mathrm{~b}^{\prime}}=2.3 \mathrm{~Hz}, J_{5 \mathrm{a}^{\prime}, 5 \mathrm{~b}^{\prime}}=13.6 \mathrm{~Hz}, \mathrm{H}-5 \mathrm{~b}^{\prime}\right), 3.76(\mathrm{dd}, 1 \mathrm{H}$, $\left.J_{2^{\prime}, 3^{\prime}}=7.3 \mathrm{~Hz}, \mathrm{H}-2^{\prime}\right), 1.54,1.36\left(2 \mathrm{~s}, 6 \mathrm{H}, 2 \mathrm{CH}_{3}\right)$; ESI-MS $(m / z) 285.25$ $\left[\mathrm{M}+\mathrm{H}^{+}\right]$; Anal. Calcd for $\mathrm{C}_{12} \mathrm{H}_{16} \mathrm{~N}_{2} \mathrm{O}_{6}$ : C 50.70, H 5.67, N 9.85. Found: C 50.85, H 5.80, N 9.98.

4c: $\left(2.81 \mathrm{~g}, 79 \%, R_{\mathrm{f}}=0.6\right.$ in EtOAc), m.p. $183-185^{\circ} \mathrm{C} .[\alpha]_{\mathrm{D}}^{22}-60.0$ (c 0.500, MeOH); UV (MeOH): $\lambda_{\max } 266 \mathrm{~nm}(\epsilon 4650) ;{ }^{1} \mathrm{H}$ NMR $\left(\mathrm{CD}_{3} \mathrm{OD}\right): \delta 7.83\left(\mathrm{~d}, 1 \mathrm{H}, J_{\mathrm{F} 5,6}=6.5 \mathrm{~Hz}, \mathrm{H}-6\right), 5.38(\mathrm{dd}, 1 \mathrm{H}$, $\left.J_{1^{\prime}, 2^{\prime}}=9.3 \mathrm{~Hz}, J_{1^{\prime}, \mathrm{F} 5}=1.5 \mathrm{~Hz}, \mathrm{H}-1^{\prime}\right), 4.30-4.16\left(\mathrm{~m}, 3 \mathrm{H}, \mathrm{H}-3^{\prime}, \mathrm{H}-4^{\prime}\right.$, $\left.\mathrm{H}-5 \mathrm{a}^{\prime}\right), 4.01\left(\mathrm{dd}, 1 \mathrm{H}, J_{4^{\prime}, 5 \mathrm{~b}^{\prime}}=2.5 \mathrm{~Hz}, J_{5 \mathrm{a}^{\prime}, 5 \mathrm{~b}^{\prime}}=13.6 \mathrm{~Hz}, \mathrm{H}-5 \mathrm{~b}^{\prime}\right), 3.76$ $\left(\mathrm{dd}, 1 \mathrm{H}, J_{2^{\prime}, 3^{\prime}}=7.0 \mathrm{~Hz}, \mathrm{H}-2^{\prime}\right), 1.56,1.37\left(2 \mathrm{~s}, 6 \mathrm{H}, 2 \mathrm{CH}_{3}\right)$; ESI-MS $(\mathrm{m} / \mathrm{z})$ $303.27\left[\mathrm{M}+\mathrm{H}^{+}\right]$; Anal. Calcd for $\mathrm{C}_{12} \mathrm{H}_{15} \mathrm{FN}_{2} \mathrm{O}_{6}$ : C 47.68, $\mathrm{H} \mathrm{5.00,} \mathrm{N}$ 9.27. Found: C 47.81, H 4.79, N 9.46.

4d: (3.15 g, 84\%, $R_{\mathrm{f}}=0.58$ in EtOAc/MeOH, 9:1), m.p. $211-213^{\circ} \mathrm{C}$. $[\alpha]_{\mathrm{D}}^{22}-22.0$ (c 0.317, MeOH); UV (MeOH): $\lambda_{\max } 262 \mathrm{~nm}(\epsilon 8737) ;{ }^{1} \mathrm{H}$ NMR (CD $\left.{ }_{3} \mathrm{OD}\right): \delta 8.12\left(\mathrm{~d}, 1 \mathrm{H}, J_{5,6}=7.4 \mathrm{~Hz}, \mathrm{H}-6\right), 7.99-7.52(\mathrm{~m}, 6 \mathrm{H}, \mathrm{Bz}$ and $\mathrm{H}-5), 5.62\left(\mathrm{~d}, 1 \mathrm{H}, J_{1^{\prime}, 2^{\prime}}=8.9 \mathrm{~Hz}, \mathrm{H}-1^{\prime}\right), 4.34-4.22\left(\mathrm{~m}, 3 \mathrm{H}, \mathrm{H}-3^{\prime}\right.$, $\left.\mathrm{H}-4^{\prime}, \mathrm{H}-5 \mathrm{a}^{\prime}\right), 4.08$ (dd, $\left.1 \mathrm{H}, J_{4^{\prime}, 5 \mathrm{~b}^{\prime}}=2.4 \mathrm{~Hz}, J_{5 \mathrm{a}^{\prime}, 5 \mathrm{~b}^{\prime}}=13.6 \mathrm{~Hz}, \mathrm{H}-5 \mathrm{~b}^{\prime}\right)$, $3.86\left(\mathrm{dd}, 1 \mathrm{H}, J_{2^{\prime}, 3^{\prime}}=8.8 \mathrm{~Hz}, \mathrm{H}-2^{\prime}\right), 1.57,1.38\left(2 \mathrm{~s}, 6 \mathrm{H}, 2 \mathrm{CH}_{3}\right)$; ESI-MS $(\mathrm{m} / z) 388.36\left[\mathrm{M}+\mathrm{H}^{+}\right]$; Anal. Calcd for $\mathrm{C}_{19} \mathrm{H}_{21} \mathrm{~N}_{3} \mathrm{O}_{6}$ : C 58.91, H 5.46, N 10.85. Found: C 58.75, H 5.70, N 10.78.

4e: $\left(1.17 \mathrm{~g}, 78 \%, R_{\mathrm{f}}=0.3 \mathrm{in}\right.$ EtOAc/hexane, 8:2), m.p. $105-107{ }^{\circ} \mathrm{C}$. $[\alpha]_{\mathrm{D}}^{22}-36.0$ (c 0.500, MeOH); UV (MeOH): $\lambda_{\max } 259 \mathrm{~nm}(\epsilon 8070) ;{ }^{1} \mathrm{H}$ NMR (CD 3 OD): $\delta 9.79$ (br s, $1 \mathrm{H}, \mathrm{NH}), 7.96(\mathrm{~s}, 1 \mathrm{H}, \mathrm{H}-6), 5.56(\mathrm{~d}, 1 \mathrm{H}$, $\left.J_{1^{\prime}, 2^{\prime}}=7.5 \mathrm{~Hz}, \mathrm{H}-1^{\prime}\right), 4.36-4.28$ (m, 3H, H-3', H-4', H-5a'), 4.04 (dd, $\left.1 \mathrm{H}, J_{4^{\prime}, 5 \mathrm{~b}^{\prime}}=2.5 \mathrm{~Hz}, J_{5 \mathrm{a}^{\prime}, 5 \mathrm{~b}^{\prime}}=13.6 \mathrm{~Hz}, \mathrm{H}-5 \mathrm{~b}^{\prime}\right), 3.80\left(\mathrm{t}, 1 \mathrm{H}, J_{2^{\prime}, 3^{\prime}}=6.5 \mathrm{~Hz}\right.$, 
$\left.\mathrm{H}-2^{\prime}\right), 1.58,1.40\left(2 \mathrm{~s}, 6 \mathrm{H}, 2 \mathrm{CH}_{3}\right)$; ESI-MS $(m / z) 353.25$ [M + $\mathrm{H}^{+}$]; Anal. Calcd for $\mathrm{C}_{13} \mathrm{H}_{15} \mathrm{~F}_{3} \mathrm{~N}_{2} \mathrm{O}_{6}$ : C 44.32, H 4.29, N 7.95. Found: C 44.51, H 4.31, N 7.98.

4.5. Synthesis of 1-(2-O-acetyl-3,4-O-isopropylidene- $\alpha-D-$ arabinopyranosyl)nucleosides $\mathbf{5}(\boldsymbol{a}-\boldsymbol{e})$

\subsubsection{1-(2-O-Acetyl-3,4-O-isopropylidene- $\alpha$-D-arabinopyranosyl)} thymine (5a)

Compound $4 \mathbf{a}$ ( $1.66 \mathrm{~g}, 5.56 \mathrm{mmol}$ ) was dissolved in a mixture of pyridine $(4.6 \mathrm{~mL})$ and $\mathrm{Ac}_{2} \mathrm{O}(2.5 \mathrm{~mL})$. The reaction was carried out at room temperature for $2 \mathrm{~h}$, then was quenched with $\mathrm{MeOH}$ at $0{ }^{\circ} \mathrm{C}$ and concentrated. The residue was purified by flash chromatography (EtOAc/hexane, 9:1) to give $\mathbf{5 a}\left(1.78 \mathrm{~g}, 94 \%, R_{\mathrm{f}}=0.50\right)$ as a white solid, m.p. $227-229{ }^{\circ} \mathrm{C}$. $[\alpha]_{\mathrm{D}}^{22}-52.0\left(\mathrm{c} 0.500, \mathrm{CHCl}_{3}\right)$; UV $\left(\mathrm{CHCl}_{3}\right): \lambda_{\max } 262 \mathrm{~nm}(\epsilon 8160) ;{ }^{1} \mathrm{H} \mathrm{NMR}\left(\mathrm{CDCl}_{3}\right): \delta 8.40$ (br s, $1 \mathrm{H}$, $\mathrm{NH}), 7.23(\mathrm{~s}, 1 \mathrm{H}, \mathrm{H}-6), 5.55\left(\mathrm{~d}, 1 \mathrm{H}, J_{1^{\prime}, 2^{\prime}}=9.3 \mathrm{~Hz}, \mathrm{H}-1^{\prime}\right), 5.12(\mathrm{dd}, 1 \mathrm{H}$, $\left.J_{2^{\prime}, 3^{\prime}}=7.0 \mathrm{~Hz}, \mathrm{H}-2^{\prime}\right), 4.41-4.28$ (m, 3H, H-3', H-4', H-5a'), 3.97 (dd, $\left.1 \mathrm{H}, J_{4^{\prime}, 5 \mathrm{~b}^{\prime}}=2.3 \mathrm{~Hz}, J_{5 \mathrm{a}^{\prime}, 5 \mathrm{~b}^{\prime}}=13.8 \mathrm{~Hz}, \mathrm{H}-5 \mathrm{~b}^{\prime}\right), 2.05$ (s, 3H, OAc), $1.94(\mathrm{~s}$, $\left.3 \mathrm{H}, 5-\mathrm{CH}_{3}\right), 1.62,1.40\left(2 \mathrm{~s}, 6 \mathrm{H}, 2 \mathrm{CH}_{3}\right)$; ESI-MS $(m / z) 341.34\left[\mathrm{M}+\mathrm{H}^{+}\right]$; Anal. Calcd for $\mathrm{C}_{15} \mathrm{H}_{20} \mathrm{~N}_{2} \mathrm{O}_{7}$ : C 52.94, H 5.92, N 8.23. Found: C 53.10, H 5.78, N 8.52.

\subsubsection{1-(2-O-Acetyl-3,4-O-isopropylidene- $\alpha$-D-arabinopyranosyl)} uracil (5b), 5-fluorouracil (5c), 5-(trifluoromethyl)uracil (5e)

Uracil, 5-fluorouracil and 5-(trifluoromethyl)uracil derivatives $\mathbf{5 b}, \mathbf{5 c}$ and $\mathbf{5 e}$ were synthesized by similar procedure as described for $\mathbf{5 a}$.

5b: $\left(1.53 \mathrm{~g}, 89 \%, R_{\mathrm{f}}=0.67\right.$ in EtOAc), m.p. $232-234{ }^{\circ} \mathrm{C} .[\alpha]_{\mathrm{D}}^{22}$ -10.0 (c $\left.0.205, \mathrm{CHCl}_{3}\right)$; UV $\left(\mathrm{CHCl}_{3}\right): \lambda_{\max } 257 \mathrm{~nm}(\epsilon 5838) ;{ }^{1} \mathrm{H} \mathrm{NMR}$ $\left(\mathrm{CDCl}_{3}\right): \delta 8.52(\mathrm{br} \mathrm{s}, 1 \mathrm{H}, \mathrm{NH}), 7.44\left(\mathrm{~d}, 1 \mathrm{H}, J_{5,6}=8.2 \mathrm{~Hz}, \mathrm{H}-6\right), 5.78(\mathrm{~d}$, $1 \mathrm{H}, \mathrm{H}-5), 5.56\left(\mathrm{~d}, 1 \mathrm{H}, J_{1^{\prime}, 2^{\prime}}=9.4 \mathrm{~Hz}, \mathrm{H}-1^{\prime}\right), 5.11\left(\mathrm{dd}, 1 \mathrm{H}, J_{2^{\prime}, 3^{\prime}}=6.8 \mathrm{~Hz}\right.$, $\left.\mathrm{H}-2^{\prime}\right), 4.40\left(\mathrm{~d}, 1 \mathrm{H}, J_{5 \mathrm{a}^{\prime}, 5 \mathrm{~b}^{\prime}}=13.7 \mathrm{~Hz}, \mathrm{H}-5 \mathrm{a}^{\prime}\right), 4.32\left(\mathrm{~m}, 2 \mathrm{H}, \mathrm{H}-3^{\prime}, \mathrm{H}-4^{\prime}\right)$, 3.98 (dd, $\left.1 \mathrm{H}, J_{4^{\prime}, 5 \mathrm{~b}^{\prime}}=2.1 \mathrm{~Hz}, \mathrm{H}-5 \mathrm{~b}^{\prime}\right), 2.06$ (s, 3H, OAc), 1.60, 1.39 (2s, $\left.6 \mathrm{H}, 2 \mathrm{CH}_{3}\right)$; ESI-MS $(\mathrm{m} / \mathrm{z}) 327.32\left[\mathrm{M}+\mathrm{H}^{+}\right]$; Anal. Calcd for $\mathrm{C}_{14} \mathrm{H}_{18} \mathrm{~N}_{2} \mathrm{O}_{7}$ : C 51.53, H 5.56, N 8.59. Found: C 51.79, H 5.38, N 8.82.

5c: $\left(1.6 \mathrm{~g}, 93 \%, R_{\mathrm{f}}=0.66\right.$ in EtOAc/hexane, 9:1), m.p. $210-212{ }^{\circ} \mathrm{C}$. $[\alpha]_{\mathrm{D}}^{22}-56.0$ (c 0.505, $\left.\mathrm{CHCl}_{3}\right) ; \mathrm{UV}\left(\mathrm{CHCl}_{3}\right): \lambda_{\max } 265 \mathrm{~nm}(\epsilon 8074) ;{ }^{1} \mathrm{H}$ NMR $\left(\mathrm{CDCl}_{3}\right): \delta 8.56$ (br s, $\left.1 \mathrm{H}, \mathrm{NH}\right), 7.54\left(\mathrm{~d}, 1 \mathrm{H}, J_{\mathrm{F} 5,6}=5.9 \mathrm{~Hz}, \mathrm{H}-6\right)$, $5.55\left(\mathrm{dd}, 1 \mathrm{H}, J_{1^{\prime}, 2^{\prime}}=8.8 \mathrm{~Hz}, J_{1^{\prime}, \mathrm{F} 5}=1.4 \mathrm{~Hz}, \mathrm{H}-1^{\prime}\right), 5.03(\mathrm{dd}, 1 \mathrm{H}$, $\left.J_{2^{\prime}, 3^{\prime}}=6.8 \mathrm{~Hz}, \mathrm{H}-2^{\prime}\right), 4.40-4.28\left(\mathrm{~m}, 3 \mathrm{H}, \mathrm{H}-3^{\prime}, \mathrm{H}-4^{\prime}, \mathrm{H}-5 \mathrm{a}^{\prime}\right), 3.97$ (dd, $\left.1 \mathrm{H}, J_{4^{\prime}, 5 \mathrm{~b}^{\prime}}=2.3 \mathrm{~Hz}, J_{5 \mathrm{a}^{\prime}, 5 \mathrm{~b}^{\prime}}=13.8 \mathrm{~Hz}, \mathrm{H}-5 \mathrm{~b}^{\prime}\right), 2.07$ (s, 3H, OAc), 1.59, $1.39\left(2 \mathrm{~s}, 6 \mathrm{H}, 2 \mathrm{CH}_{3}\right)$; ESI-MS $(\mathrm{m} / \mathrm{z}) 345.31\left[\mathrm{M}+\mathrm{H}^{+}\right.$]; Anal. Calcd for $\mathrm{C}_{14} \mathrm{H}_{17} \mathrm{FN}_{2} \mathrm{O}_{7}$ : C 48.84, H 4.98, N 8.14. Found: C 48.70, H 5.09, N 8.45.

5e: $\left(1.21 \mathrm{~g}, 93 \%, R_{\mathrm{f}}=0.3\right.$ in EtOAc/hexane, $\left.4: 6\right) \cdot[\alpha]_{\mathrm{D}}^{22}-28.0(\mathrm{c}$ $\left.0.389, \mathrm{CHCl}_{3}\right) ; \mathrm{UV}\left(\mathrm{CHCl}_{3}\right): \lambda_{\max } 265 \mathrm{~nm}(\epsilon 8163) ;{ }^{1} \mathrm{H} \mathrm{NMR}\left(\mathrm{CDCl}_{3}\right)$ : $\delta 8.56$ (br s, $1 \mathrm{H}, \mathrm{NH}), 8.05$ (s, $1 \mathrm{H}, \mathrm{H}-6), 5.64\left(\mathrm{~d}, 1 \mathrm{H}, J_{1^{\prime}, 2^{\prime}}=7.7 \mathrm{~Hz}, \mathrm{H}-\right.$ $\left.1^{\prime}\right), 5.06\left(\mathrm{~m}, 1 \mathrm{H}, J_{2^{\prime}, 3^{\prime}}=6.6 \mathrm{~Hz}, \mathrm{H}-2^{\prime}\right), 4.43-4.32\left(\mathrm{~m}, 3 \mathrm{H}, \mathrm{H}-3^{\prime}, \mathrm{H}-4^{\prime}\right.$, $\left.\mathrm{H}-5 \mathrm{a}^{\prime}\right), 3.97\left(\mathrm{dd}, 1 \mathrm{H}, J_{4^{\prime}, 5 \mathrm{~b}^{\prime}}=2.31 \mathrm{~Hz}, J_{5 \mathrm{a}^{\prime}, 5 \mathrm{~b}^{\prime}}=13.6 \mathrm{~Hz}, \mathrm{H}-5 \mathrm{~b}^{\prime}\right), 2.10(\mathrm{~s}$, $3 \mathrm{H}, \mathrm{OAc}), 1.61,1.42\left(2 \mathrm{~s}, 6 \mathrm{H}, 2 \mathrm{CH}_{3}\right)$; ESI-MS $(\mathrm{m} / \mathrm{z}) 395.29\left[\mathrm{M}+\mathrm{H}^{+}\right]$; Anal. Calcd for $\mathrm{C}_{15} \mathrm{H}_{17} \mathrm{~F}_{3} \mathrm{~N}_{2} \mathrm{O}_{7}$ : C 45.69, H 4.35, N 7.10. Found: C 45.81, H 4.49, N 7.41 .

\subsubsection{1-(2-O-Acetyl-3,4-O-isopropylidene- $\alpha$-D-arabinopyranosyl)-} $N^{4}$-benzoyl cytosine $(\mathbf{5 d})$

Compound $4 \mathbf{d}$ ( $1.57 \mathrm{~g}, 4.06 \mathrm{mmol})$ was dissolved in a mixture of pyridine $(24.1 \mathrm{~mL})$ and $\mathrm{Ac}_{2} \mathrm{O}(0.36 \mathrm{~mL})$. The reaction was carried out at $4{ }^{\circ} \mathrm{C}$ overnight, then was quenched with $\mathrm{MeOH}$ at $0{ }^{\circ} \mathrm{C}$ and concentrated. It was purified by flash chromatography (EtOAc/ hexane, 8:2) (1.45 g, 83\%, $R_{\mathrm{f}}=0.53$ in EtOAc/MeOH, 9.5:0.5) and 5d was obtained as a white solid, m.p. $133-135^{\circ} \mathrm{C}$. $[\alpha]_{\mathrm{D}}^{22}-42.0$ (c 0.500 , $\left.\mathrm{CHCl}_{3}\right) ; \mathrm{UV}\left(\mathrm{CHCl}_{3}\right): \lambda_{\max } 261 \mathrm{~nm}(\epsilon 18443) ;{ }^{1} \mathrm{H} \mathrm{NMR}\left(\mathrm{CDCl}_{3}\right): \delta 7.65$ $\left(\mathrm{d}, 1 \mathrm{H}, J_{5,6}=7.3 \mathrm{~Hz}, \mathrm{H}-6\right), 7.98-7.54(\mathrm{~m}, 6 \mathrm{H}, \mathrm{Bz}$ and $\mathrm{H}-5), 5.83(\mathrm{~d}, 1 \mathrm{H}$, $\left.J_{1^{\prime}, 2^{\prime}}=8.7 \mathrm{~Hz}, \mathrm{H}-1^{\prime}\right), 5.15-5.12\left(\mathrm{~m}, 1 \mathrm{H}, J_{2^{\prime}, 3^{\prime}}=7.4 \mathrm{~Hz}, \mathrm{H}-2^{\prime}\right), 4.43-4.34$ $\left(\mathrm{m}, 3 \mathrm{H}, \mathrm{H}-3^{\prime}, \mathrm{H}-4^{\prime}, \mathrm{H}-5 \mathrm{a}^{\prime}\right), 4.04$ (dd, $1 \mathrm{H}, J_{4^{\prime}, 5 \mathrm{~b}^{\prime}}=1.3 \mathrm{~Hz}$,

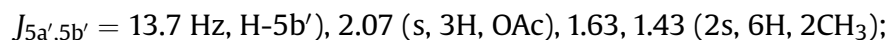
ESI-MS $(\mathrm{m} / z) 430.41\left[\mathrm{M}+\mathrm{H}^{+}\right]$; Anal. Calcd for $\mathrm{C}_{21} \mathrm{H}_{23} \mathrm{~N}_{3} \mathrm{O}_{7}$ : C 58.74, H 5.40, N 9.79. Found: C 58.89, H 5.38, N 9.85.

\subsection{Synthesis of 1-(2-O-acetyl- $\alpha$-D-arabinopyranosyl)nucleosides $\mathbf{6}$} $(\boldsymbol{a}-\boldsymbol{e})$

\subsubsection{1-(2-O-Acetyl- $\alpha$-D-arabinopyranosyl)thymine (6a)}

Compound $\mathbf{5 a}(1.78 \mathrm{~g}, 5.23 \mathrm{mmol})$ was dissolved in a mixture of $\mathrm{CH}_{2} \mathrm{Cl}_{2}(17.8 \mathrm{~mL})$ and formic acid $(17.8 \mathrm{~mL}, 90 \%)$. The solution was stirred for $3 \mathrm{~h}$ at room temperature and then was concentrated under reduced pressure. The residue was purified by flash chromatography (EtOAc) to give $\mathbf{6 a}\left(1.41 \mathrm{~g}, 90 \%, R_{\mathrm{f}}=0.12\right)$ as a white solid, m.p. $232-234{ }^{\circ} \mathrm{C}$. $[\alpha]^{22}-38.0$ (c 0.500, MeOH); UV (MeOH): $\lambda_{\max } 262 \mathrm{~nm}(\epsilon 14420) ;{ }^{1} \mathrm{H}$ NMR $\left(\mathrm{CD}_{3} \mathrm{OD}\right): \delta 7.67$ (br s, $\left.1 \mathrm{H}, \mathrm{NH}\right), 5.59$ $\left(\mathrm{d}, 1 \mathrm{H}, J_{1^{\prime}, 2^{\prime}}=9.2 \mathrm{~Hz}, \mathrm{H}-1^{\prime}\right), 5.23\left(\mathrm{t}, 1 \mathrm{H}, J_{2^{\prime}, 3^{\prime}}=9.4 \mathrm{~Hz}, \mathrm{H}-2^{\prime}\right), 4.03,3.82$ (q, AB-system, $\left.2 \mathrm{H}, J=12.6 \mathrm{~Hz}, \mathrm{H}-5^{\prime}\right), 3.97\left(\mathrm{~m}, 1 \mathrm{H}, \mathrm{H}^{\prime} 4^{\prime}\right), 3.90(\mathrm{dd}, 1 \mathrm{H}$, $\left.J_{3^{\prime}, 4^{\prime}}=3.0 \mathrm{~Hz}, \mathrm{H}-3^{\prime}\right), 2.02(\mathrm{~s}, 3 \mathrm{H}, \mathrm{OAc}), 1.90\left(\mathrm{~s}, 3 \mathrm{H}, 5-\mathrm{CH}_{3}\right)$; ESI-MS $(\mathrm{m} /$ z) $301.24\left[\mathrm{M}+\mathrm{H}^{+}\right]$; Anal. Calcd for $\mathrm{C}_{12} \mathrm{H}_{16} \mathrm{~N}_{2} \mathrm{O}_{7}$ : C 48.00, $\mathrm{H}$ 5.37, $\mathrm{N}$ 9.33. Found: C 47.72, H 5.77, N 9.64.

4.6.2. 1-(2-O-Acetyl- $\alpha$-D-arabinopyranosyl)uracil (6b), 5-fluorouracil (6c), $N^{4}$-benzoyl cytosine (6d), 5-(trifluoromethyl)uracil (6e)

Uracil, 5-fluorouracil, $N^{4}$-benzoyl cytosine and 5-(trifluoromethyl)uracil derivatives $\mathbf{6 b}, \mathbf{6 c}, \mathbf{6 d}$ and $\mathbf{6 e}$ were synthesized by similar procedure as described for $\mathbf{6 a}$.

6b: $\left(1.13 \mathrm{~g}, 84 \%, R_{\mathrm{f}}=0.14 \text { in EtOAc), m.p. } 115-117{ }^{\circ} \mathrm{C} \text {. [ } \alpha\right]_{\mathrm{D}}^{22}-40.0$ (c 0.500, MeOH); UV $(\mathrm{MeOH}): \lambda_{\max } 259 \mathrm{~nm}(\epsilon 6471) ;{ }^{1} \mathrm{H}$ NMR $\left(\mathrm{CD}_{3} \mathrm{OD}\right): \delta 7.76\left(\mathrm{~d}, 1 \mathrm{H}, J_{5,6}=8.1 \mathrm{~Hz}, \mathrm{H}-6\right), 5.70(\mathrm{~d}, 1 \mathrm{H}, \mathrm{H}-5), 5.57(\mathrm{~d}$, $\left.1 \mathrm{H}, J_{1^{\prime}, 2^{\prime}}=9.3 \mathrm{~Hz}, \mathrm{H}-1^{\prime}\right), 5.18\left(\mathrm{t}, 1 \mathrm{H}, J_{2^{\prime}, 3^{\prime}}=9.3 \mathrm{~Hz}, \mathrm{H}-2^{\prime}\right), 4.61(\mathrm{dd}, 1 \mathrm{H}$, $\left.J_{4^{\prime}, 5 \mathrm{~b}^{\prime}}=1.9 \mathrm{~Hz}, J_{5 \mathrm{a}^{\prime}, 5 \mathrm{~b}^{\prime}}=12.7 \mathrm{~Hz}, \mathrm{H}-5 \mathrm{~b}^{\prime}\right), 3.93\left(\mathrm{~m}, 1 \mathrm{H}, \mathrm{H}-4^{\prime}\right), 3.86(\mathrm{dd}$, $\left.1 \mathrm{H}, J_{3^{\prime}, 4^{\prime}}=3.3 \mathrm{~Hz}, \mathrm{H}-3^{\prime}\right), 3.79$ (d, $\left.1 \mathrm{H}, \mathrm{H}-5 \mathrm{a}^{\prime}\right), 1.99$ (s, 3H, OAc); ESI-MS $(\mathrm{m} / \mathrm{z}) 287.25\left[\mathrm{M}+\mathrm{H}^{+}\right]$; Anal. Calcd for $\mathrm{C}_{11} \mathrm{H}_{14} \mathrm{~N}_{2} \mathrm{O}_{7}$ : C 46.16, $\mathrm{H}$ 4.93, N 9.79. Found: C 46.32, H 4.75, N 9.83.

6c: $\left(1.26 \mathrm{~g}, 89 \%, R_{\mathrm{f}}=0.28\right.$ in EtOAc). $[\alpha]_{\mathrm{D}}^{22}-52.0$ (c 0.505, MeOH); $\mathrm{UV}(\mathrm{MeOH}): \lambda_{\max } 264 \mathrm{~nm}(\epsilon 8416) ;{ }^{1} \mathrm{H}$ NMR $\left(\mathrm{CD}_{3} \mathrm{OD}\right): \delta 8.05(\mathrm{~d}, 1 \mathrm{H}$ $\left.J_{\mathrm{F} 5,6}=6.3 \mathrm{~Hz}, \mathrm{H}-6\right), 5.60\left(\mathrm{~d}, 1 \mathrm{H}, J_{1^{\prime}, 2^{\prime}}=8.8 \mathrm{~Hz}, \mathrm{H}-1^{\prime}\right), 5.15(\mathrm{t}, 1 \mathrm{H}$, $\left.J_{2^{\prime}, 3^{\prime}}=8.8 \mathrm{~Hz}, \mathrm{H}-2^{\prime}\right), 4.04,3.84$ (q, AB-system, $2 \mathrm{H}, J=12.5 \mathrm{~Hz}, \mathrm{H}-5^{\prime}$ ), $3.96\left(\mathrm{~m}, 1 \mathrm{H}, \mathrm{H}-4^{\prime}\right), 3.91\left(\mathrm{dd}, 1 \mathrm{H}, J_{3^{\prime}, 4^{\prime}}=2.6 \mathrm{~Hz}, \mathrm{H}-3^{\prime}\right), 2.03(\mathrm{~s}, 3 \mathrm{H}$, OAc); ESI-MS $(m / z) 305.21\left[\mathrm{M}+\mathrm{H}^{+}\right]$; Anal. Calcd for $\mathrm{C}_{11} \mathrm{H}_{13} \mathrm{FN}_{2} \mathrm{O}_{7}$ : C 43.43, H 4.31, N 9.21. Found: C 43.51, H 4.66, N 9.43.

6d: $\left(1.04 \mathrm{~g}, 79 \%, R_{\mathrm{f}}=0.15\right.$ in EtOAc/MeOH, 9.5:0.5), m.p. $213-215{ }^{\circ} \mathrm{C}$. $[\alpha]_{\mathrm{D}}^{22}-50.0$ (c 0.500, MeOH); UV (MeOH): $\lambda_{\max } 263 \mathrm{~nm}$ ( $\epsilon$ 11313); ${ }^{1} \mathrm{H}$ NMR (CD $\left.3 \mathrm{OD}\right): \delta 8.25$ (d, $\left.1 \mathrm{H}, J_{5,6}=7.5 \mathrm{~Hz}, \mathrm{H}-6\right)$, 7.98-7.51 ( $\mathrm{m}, 6 \mathrm{H}, \mathrm{Bz}$ and $\mathrm{H}-5), 5.80\left(\mathrm{~d}, 1 \mathrm{H}, J_{1^{\prime}, 2^{\prime}}=9.2 \mathrm{~Hz}, \mathrm{H}-1^{\prime}\right), 5.21$ $\left(\mathrm{t}, 1 \mathrm{H}, J_{2^{\prime}, 3^{\prime}}=9.2 \mathrm{~Hz}, \mathrm{H}-2^{\prime}\right), 4.06\left(\mathrm{dd}, 1 \mathrm{H}, J_{4^{\prime}, 5 \mathrm{~b}^{\prime}}=1.8 \mathrm{~Hz}\right.$, $\left.J_{5 \mathrm{a}^{\prime}, 5 \mathrm{~b}^{\prime}}=12.7 \mathrm{~Hz}, \mathrm{H}-5 \mathrm{~b}^{\prime}\right), 3.97\left(\mathrm{~m}, 1 \mathrm{H}, \mathrm{H}-4^{\prime}\right), 3.92(\mathrm{dd}, 1 \mathrm{H}$, $\left.J_{3^{\prime}, 4^{\prime}}=3.3 \mathrm{~Hz}, \mathrm{H}-3^{\prime}\right), 3.86\left(\mathrm{~d}, 1 \mathrm{H}, \mathrm{H}-5 \mathrm{a}^{\prime}\right), 1.96(\mathrm{~s}, 3 \mathrm{H}, \mathrm{OAc})$; ESI-MS $(m /$ z) $390.38\left[\mathrm{M}+\mathrm{H}^{+}\right]$; Anal. Calcd for $\mathrm{C}_{18} \mathrm{H}_{19} \mathrm{~N}_{3} \mathrm{O}_{7}$ : C 55.53, H 4.92, N 10.79. Found: C 55.32, H 4.75, N 10.83 .

6e: $\left(1.0 \mathrm{~g}, 95 \%, R_{\mathrm{f}}=0.28 \text { in EtOAc). [ } \alpha\right]_{\mathrm{D}}^{22}-28.0$ (c $\left.0.483, \mathrm{MeOH}\right)$; $\mathrm{UV}(\mathrm{MeOH}): \lambda_{\max } 260 \mathrm{~nm}(\epsilon 7913) ;{ }^{1} \mathrm{H}$ NMR $\left(\mathrm{CD}_{3} \mathrm{OD}\right): \delta 8.37(\mathrm{~s}, 1 \mathrm{H}$ $\mathrm{H}-6), 5.57\left(\mathrm{~d}, 1 \mathrm{H}, J_{1^{\prime}, 2^{\prime}}=9.3 \mathrm{~Hz}, \mathrm{H}-1^{\prime}\right), 5.06\left(\mathrm{t}, 1 \mathrm{H}, J_{2^{\prime}, 3^{\prime}}=9.4 \mathrm{~Hz}, \mathrm{H}-2^{\prime}\right)$, 3.99-3.75 (m, 4H, H-5', H-4', H-3'), 1.94 (s, 3H, OAc); ESI-MS $(m / z)$ 355.26 [M $\left.+\mathrm{H}^{+}\right]$; Anal. Calcd for $\mathrm{C}_{12} \mathrm{H}_{13} \mathrm{~F}_{3} \mathrm{~N}_{2} \mathrm{O}_{7}$ : C 40.69, H 3.70, $\mathrm{N}$ 7.91. Found: C 40.82, H 3.78, N 7.99.

\subsection{Synthesis of 1-(2-O-acetyl-3,4-dideoxy- $\alpha$-D-glycero-pent-3- enopyranosyl)nucleosides $7(\boldsymbol{a}-\boldsymbol{e})$}

\subsubsection{1-(2-O-Acetyl-3,4-dideoxy- $\alpha$-D-glycero-pent-3- enopyranosyl)thymine ( $7 \boldsymbol{a})$}

Imidazole (0.67 g, $9.88 \mathrm{mmol}), \mathrm{Ph}_{3} \mathrm{P}(5.18 \mathrm{~g}, 19.77 \mathrm{mmol})$ and iodoform (3.89 g, $9.88 \mathrm{mmol}$ ) were added to the suspension of $\mathbf{6 a}$ $(1.41 \mathrm{~g}, 4.71 \mathrm{mmol})$ in $40 \mathrm{~mL}$ of dry Tol/DMF (4:1). The reaction 
mixture was heated $\left(120^{\circ} \mathrm{C}\right.$, oil bath) under nitrogen for $1.5 \mathrm{~h}$, concentrated in vacuum and the residue diluted with EtOAc, washed with saturated sodium bicarbonate, sodium thiosulfate and water. The organic extract was dried over anhydrous sodium sulfate, filtered and evaporated to dryness. The residue was purified by flash chromatography (EtOAc/hexane, 6:4) yielded 7a $(0.81 \mathrm{~g}$, $65 \%, R_{\mathrm{f}}=0.68$ in EtOAc), as a colorless oil. $[\alpha]_{\mathrm{D}}^{22} 4.0\left(\mathrm{c} 0.500, \mathrm{CHCl}_{3}\right)$; $\mathrm{UV}\left(\mathrm{CHCl}_{3}\right): \lambda_{\max } 264 \mathrm{~nm}(\epsilon 8684) ;{ }^{1} \mathrm{H}$ NMR $\left(\mathrm{CDCl}_{3}\right): \delta 8.44(\mathrm{br} \mathrm{s}, 1 \mathrm{H}$, $\mathrm{NH}), 7.19(\mathrm{~s}, 1 \mathrm{H}, \mathrm{H}-6), 6.00-5.97\left(\mathrm{~m}, 1 \mathrm{H}, J_{3^{\prime}, 4^{\prime}}=10.3 \mathrm{~Hz}, \mathrm{H}-3^{\prime}\right)$, 5.79-5.75 (m, 2H, $\left.J_{4^{\prime}, 5 \mathrm{~b}^{\prime}}=2.4 \mathrm{~Hz}, \mathrm{H}-1^{\prime}, \mathrm{H}-4^{\prime}\right), 5.51(\mathrm{~m}, 1 \mathrm{H}$, $\left.J_{2^{\prime}, 3^{\prime}}=7.9 \mathrm{~Hz}, \mathrm{H}-2^{\prime}\right), 4.48-4.37\left(\mathrm{~m}, 2 \mathrm{H}, J_{5 \mathrm{a}^{\prime}, 5 \mathrm{~b}^{\prime}}=17.0 \mathrm{~Hz}, \mathrm{H}-5 \mathrm{a}^{\prime}\right.$, $\left.\mathrm{H}-5 \mathrm{~b}^{\prime}\right), 2.05$ (s, 3H, OAc), $1.94\left(\mathrm{~s}, 3 \mathrm{H}, 5-\mathrm{CH}_{3}\right)$; ESI-MS $(\mathrm{m} / \mathrm{z}) 267.26$ $\left[\mathrm{M}+\mathrm{H}^{+}\right]$; Anal. Calcd for $\mathrm{C}_{12} \mathrm{H}_{14} \mathrm{~N}_{2} \mathrm{O}_{5}$ : C 54.13, H 5.30, N 10.52 . Found: C 54.35, H 5.41, N 10.68.

\subsubsection{1-(2-O-Acetyl-3,4-dideoxy- $\alpha$-D-glycero-pent-3-enopyranosyl)} uracil (7b), 5-fluorouracil (7c), $N^{4}$-benzoyl cytosine (7d), 5-

(trifluoromethyl)uracil (7e)

Uracil, 5-fluorouracil, $N^{4}$-benzoyl cytosine and 5-(trifluoromethyl)uracil derivatives $\mathbf{7 b}, \mathbf{7 c}, \mathbf{7 d}$ and $\mathbf{7 e}$ were synthesized by similar procedure as described for $\mathbf{7 a}$.

7b: $\left(0.66 \mathrm{~g}, 66 \%, R_{\mathrm{f}}=0.68\right.$ in EtOAc). $[\alpha]_{\mathrm{D}}^{22}-4.0\left(\mathrm{c} 0.500, \mathrm{CHCl}_{3}\right)$; $\mathrm{UV}\left(\mathrm{CHCl}_{3}\right): \lambda_{\max } 258 \mathrm{~nm}(\epsilon 7583) ;{ }^{1} \mathrm{H} \mathrm{NMR}\left(\mathrm{CDCl}_{3}\right): \delta 8.41$ (br s, $1 \mathrm{H}$, $\mathrm{NH}), 7.38\left(\mathrm{~d}, 1 \mathrm{H}, J_{5,6}=8.2 \mathrm{~Hz}, \mathrm{H}-6\right), 5.99\left(\mathrm{~m}, 1 \mathrm{H}, \mathrm{H}-1^{\prime}\right), 5.78(\mathrm{~m}, 3 \mathrm{H}$, $\left.\mathrm{H}-2^{\prime}, \mathrm{H}-3^{\prime}, \mathrm{H}-4^{\prime}\right), 5.50$ (d, 1H, H-5), 4.48-4.37 (m, 2H, H-5a', H-5b'), $2.06(\mathrm{~s}, 3 \mathrm{H}, \mathrm{OAc})$; ESI-MS $(\mathrm{m} / \mathrm{z}) 253.21\left[\mathrm{M}+\mathrm{H}^{+}\right]$; Anal. Calcd for $\mathrm{C}_{11} \mathrm{H}_{12} \mathrm{~N}_{2} \mathrm{O}_{5}$ : C 52.38, H 4.80, N 11.11. Found: C 52.51, H 5.02, N 11.48.

7c: $\left(0.65 \mathrm{~g}, 56 \%, R_{\mathrm{f}}=0.8\right.$ in EtOAc). $[\alpha]_{\mathrm{D}}^{22}-10.0\left(\mathrm{c} 0.460, \mathrm{CHCl}_{3}\right)$; $\mathrm{UV}\left(\mathrm{CHCl}_{3}\right): \lambda_{\max } 266 \mathrm{~nm}(\epsilon 7726) ;{ }^{1} \mathrm{H} \mathrm{NMR}\left(\mathrm{CDCl}_{3}\right): \delta 8.71(\mathrm{br} \mathrm{s}, 1 \mathrm{H}$, $\mathrm{NH}), 7.46\left(\mathrm{~d}, 1 \mathrm{H}, J_{\mathrm{F} 5,6}=5.6 \mathrm{~Hz}, \mathrm{H}-6\right), 6.02\left(\mathrm{~d}, 1 \mathrm{H}, J_{2^{\prime}, 3^{\prime}}=9.9 \mathrm{~Hz}, \mathrm{H}-3^{\prime}\right)$, $5.77\left(\mathrm{~m}, 2 \mathrm{H}, \mathrm{H}-1^{\prime}, \mathrm{H}-4^{\prime}\right), 5.47\left(\mathrm{~d}, 1 \mathrm{H}, J_{1^{\prime}, 2^{\prime}}=6.8 \mathrm{~Hz}, \mathrm{H}-2^{\prime}\right), 4.51,4.42(\mathrm{q}$, AB-system, $\left.2 \mathrm{H}, J=17.0 \mathrm{~Hz}, \mathrm{H}-5^{\prime}\right), 2.09$ (s, 3H, OAc); ESI-MS $(m / z)$ $271.22\left[\mathrm{M}+\mathrm{H}^{+}\right]$; Anal. Calcd for $\mathrm{C}_{11} \mathrm{H}_{11} \mathrm{FN}_{2} \mathrm{O}_{5}$ : C 48.89, $\mathrm{H} 4.10, \mathrm{~N}$ 10.37. Found: C 48.72, H 4.43, N 10.44 .

7d: $\left(0.58 \mathrm{~g}, 61 \%, R_{\mathrm{f}}=0.73\right.$ in EtOAc/MeOH, 9.5:0.5). $[\alpha]_{\mathrm{D}}^{22}-12.0$ (c $\left.0.300, \mathrm{CHCl}_{3}\right) ; \mathrm{UV}\left(\mathrm{CHCl}_{3}\right): \lambda_{\max } 262 \mathrm{~nm}\left(\epsilon\right.$ 28770); ${ }^{1} \mathrm{H}$ NMR $\left(\mathrm{CDCl}_{3}\right): \delta 7.82\left(\mathrm{~d}, 1 \mathrm{H}, J_{5,6}=7.4 \mathrm{~Hz}, \mathrm{H}-6\right), 7.92-7.49(\mathrm{~m}, 6 \mathrm{H}, \mathrm{Bz}$ and $\mathrm{H}-$ 5), 6.06-5.99 (m, 2H, H-1', H-3') $5.78\left(\mathrm{dd}, 1 \mathrm{H}, J_{3^{\prime}, 4^{\prime}}=10.1 \mathrm{~Hz}\right.$, $\left.J_{4^{\prime}, 5 \mathrm{~b}^{\prime}}=1.8 \mathrm{~Hz}, \mathrm{H}-4^{\prime}\right), 5.55-5.51\left(\mathrm{~m}, 1 \mathrm{H}, \mathrm{H}-2^{\prime}\right), 4.52-4.41(\mathrm{~m}, 2 \mathrm{H}$, $\left.J_{5 \mathrm{a}^{\prime}, 5 \mathrm{~b}^{\prime}}=17.3 \mathrm{~Hz}, \mathrm{H}-5 \mathrm{a}^{\prime}, \mathrm{H}-5 \mathrm{~b}^{\prime}\right), 2.05(\mathrm{~s}, 3 \mathrm{H}, \mathrm{OAc})$; ESI-MS $(m / z)$ $356.32\left[\mathrm{M}+\mathrm{H}^{+}\right]$; Anal. Calcd for $\mathrm{C}_{18} \mathrm{H}_{17} \mathrm{~N}_{3} \mathrm{O}_{5}$ : C 60.84, $\mathrm{H} 4.82, \mathrm{~N}$ 11.83. Found: C 60.51, H 4.42, N 11.48.

7e: $\left(0.603 \mathrm{~g}, 65 \%, R_{\mathrm{f}}=0.28\right.$ in EtOAc/hexane, $\left.3: 7\right) \cdot[\alpha]_{\mathrm{D}}^{22}-16.0(\mathrm{c}$ $\left.0.633, \mathrm{CHCl}_{3}\right) ; \mathrm{UV}\left(\mathrm{CHCl}_{3}\right): \lambda_{\max } 258 \mathrm{~nm}(\epsilon 8627) ;{ }^{1} \mathrm{H} \mathrm{NMR}\left(\mathrm{CDCl}_{3}\right)$ : $\delta 8.25$ (br s, $1 \mathrm{H}, \mathrm{NH}), 7.79$ (s, $1 \mathrm{H}, \mathrm{H}-6), 5.98-5.92\left(\mathrm{~m}, 1 \mathrm{H}, \mathrm{H}-3^{\prime}\right)$, 5.72-5.68 (m, 2H, H-1' $\left.{ }^{\prime}, \mathrm{H}-4^{\prime}\right), 5.40-5.35\left(\mathrm{~m}, 1 \mathrm{H}, \mathrm{H}-2^{\prime}\right), 4.47-4.31$ $\left(\mathrm{m}, 2 \mathrm{H}, \mathrm{H}-5^{\prime}\right), 1.99$ (s, 3H, OAc); ESI-MS $(\mathrm{m} / z) 321.24\left[\mathrm{M}+\mathrm{H}^{+}\right]$; Anal. Calcd for $\mathrm{C}_{12} \mathrm{H}_{11} \mathrm{~F}_{3} \mathrm{~N}_{2} \mathrm{O}_{5}$ : C 45.01, H 3.46, N 8.75. Found: C 45.17, $\mathrm{H}$ 3.52, N 8.84.

\subsection{Synthesis of 1-(3,4-dideoxy- $\alpha$-D-glycero-pent-3-enopyranosyl) nucleosides $8(\boldsymbol{a}-\boldsymbol{e})$}

\subsubsection{1-(3,4-Dideoxy- $\alpha$-D-glycero-pent-3-enopyranosyl)thymine} (8a)

Compound 7a $(0.81 \mathrm{~g}, 3.06 \mathrm{mmol})$ was treated with ammonia/ $\mathrm{MeOH}$ (saturated at $0{ }^{\circ} \mathrm{C}, 184 \mathrm{~mL}$ ). The solution was stirred for $3 \mathrm{~h}$ at room temperature and then was concentrated under reduced pressure. Purification by flash chromatography (EtOAc) yielded 8a $\left(0.50 \mathrm{~g}, 73 \%, R_{\mathrm{f}}=0.37\right)$ as a white foam. $[\alpha]_{\mathrm{D}}^{22} 22.0\left(\mathrm{c} 0.500, \mathrm{CHCl}_{3}\right)$; $\mathrm{UV}\left(\mathrm{CHCl}_{3}\right): \lambda_{\max } 260 \mathrm{~nm}(\epsilon 7769) ;{ }^{1} \mathrm{H} \mathrm{NMR}\left(\mathrm{CD}_{3} \mathrm{OD}\right): \delta 7.76$ (br s, $1 \mathrm{H}$, $\mathrm{NH}), 7.53(\mathrm{~s}, 1 \mathrm{H}, \mathrm{H}-6), 5.92-5.81\left(\mathrm{~m}, 2 \mathrm{H}, J_{3^{\prime}, 4^{\prime}}=10.3 \mathrm{~Hz}\right.$, $\left.J_{4^{\prime}, 5 \mathrm{~b}^{\prime}}=3.0 \mathrm{~Hz}, \mathrm{H}-3^{\prime}, \mathrm{H}-4^{\prime}\right), 5.52\left(\mathrm{~d}, 1 \mathrm{H}, J_{1^{\prime}, 2^{\prime}}=8.2 \mathrm{~Hz}, \mathrm{H}-1^{\prime}\right)$, $4.44-4.29\left(\mathrm{~m}, 3 \mathrm{H}, J_{5 \mathrm{a}^{\prime}, 5 \mathrm{~b}^{\prime}}=17.5 \mathrm{~Hz}, \mathrm{H}-2^{\prime}, \mathrm{H}-5 \mathrm{a}^{\prime}, \mathrm{H}^{-5 \mathrm{~b}^{\prime}}\right), 1.91$ (s, 3H, 5-
$\left.\mathrm{CH}_{3}\right)$; ESI-MS: $(m / z) 225.23\left[\mathrm{M}+\mathrm{H}^{+}\right]$; Anal. Calcd for $\mathrm{C}_{10} \mathrm{H}_{12} \mathrm{~N}_{2} \mathrm{O}_{4}$ : C 53.57, H 5.39, N 12.49. Found: C 53.42, H 5.47, N 12.58.

\subsubsection{1-(3,4-Dideoxy- $\alpha$-D-glycero-pent-3-enopyranosyl)uracil}

$(\boldsymbol{8 b})$, 5-fluorouracil $(\mathbf{8 c})$, 5-(trifluoromethyl)uracil (8e)

Uracil, 5-fluorouracil and 5-(trifluoromethyl)uracil derivatives $\mathbf{8 b}, \mathbf{8 c}$ and $8 \mathbf{e}$ were synthesized by similar procedure as described for $8 \mathbf{a}$.

8b: $\left(0.40 \mathrm{~g}, 74 \%, R_{\mathrm{f}}=0.23\right.$ in EtOAc). $[\alpha]_{\mathrm{D}}^{22} 4.0$ (c $\left.0.454, \mathrm{MeOH}\right)$; $\mathrm{UV}(\mathrm{MeOH}): \lambda_{\max } 260 \mathrm{~nm}(\epsilon 3985) ;{ }^{1} \mathrm{H}$ NMR $\left(\mathrm{CDCl}_{3}\right): \delta 7.66(\mathrm{~d}, 1 \mathrm{H}$, $\left.J_{5,6}=8.1 \mathrm{~Hz}, \mathrm{H}-6\right), 5.89-5.87\left(\mathrm{~m}, 1 \mathrm{H}, J_{3^{\prime}, 4^{\prime}}=10.2 \mathrm{~Hz}, \mathrm{H}-3^{\prime}\right)$, $5.81-5.79\left(\mathrm{~m}, 1 \mathrm{H}, J_{4^{\prime}, 5 \mathrm{~b}^{\prime}}=3.8 \mathrm{~Hz}, \mathrm{H}-4^{\prime}\right), 5.72(\mathrm{~d}, 1 \mathrm{H}, \mathrm{H}-5), 5.50(\mathrm{~d}, 1 \mathrm{H}$, $\left.J_{1^{\prime}, 2^{\prime}}=8.1 \mathrm{~Hz}, \mathrm{H}-1^{\prime}\right), 4.40-4.36\left(\mathrm{~m}, 2 \mathrm{H}, \mathrm{H}-2^{\prime}, \mathrm{H}-5 \mathrm{a}^{\prime}\right), 4.32-4.28(\mathrm{~m}$, 1H, H-5b'); ESI-MS: $(\mathrm{m} / \mathrm{z}) 211.17\left[\mathrm{M}+\mathrm{H}^{+}\right]$; Anal. Calcd for $\mathrm{C}_{9} \mathrm{H}_{10} \mathrm{~N}_{2} \mathrm{O}_{4}$ : C 51.43, $\mathrm{H} 4.80, \mathrm{~N}$ 13.33. Found: C 51.52, H 4.67, N 13.57.

8c: $\left(0.40 \mathrm{~g}, 75 \%, R_{\mathrm{f}}=0.55\right.$ in EtOAc), m.p. $222-224^{\circ} \mathrm{C}$. $[\alpha]_{\mathrm{D}}^{22} 18.0$ (c 0.500, MeOH); UV (MeOH): $\lambda_{\max } 269 \mathrm{~nm}\left(\epsilon\right.$ 6732); ${ }^{1} \mathrm{H}$ NMR $\left(\mathrm{CDCl}_{3}\right): \delta 7.93\left(\mathrm{~d}, 1 \mathrm{H}, J_{\mathrm{F} 5,6}=6.5 \mathrm{~Hz}, \mathrm{H}-6\right), 5.91(\mathrm{dd}, 1 \mathrm{H}$, $\left.J_{3^{\prime}, 4^{\prime}}=10.9 \mathrm{~Hz}, J_{4^{\prime}, 5 \mathrm{~b}^{\prime}}=1.9 \mathrm{~Hz}, \mathrm{H}-4^{\prime}\right), 5.81\left(\mathrm{~m}, 1 \mathrm{H}, \mathrm{H}-3^{\prime}\right), 5.52(\mathrm{~d}, 1 \mathrm{H}$, $J_{1^{\prime}, 2^{\prime}}=7.9 \mathrm{~Hz}, \mathrm{H}-1^{\prime}$ ), 4.45-4.33 (m, 3H, H-2', H-5a', H-5b'); ESI-MS: $(\mathrm{m} / z) 229.16\left[\mathrm{M}+\mathrm{H}^{+}\right]$; Anal. Calcd for $\mathrm{C}_{9} \mathrm{H}_{9} \mathrm{FN}_{2} \mathrm{O}_{4}: \mathrm{C} 47.37, \mathrm{H} 3.98, \mathrm{~N}$ 12.28. Found: C 47.59, H 4.08, N 12.57.

8e: $\left(0.489 \mathrm{~g}, 95 \%, R_{\mathrm{f}}=0.25\right.$ in EtOAc/hexane, 1:1), m.p. $119-121^{\circ} \mathrm{C}$. $[\alpha]_{\mathrm{D}}^{22}-2.0$ (c $\left.0.500, \mathrm{CHCl}_{3}\right) ; \mathrm{UV}\left(\mathrm{CHCl}_{3}\right): \lambda_{\max } 260 \mathrm{~nm}(\epsilon$ 9787); ${ }^{1} \mathrm{H} \mathrm{NMR}\left(\mathrm{CDCl}_{3}\right): \delta 9.31$ (br s, $\left.1 \mathrm{H}, \mathrm{NH}\right), 7.85$ (s, 1H, H-6), 5.89 $\left(\mathrm{m}, 2 \mathrm{H}, \mathrm{H}-4^{\prime}, \mathrm{H}-3^{\prime}\right), 5.63\left(\mathrm{~d}, 1 \mathrm{H}, J_{1^{\prime}, 2^{\prime}}=7.9 \mathrm{~Hz}, \mathrm{H}-1^{\prime}\right), 4.52-4.26(\mathrm{~m}$, $\left.3 \mathrm{H}, \mathrm{H}-2^{\prime}, \mathrm{H}-5 \mathrm{a}^{\prime}, \mathrm{H}-5 \mathrm{~b}^{\prime}\right)$; ESI-MS: $(\mathrm{m} / z) 279.20\left[\mathrm{M}+\mathrm{H}^{+}\right]$; Anal. Calcd for $\mathrm{C}_{10} \mathrm{H}_{9} \mathrm{~F}_{3} \mathrm{~N}_{2} \mathrm{O}_{4}$ : C 43.18, $\mathrm{H} 3.26, \mathrm{~N}$ 10.07. Found: C 43.51, H 3.34, $\mathrm{N}$ 10.26 .

\subsubsection{1-(3,4-Dideoxy- $\alpha$-D-glycero-pent-3-enopyranosyl)- $N^{4}$ -} benzoyl cytosine $(\boldsymbol{8 d})$

$N^{4}$-benzoyl cytosine derivative $\mathbf{8 d}$ was synthesized from $7 \mathbf{d}$ by similar procedure as described for 3d. $\left(0.33 \mathrm{~g}, 66 \%, R_{\mathrm{f}}=0.36\right.$ in $\mathrm{CH}_{2} \mathrm{Cl}_{2} / \mathrm{MeOH}, 9.5: 0.5$ ), m.p. $108-110{ }^{\circ} \mathrm{C}$. $[\alpha]_{\mathrm{D}}^{22}-44.0$ (c 0.500 , $\mathrm{MeOH}) ; \mathrm{UV}(\mathrm{MeOH}): \lambda_{\max } 262 \mathrm{~nm}(\epsilon 19310) ;{ }^{1} \mathrm{H}$ NMR $\left(\mathrm{CDCl}_{3}\right): \delta 7.91$ (d, $\left.1 \mathrm{H}, J_{5,6}=7.6 \mathrm{~Hz}, \mathrm{H}-6\right), 7.97-7.50(\mathrm{~m}, 6 \mathrm{H}, \mathrm{Bz}$ and $\mathrm{H}-5), 5.93-5.85$ ( $\left.\mathrm{m}, 2 \mathrm{H}, \mathrm{H}-3^{\prime}, \mathrm{H}-4^{\prime}\right), 5.75$ (d, $\left.1 \mathrm{H}, J_{1^{\prime}, 2^{\prime}}=7.6 \mathrm{~Hz}, \mathrm{H}-1^{\prime}\right), 4.52-4.38(\mathrm{~m}$, $\left.2 \mathrm{H}, \mathrm{H}-5 \mathrm{a}^{\prime}, \mathrm{H}-5 \mathrm{~b}^{\prime}\right), 4.31-4.28\left(\mathrm{~m}, 1 \mathrm{H}, \mathrm{H}-2^{\prime}\right)$; ESI-MS: $(\mathrm{m} / \mathrm{z}) 314.28$ $\left[\mathrm{M}+\mathrm{H}^{+}\right]$; Anal. Calcd for $\mathrm{C}_{16} \mathrm{H}_{15} \mathrm{~N}_{3} \mathrm{O}_{4}$ : C 61.34, H 4.83, N 13.41 . Found: C 61.56, H 4.67, N 13.57.

4.9. Synthesis of 1-(3,4-dideoxy- $\alpha$-pent-3-enopyranosyl-2-ulose) nucleosides $\mathbf{9}(\boldsymbol{a}-\boldsymbol{e})$

\subsubsection{1-(3,4-Dideoxy- $\alpha$-pent-3-enopyranosyl-2-ulose)thymine (9a)}

A mixture of $8 \mathrm{a}(0.50 \mathrm{~g}, 2.24 \mathrm{mmol}), \operatorname{PDC}(1.01 \mathrm{~g}, 2.69 \mathrm{mmol})$ and $\mathrm{Ac}_{2} \mathrm{O}(0.63 \mathrm{~mL}, 6.72 \mathrm{mmol})$ was stirred in dry $\mathrm{CH}_{2} \mathrm{Cl}_{2}(38 \mathrm{~mL})$ for $3 \mathrm{~h}$, under nitrogen at room temperature. Purification by flash chromatography (EtOAc/hexane, 8:2) yielded pure $9 \mathbf{a}\left(0.40 \mathrm{~g}, 80 \%, R_{\mathrm{f}}=0.53\right.$ in EtOAc) as a white solid m.p. $186-188^{\circ} \mathrm{C}$. $[\alpha]_{\mathrm{D}}^{22} 6.0$ (c $\left.0.500, \mathrm{CHCl}_{3}\right)$; $\mathrm{UV}\left(\mathrm{CHCl}_{3}\right): \lambda_{\max } 260 \mathrm{~nm}(\epsilon 9409) ;{ }^{1} \mathrm{H} \mathrm{NMR}\left(\mathrm{CDCl}_{3}\right): \delta 8.67$ (br s, $1 \mathrm{H}$, $\mathrm{NH}), 7.23-7.19\left(\mathrm{~m}, 1 \mathrm{H}, J_{3^{\prime}, 4^{\prime}}=10.3 \mathrm{~Hz}, J_{4^{\prime}, 5 \mathrm{~b}^{\prime}}=2.1 \mathrm{~Hz}, \mathrm{H}-4^{\prime}\right), 6.93(\mathrm{~s}, 1 \mathrm{H}$, H-6), 6.36-6.32 (m, 1H, H-3'), 6.18 (br s, $\left.1 \mathrm{H}, \mathrm{H}-1^{\prime}\right), 4.78-4.63(\mathrm{~m}, 2 \mathrm{H}$, $\left.J_{5 \mathrm{a}^{\prime}, 5 \mathrm{~b}^{\prime}}=18.9 \mathrm{~Hz}, \mathrm{H}-5 \mathrm{a}^{\prime}, \mathrm{H}-5 \mathrm{~b}^{\prime}\right), 1.93\left(\mathrm{~s}, 3 \mathrm{H}, 5-\mathrm{CH}_{3}\right) ;{ }^{13} \mathrm{C} \mathrm{NMR}\left(\mathrm{CDCl}_{3}\right)$ : $\delta$ 13.27, 63.12, 96.39, 112.30, 130.21, 139.01, 151.21, 154.32, 160.92, 198.39; ESI-MS (m/z) 223.18 [M + $\left.\mathrm{H}^{+}\right]$; Anal. Calcd for $\mathrm{C}_{10} \mathrm{H}_{10} \mathrm{~N}_{2} \mathrm{O}_{4}$ : C 54.05, H 4.54, N 12.61. Found: C 54.22, H 4.38, N 12.71.

4.9.2. 1-(3,4-Dideoxy- $\alpha$-pent-3-enopyranosyl-2-ulose)uracil (9b), 5-fluorouracil $(\mathbf{9 c}), N^{4}$-benzoyl cytosine (9d), 5-(trifluoromethyl) uracil $(\mathbf{9 e})$

Uracil, 5-fluorouracil, $N^{4}$-benzoyl cytosine and 5-(trifluoromethyl)uracil derivatives $\mathbf{9 b}, \mathbf{9 c}, \mathbf{9 d}$ and $9 \mathbf{e}$ were synthesized by similar procedure as described for $\mathbf{9 a}$. 
9b: $\left(0.31 \mathrm{~g}, 78 \%, R_{\mathrm{f}}=0.46\right.$ in EtOAc). $[\alpha]_{\mathrm{D}}^{22}-2.0\left(\right.$ c $\left.0.500, \mathrm{CHCl}_{3}\right)$; $\mathrm{UV}\left(\mathrm{CHCl}_{3}\right): \lambda_{\max } 254 \mathrm{~nm}(\epsilon 8902) ;{ }^{1} \mathrm{H} \mathrm{NMR}\left(\mathrm{CDCl}_{3}\right): \delta 8.30(\mathrm{br} \mathrm{s}, 1 \mathrm{H}$, $\mathrm{NH}$ ), 7.23-7.18 (m, $\left.1 \mathrm{H}, J_{3^{\prime}, 4^{\prime}}=10.5 \mathrm{~Hz}, J_{4^{\prime}, 5 \mathrm{~b}^{\prime}}=2.3 \mathrm{~Hz}, \mathrm{H}-4^{\prime}\right), 7.08$ (d, $\left.1 \mathrm{H}, J_{5,6}=8.1 \mathrm{~Hz} \mathrm{H}-6\right), 6.36-6.31\left(\mathrm{~m}, 1 \mathrm{H}, \mathrm{H}-3{ }^{\prime}\right), 6.16\left(\mathrm{~s}, 1 \mathrm{H}, \mathrm{H}-1^{\prime}\right), 5.76$ (d, 1H, H-5), 4.80-4.61 (m, 2H, H-5a', H-5b'); ${ }^{13} \mathrm{C}$ NMR $\left(\mathrm{CDCl}_{3}\right)$ : $\delta$ 63.11, 93.56, 104.01, 127.93, 143.09, 148.10, 151.01, 161.99, 198.02; ESI-MS $(m / z) 209.19\left[\mathrm{M}+\mathrm{H}^{+}\right]$; Anal. Calcd for $\mathrm{C}_{9} \mathrm{H}_{8} \mathrm{~N}_{2} \mathrm{O}_{4}$ : C 51.93, $\mathrm{H}$ 3.87, N 13.46. Found: C 52.24, H 3.68, N 13.61.

9c: $\left(0.34 \mathrm{~g}, 84 \%, R_{\mathrm{f}}=0.37\right.$ in EtOAc/hexane, 7:3), m.p. $182-184{ }^{\circ} \mathrm{C} .[\alpha]_{\mathrm{D}}^{22}-8.0\left(\mathrm{c} 0.385, \mathrm{CHCl}_{3}\right) ; \mathrm{UV}\left(\mathrm{CHCl}_{3}\right): \lambda_{\max } 266 \mathrm{~nm}$ $(\epsilon 5501) ;{ }^{1} \mathrm{H} \mathrm{NMR}\left(\mathrm{CDCl}_{3}\right): \delta 8.66($ br s, $1 \mathrm{H}, \mathrm{NH}), 7.24-7.22(\mathrm{~m}, 1 \mathrm{H}$, $\left.J_{3^{\prime}, 4^{\prime}}=10.2 \mathrm{~Hz}, J_{4^{\prime}, 5 \mathrm{~b}^{\prime}}=1.4 \mathrm{~Hz}, \mathrm{H}-4^{\prime}\right), 7.18\left(\mathrm{~d}, 1 \mathrm{H}, J_{\mathrm{F} 5,6}=5.5 \mathrm{~Hz}, \mathrm{H}-6\right)$, $6.36\left(\mathrm{~d}, 1 \mathrm{H}, \mathrm{H}-3^{\prime}\right), 6.20\left(\mathrm{~s}, 1 \mathrm{H}, \mathrm{H}-1^{\prime}\right), 4.81-4.67(\mathrm{~m}, 2 \mathrm{H}$, $\left.J_{5 \mathrm{a}^{\prime}, 5 \mathrm{~b}^{\prime}}=18.8 \mathrm{~Hz}, \mathrm{H}-5 \mathrm{a}^{\prime}, \mathrm{H}-5 \mathrm{~b}^{\prime}\right) ;{ }^{13} \mathrm{C}$ NMR $\left(\mathrm{CDCl}_{3}\right): \delta 62.91,96.11$, 130.12, 130.97, 142.77, 151.52, 152.73, 163.77, 197.96; ESI-MS $(m / z)$ $227.17\left[\mathrm{M}+\mathrm{H}^{+}\right]$; Anal. Calcd for $\mathrm{C}_{9} \mathrm{H}_{7} \mathrm{FN}_{2} \mathrm{O}_{4}: \mathrm{C}$ 47.80, H 3.12, N 12.39. Found: C 47.46, H 3.43, N 12.22.

9d: $\left(0.21 \mathrm{~g}, 63 \%, R_{\mathrm{f}}=0.68\right.$ in $\left.\mathrm{CH}_{2} \mathrm{Cl}_{2} / \mathrm{MeOH}, 9.5: 0.5\right) \cdot[\alpha]_{\mathrm{D}}^{22}-12.0$ (c $\left.0.500, \mathrm{CHCl}_{3}\right)$; UV $\left(\mathrm{CHCl}_{3}\right): \lambda_{\max } 262 \mathrm{~nm}(\epsilon 24840) ;{ }^{1} \mathrm{H}$ NMR $\left(\mathrm{CDCl}_{3}\right): \delta 7.62\left(\mathrm{~d}, 1 \mathrm{H}, J_{5,6}=7.1 \mathrm{~Hz}, \mathrm{H}-6\right), 7.94-7.44(\mathrm{~m}, 6 \mathrm{H}, \mathrm{Bz}$ and $\mathrm{H}-$ 5), $7.20\left(\mathrm{~d}, 1 \mathrm{H}, J_{3^{\prime}, 4^{\prime}}=10.6 \mathrm{~Hz}, \mathrm{H}-4^{\prime}\right), 6.37-6.34\left(\mathrm{~m}, 2 \mathrm{H}, \mathrm{H}-1^{\prime}, \mathrm{H}-3^{\prime}\right)$, 4.81-4.66 (m, $\left.2 \mathrm{H}, \mathrm{H}-5 \mathrm{a}^{\prime}, \mathrm{H}-5 \mathrm{~b}^{\prime}\right) ;{ }^{13} \mathrm{C}$ NMR $\left(\mathrm{CDCl}_{3}\right): \delta$ 61.72, 62.97, 96.97, 109.37, 128.36, 129.92, 130.18, 132.11, 132.27, 133.98, 151.71, 152.17, 174.16, 198.31; ESI-MS $(m / z) 312.31\left[\mathrm{M}+\mathrm{H}^{+}\right]$; Anal. Calcd for $\mathrm{C}_{16} \mathrm{H}_{13} \mathrm{~N}_{3} \mathrm{O}_{4}$ : C 61.73, H 4.21, N 13.50. Found: C 61.44, H 4.28, N 13.71.

9e: $\left(0.289 \mathrm{~g}, 58 \%, R_{\mathrm{f}}=0.32\right.$ in $\mathrm{CH}_{2} \mathrm{Cl}_{2} / \mathrm{MeOH}$, 9.8:0.2), m.p. 189-191 ${ }^{\circ} \mathrm{C} .[\alpha]_{\mathrm{D}}^{22}-4.0\left(\mathrm{c} 0.350, \mathrm{CHCl}_{3}\right) ; \mathrm{UV}\left(\mathrm{CHCl}_{3}\right): \lambda_{\max } 260 \mathrm{~nm}$ ( $\epsilon$ 9981); ${ }^{1} \mathrm{H} \mathrm{NMR}\left(\mathrm{CDCl}_{3}\right): \delta 8.58$ (br s, $\left.1 \mathrm{H}, \mathrm{NH}\right), 7.57(\mathrm{~s}, 1 \mathrm{H}, \mathrm{H}-6)$, $7.24-7.19\left(\mathrm{~m}, 1 \mathrm{H}, J_{3^{\prime}} 4^{\prime}=10.2 \mathrm{~Hz}, \mathrm{H}-4^{\prime}\right), 6.36\left(\mathrm{~d}, 1 \mathrm{H}, \mathrm{H}-3^{\prime}\right), 6.19(\mathrm{~s}, 1 \mathrm{H}$, $\left.\mathrm{H}-1^{\prime}\right), 4.82-4.65\left(\mathrm{~m}, 2 \mathrm{H}, J_{5 \mathrm{a}^{\prime}, 5 \mathrm{~b}^{\prime}}=19.0 \mathrm{~Hz}, \mathrm{H}-5 \mathrm{a}^{\prime}, \mathrm{H}-5 \mathrm{~b}^{\prime}\right) ;{ }^{13} \mathrm{C} \mathrm{NMR}$ $\left(\mathrm{CDCl}_{3}\right): \delta 66.06,104.5,110.23,126.63,127.24,142.41,148.85,149.0$, 165.76, 192.67; ESI-MS $(\mathrm{m} / \mathrm{z}) 277.18\left[\mathrm{M}+\mathrm{H}^{+}\right.$]; Anal. Calcd for $\mathrm{C}_{10} \mathrm{H}_{7} \mathrm{~F}_{3} \mathrm{~N}_{2} \mathrm{O}_{4}$ : C 43.49, H 2.55, N 10.14. Found: C 43.62, H 2.71, N 10.33 .

4.10. Synthesis of 1-(2,3,4-trideoxy-2-methylene- $\alpha$-pent-3enopyranosyl)nucleosides $10(\boldsymbol{a}-\boldsymbol{d}, \boldsymbol{f})$

\subsubsection{1-(2,3,4-Trideoxy-2-methylene- $\alpha$-pent-3-enopyranosyl) thymine (10a)}

To a stirred suspension of $\mathrm{Ph}_{3} \mathrm{PCH}_{3} \mathrm{Br}(2.11 \mathrm{~g}, 5.91 \mathrm{mmol})$ and t-amyl alcohol $(0.71 \mathrm{~mL}, 6.45 \mathrm{mmol})$ in dry THF $(18.5 \mathrm{~mL})$ was added $\mathrm{NaH}(0.25 \mathrm{~g}, 60 \%$ in oil, $10.32 \mathrm{mmol})$ at $0{ }^{\circ} \mathrm{C}$ under nitrogen and the reaction mixture was stirred for $2 \mathrm{~h}$ at ambient temperature. To this yellow phosphorous ylide was added a solution of $\mathbf{9 a}$ $(0.40 \mathrm{~g}, 1.79 \mathrm{mmol})$ in dry THF $(1.1 \mathrm{~mL})$ dropwise, at $0{ }^{\circ} \mathrm{C}$ under nitrogen. After the mixture was stirred for $30 \mathrm{~min}$ at ambient temperature, the reaction mixture was quenched with saturated sodium bicarbonate and extracted with EtOAc. The organic layer was washed with water, dried with sodium sulfate and evaporated. The residue was purified by flash chromatography (EtOAc/hexane, $9: 1)$ to give $10 \mathrm{a}\left(0.24 \mathrm{~g}, 60 \%, R_{\mathrm{f}}=0.64\right)$, as a white foam. $[\alpha]_{\mathrm{D}}^{22} 12.0$ (c $\left.0.500, \mathrm{CHCl}_{3}\right)$; UV $\left(\mathrm{CHCl}_{3}\right): \lambda_{\max } 263 \mathrm{~nm}(\epsilon 8478) ;{ }^{1} \mathrm{H} \mathrm{NMR}\left(\mathrm{CDCl}_{3}\right)$ : $\delta 8.74(\mathrm{br} \mathrm{s}, 1 \mathrm{H}, \mathrm{NH}), 7.09(\mathrm{~s}, 1 \mathrm{H}, \mathrm{H}-6), 6.46\left(\mathrm{~s}, 1 \mathrm{H}, \mathrm{H}-1^{\prime}\right), 6.42(\mathrm{~d}, 1 \mathrm{H}$, $\left.J_{3^{\prime}, 4^{\prime}}=10.0 \mathrm{~Hz}, \mathrm{H}-4^{\prime}\right), 6.03\left(\mathrm{~d}, 1 \mathrm{H}, \mathrm{H}-3^{\prime}\right), 5.17,4.87$ (br s, $2 \mathrm{H}$, methylene), 4.51, 4.35 (q, AB-system, $2 \mathrm{H}, J=17.4 \mathrm{~Hz}, \mathrm{H}-5^{\prime}$ ) 1.94 (s, 3H, 5$\left.\mathrm{CH}_{3}\right) ;{ }^{13} \mathrm{C} \mathrm{NMR}\left(\mathrm{CDCl}_{3}\right): \delta 13.24,63.79,92.36,108.25,112.23,125.34$, 138.92, 140.32, 154.11, 154.92, 161.33; ESI-MS $(\mathrm{m} / \mathrm{z}) 221.21$ $\left[\mathrm{M}+\mathrm{H}^{+}\right]$; Anal. Calcd for $\mathrm{C}_{11} \mathrm{H}_{12} \mathrm{~N}_{2} \mathrm{O}_{3}$ : C 59.99, H 5.49, N 12.72 . Found: C 59.82, H 5.68, N 12.93.

4.10.2. 1-(2,3,4-Trideoxy-2-methylene- $\alpha$-pent-3-enopyranosyl) uracil (10b), 5-fluorouracil (10c), $N^{4}$-benzoyl cytosine (10d)

Uracil, 5-fluorouracil and $N^{4}$-benzoyl cytosine $10 \mathrm{~b}, 10 \mathrm{c}$ and $10 \mathrm{~d}$ were synthesized by similar procedure as described for $\mathbf{1 0 a}$. 10b: $\left(0.19 \mathrm{~g}, 62 \%, R_{\mathrm{f}}=0.62\right.$ in EtOAc). $[\alpha]_{\mathrm{D}}^{22}-4.0\left(\mathrm{c} 0.550, \mathrm{CHCl}_{3}\right)$; $\mathrm{UV}\left(\mathrm{CHCl}_{3}\right): \lambda_{\max } 258 \mathrm{~nm}(\epsilon 7559) ;{ }^{1} \mathrm{H}$ NMR $\left(\mathrm{CDCl}_{3}\right): \delta 8.43(\mathrm{br} \mathrm{s}, 1 \mathrm{H}$, $\mathrm{NH}$ ), 7.17 (d, 1H, $\left.J_{5,6}=8.1 \mathrm{~Hz}, \mathrm{H}-6\right), 6.38\left(\mathrm{~s}, 1 \mathrm{H}, \mathrm{H}-1^{\prime}\right), 6.33$ (d, 1H, $\left.J_{3^{\prime}, 4^{\prime}}=10.1 \mathrm{~Hz}, \mathrm{H}-4^{\prime}\right), 5.95$ (d, 1H, H-3'), 5.66 (d, 1H, H-5), 5.11, 4.81 (br s, $2 \mathrm{H}$, methylene), 4.41, 4.24 (q, AB-system, $2 \mathrm{H}, J=17.6 \mathrm{~Hz}$, $\left.\mathrm{H}-5^{\prime}\right) ;{ }^{13} \mathrm{C} \mathrm{NMR}\left(\mathrm{CDCl}_{3}\right): \delta 65.57,87.93,103.27,114.56,125.36$, 136.90, 142.07, 150.07, 151.92, 162.61; ESI-MS $(m / z) 207.19\left[\mathrm{M}+\mathrm{H}^{+}\right]$; Anal. Calcd for $\mathrm{C}_{10} \mathrm{H}_{10} \mathrm{~N}_{2} \mathrm{O}_{3}$ : C 58.25, H 4.89, N 13.59. Found: C 58.03 , H 5.08, N 13.89 .

10c: $\left(0.19 \mathrm{~g}, 56 \%, R_{\mathrm{f}}=0.76\right.$ in EtOAc/hexane, $\left.9: 1\right) \cdot[\alpha]_{\mathrm{D}}^{22}-4.0(\mathrm{c}$ $\left.0.100, \mathrm{CHCl}_{3}\right)$; UV $\left(\mathrm{CHCl}_{3}\right): \lambda_{\max } 266 \mathrm{~nm}(\epsilon 4790) ;{ }^{1} \mathrm{H} \mathrm{NMR}\left(\mathrm{CDCl}_{3}\right)$ : $\delta 8.76(\mathrm{br} \mathrm{s}, 1 \mathrm{H}, \mathrm{NH}), 5.91\left(\mathrm{~d}, 1 \mathrm{H}, J_{\mathrm{F} 5,6}=5.9 \mathrm{~Hz}, \mathrm{H}-6\right), 6.43(\mathrm{~s}, 1 \mathrm{H}$, $\left.\mathrm{H}-1^{\prime}\right), 6.39\left(\mathrm{~m}, 1 \mathrm{H}, \mathrm{H}-4^{\prime}\right), 6.03\left(\mathrm{~d}, 1 \mathrm{H}, J_{3^{\prime}, 4^{\prime}}=9.4 \mathrm{~Hz}, \mathrm{H}-3^{\prime}\right), 5.21,4.91$ (br s, $2 \mathrm{H}$, methylene), 4.48, 4.32 (q, AB-system, $2 \mathrm{H}, J=17.7 \mathrm{~Hz}, \mathrm{H}-$ $\left.5^{\prime}\right) ;{ }^{13} \mathrm{C} \mathrm{NMR}\left(\mathrm{CDCl}_{3}\right): \delta 64.52,93.72,108.98,123.36,130.14,141.99$, 143.76, 152.76, 153.01, 162.02; ESI-MS $(\mathrm{m} / z) 225.20\left[\mathrm{M}+\mathrm{H}^{+}\right]$; Anal. Calcd for $\mathrm{C}_{10} \mathrm{H}_{9} \mathrm{FN}_{2} \mathrm{O}_{3}$ : C 53.57, H 4.05, N 12.50. Found: C 53.88, H 4.28, N 12.71.

10d: $\left(0.11 \mathrm{~g}, 53 \%, R_{\mathrm{f}}=0.43\right.$ in EtOAc/hexane, 9:1). $[\alpha]_{\mathrm{D}}^{22} 96.0$ (c $\left.0.250, \mathrm{CHCl}_{3}\right) ; \mathrm{UV}\left(\mathrm{CHCl}_{3}\right): \lambda_{\max } 266 \mathrm{~nm}(\epsilon 3988) ;{ }^{1} \mathrm{H}$ NMR $\left(\mathrm{CD}_{3} \mathrm{OD}\right)$ : $\delta 7.92\left(\mathrm{~d}, 1 \mathrm{H}, J_{5,6}=7.2 \mathrm{~Hz}, \mathrm{H}-6\right), 7.69-7.45(\mathrm{~m}, 6 \mathrm{H}, \mathrm{Bz}$ and $\mathrm{H}-5), 6.66(\mathrm{~s}$, $\left.1 \mathrm{H}, \mathrm{H}-1^{\prime}\right), 6.43\left(\mathrm{~m}, 1 \mathrm{H}, J_{3^{\prime}, 4^{\prime}}=10.2 \mathrm{~Hz}, \mathrm{H}-4^{\prime}\right), 6.03$ (d, 1H, H-3'), 5.17, 4.83 (br s, $2 \mathrm{H}$, methylene), 4.50, 4.32 (q, AB-system, $2 \mathrm{H}, J=17.7 \mathrm{~Hz}$, $\left.\mathrm{H}-5^{\prime}\right) ;{ }^{13} \mathrm{C}$ NMR $\left(\mathrm{CD}_{3} \mathrm{OD}\right): \delta 61.27,63.08,92.17,111.16,113.22,127.72$, 129.39, 130.01, 130.99, 132.16, 134.23, 142.15, 152.11, 153.77, 173.48; ESI-MS $(m / z) 310.33\left[\mathrm{M}+\mathrm{H}^{+}\right]$; Anal. Calcd for $\mathrm{C}_{17} \mathrm{H}_{15} \mathrm{~N}_{3} \mathrm{O}_{3}: \mathrm{C} 66.01, \mathrm{H}$ 4.89, N 13.58. Found: C 66.24, H 4.68, N 13.61.

\subsubsection{1-(2,3,4-Trideoxy-2-methylene- $\alpha$-pent-3-enopyranosyl) cytosine (10f)}

Cytosine derivative $10 \mathrm{f}$ was synthesized from 10d by the similar procedure as described for 3a. It was purified by flash chromatography (EtOAc/MeOH, 9:1) $\left(0.44 \mathrm{~g}, 61 \%, R_{\mathrm{f}}=0.11\right)$. $[\alpha]_{\mathrm{D}}^{22} 2.0$ (c 0.289 , $\mathrm{MeOH}) ; \mathrm{UV}(\mathrm{MeOH}): \lambda_{\max } 277 \mathrm{~nm}(\epsilon 1689) ;{ }^{1} \mathrm{H}$ NMR $\left(\mathrm{CD}_{3} \mathrm{OD}\right): \delta 7.53$ $\left(\mathrm{d}, 1 \mathrm{H}, J_{5,6}=7.3 \mathrm{~Hz}, \mathrm{H}-6\right), 7.29(\mathrm{~d}, 1 \mathrm{H}, \mathrm{H}-5), 6.44(\mathrm{~d}, 1 \mathrm{H}$, $\left.J_{3^{\prime}, 4^{\prime}}=10.3 \mathrm{~Hz}, \mathrm{H}-4^{\prime}\right), 6.33\left(\mathrm{~s}, 1 \mathrm{H}, \mathrm{H}-1^{\prime}\right), 6.06\left(\mathrm{~d}, 1 \mathrm{H}, \mathrm{H}-3^{\prime}\right), 5.10,4.67$ (br s, 2H, methylene), 4.35, 4.18 (q, AB-system, $2 \mathrm{H}, J=17.7 \mathrm{~Hz}, \mathrm{H}-$ $\left.5^{\prime}\right) ;{ }^{13} \mathrm{C}$ NMR $\left(\mathrm{CD}_{3} \mathrm{OD}\right): \delta$ 63.71, 63.99, 93.18, 110.31, 112.74, 128.10, 130.31, 140.15, 152.32, 153.96; ESI-MS $(\mathrm{m} / \mathrm{z}) 206.22\left[\mathrm{M}+\mathrm{H}^{+}\right]$; Anal. Calcd for $\mathrm{C}_{10} \mathrm{H}_{11} \mathrm{~N}_{3} \mathrm{O}_{2}$ : C 58.53, $\mathrm{H} \mathrm{5.40,N} \mathrm{20.48.} \mathrm{Found:} \mathrm{C} 58.71, \mathrm{H}$ 5.59, N 20.59.

\subsection{Synthesis of 1-(3,4-O-isopropylidene- $\alpha$-D-erythro- pentopyranosyl-2-ulose)nucleosides $\mathbf{1 1}(\boldsymbol{a}-\mathbf{d})$}

\subsubsection{1-(3,4-O-Isopropylidene- $\alpha$-D-erythro-pentopyranosyl-2- ulose)thymine (11a)}

A mixture of $4 \mathrm{a}(1.20 \mathrm{~g}, 4.02 \mathrm{mmol}), \mathrm{PDC}(1.81 \mathrm{~g}, 4.82 \mathrm{mmol})$ and $\mathrm{Ac}_{2} \mathrm{O}$ (1.14 mL, $12.06 \mathrm{mmol}$ ) was stirred in $67 \mathrm{~mL}$ of dry $\mathrm{CH}_{2} \mathrm{Cl}_{2}$ for $1 \mathrm{~h}$ under nitrogen at room temperature and was concentrated in vacuum. Purification by flash chromatography (EtOAc/hexane, 8:2) yielded pure 11a $\left(0.99 \mathrm{~g}, 83 \%, R_{\mathrm{f}}=0.36\right.$ in EtOAc/hexane, $\left.9: 1\right)$ as a white foam. $[\alpha]_{\mathrm{D}}^{22}-12.0\left(\mathrm{c} 0.500, \mathrm{CHCl}_{3}\right) ; \mathrm{UV}\left(\mathrm{CHCl}_{3}\right): \lambda_{\max } 262 \mathrm{~nm}$ $(\epsilon 4948) ;{ }^{1} \mathrm{H} \mathrm{NMR}\left(\mathrm{CDCl}_{3}\right): \delta 8.62($ br s, $1 \mathrm{H}, \mathrm{NH}), 6.97(\mathrm{~s}, 1 \mathrm{H}, \mathrm{H}-6)$, $6.15\left(\mathrm{~s}, 1 \mathrm{H}, \mathrm{H}-1^{\prime}\right), 4.73-4.67\left(\mathrm{~m}, 2 \mathrm{H}, J_{3^{\prime}} 4^{\prime}=5.5 \mathrm{~Hz}, \mathrm{H}-3^{\prime}, \mathrm{H}-4^{\prime}\right), 4.49$ $\left(\mathrm{d}, 1 \mathrm{H}, J_{5 \mathrm{a}^{\prime}, 5 \mathrm{~b}^{\prime}}=13.6 \mathrm{~Hz}, \mathrm{H}-5 \mathrm{a}^{\prime}\right), 4.25\left(\mathrm{dd}, 1 \mathrm{H}, J_{4^{\prime}, 5 \mathrm{~b}^{\prime}}=1.7 \mathrm{~Hz}, \mathrm{H}-5 \mathrm{~b}^{\prime}\right)$, $1.94\left(\mathrm{~s}, 3 \mathrm{H}, 5-\mathrm{CH}_{3}\right), 1.53,1.45\left(2 \mathrm{~s}, 6 \mathrm{H}, 2 \mathrm{CH}_{3}\right)$; ESI-MS $(\mathrm{m} / \mathrm{z}) 297.26$ $\left[\mathrm{M}+\mathrm{H}^{+}\right]$; Anal. Calcd for $\mathrm{C}_{13} \mathrm{H}_{16} \mathrm{~N}_{2} \mathrm{O}_{6}$ : C 52.70, H 5.44, N 9.46. Found: C 52.92, H 5.78, N 9.61.

4.11.2. 1-(3,4-O-Isopropylidene- $\alpha$-D-erythro-pentopyranosyl-2ulose)uracil (11b), 5-fluorouracil (11c), $N^{4}$-benzoyl cytosine (11d)

Uracil, 5-fluorouracil and $N^{4}$-benzoyl cytosine derivatives $\mathbf{1 1 b}$, 11c and 11d were synthesized by similar procedure as described for 11a. 
11b: $\left(0.99 \mathrm{~g}, 79 \%, R_{\mathrm{f}}=0.42\right.$ in EtOAc). $[\alpha]_{\mathrm{D}}^{22}-4.0\left(\mathrm{c} 0.298, \mathrm{CHCl}_{3}\right)$; $\mathrm{UV}\left(\mathrm{CHCl}_{3}\right): \lambda_{\max } 257 \mathrm{~nm}(\epsilon 8850) ;{ }^{1} \mathrm{H} \mathrm{NMR}\left(\mathrm{CDCl}_{3}\right): \delta 9.02(\mathrm{br} \mathrm{s}, 1 \mathrm{H}$, $\mathrm{NH}), 7.15\left(\mathrm{~d}, 1 \mathrm{H}, J_{5,6}=8.1 \mathrm{~Hz}, \mathrm{H}-6\right), 6.16\left(\mathrm{~s}, 1 \mathrm{H}, \mathrm{H}-1^{\prime}\right), 5.79(\mathrm{~d}, 1 \mathrm{H}, \mathrm{H}-$ 5), $4.74\left(\mathrm{~d}, 1 \mathrm{H}, J_{3^{\prime}, 4^{\prime}}=5.6 \mathrm{~Hz}, \mathrm{H}-3^{\prime}\right), 4.67\left(\mathrm{~d}, 1 \mathrm{H}, \mathrm{H}-4^{\prime}\right), 4.49(\mathrm{~d}, 1 \mathrm{H}$, $\left.J_{5 \mathrm{a}^{\prime}, 5 \mathrm{~b}^{\prime}}=13.7 \mathrm{~Hz}, \mathrm{H}-5 \mathrm{a}^{\prime}\right), 4.26\left(\mathrm{dd}, 1 \mathrm{H}, J_{4^{\prime}, 5 \mathrm{~b}^{\prime}}=1.0 \mathrm{~Hz}, \mathrm{H}-5 \mathrm{~b}^{\prime}\right), 1.49$, $1.44\left(2 \mathrm{~s}, 6 \mathrm{H}, 2 \mathrm{CH}_{3}\right)$; ESI-MS $(\mathrm{m} / \mathrm{z}) 283.22\left[\mathrm{M}+\mathrm{H}^{+}\right]$; Anal. Calcd for $\mathrm{C}_{12} \mathrm{H}_{14} \mathrm{~N}_{2} \mathrm{O}_{6}$ : C 51.06, H 5.00, N 9.93. Found: C 51.38, H 5.11, N 9.68.

11c: $\left(1.12 \mathrm{~g}, 85 \%, R_{\mathrm{f}}=0.36\right.$ in EtOAc/hexane, 9:1), m.p. $146-148{ }^{\circ} \mathrm{C} .[\alpha]_{\mathrm{D}}^{22} 16.0\left(\mathrm{c} 0.500, \mathrm{CHCl}_{3}\right) ; \mathrm{UV}\left(\mathrm{CHCl}_{3}\right): \lambda_{\max } 265 \mathrm{~nm}$ $\left(\epsilon\right.$ 2354); ${ }^{1} \mathrm{H}$ NMR $\left(\mathrm{CDCl}_{3}\right): \delta 8.47(\mathrm{~s}, 1 \mathrm{H}, \mathrm{H}-6), 6.11\left(\mathrm{~s}, 1 \mathrm{H}, \mathrm{H}-1^{\prime}\right)$, 4.73-4.69 (m, 2H, $\left.J_{3^{\prime}, 4^{\prime}}=5.6 \mathrm{~Hz}, \mathrm{H}-3^{\prime}, \mathrm{H}-4^{\prime}\right), 4.52(\mathrm{~d}, 1 \mathrm{H}$, $\left.J_{5 \mathrm{a}^{\prime}, 5 \mathrm{~b}^{\prime}}=13.7 \mathrm{~Hz}, \mathrm{H}-5 \mathrm{a}^{\prime}\right), 4.26\left(\mathrm{dd}, 1 \mathrm{H}, J_{4^{\prime}, 5 \mathrm{~b}^{\prime}}=1.2 \mathrm{~Hz}, \mathrm{H}-5 \mathrm{~b}^{\prime}\right), 1.53$ and $1.46\left(2 \mathrm{~s}, 6 \mathrm{H}, 2 \mathrm{CH}_{3}\right)$; ESI-MS $(\mathrm{m} / \mathrm{z}) 301.25\left[\mathrm{M}+\mathrm{H}^{+}\right]$; Anal. Calcd for $\mathrm{C}_{12} \mathrm{H}_{13} \mathrm{FN}_{2} \mathrm{O}_{6}$ : C 48.00, H 4.36, N 9.33. Found: C 48.38, H 4.08, N 9.12.

11d: $\left(1.3 \mathrm{~g}, 83 \%, R_{\mathrm{f}}=0.43\right.$ in EtOAc/MeOH, 9.5:0.5). $[\alpha]_{\mathrm{D}}^{22}-36.0(\mathrm{c}$ $\left.0.250, \mathrm{CHCl}_{3}\right) ; \mathrm{UV}\left(\mathrm{CHCl}_{3}\right): \lambda_{\max } 261 \mathrm{~nm}(\epsilon 17661) ;{ }^{1} \mathrm{H} \mathrm{NMR}\left(\mathrm{CDCl}_{3}\right)$ : $\delta 7.97\left(\mathrm{~d}, 1 \mathrm{H}, J_{5,6}=7.3 \mathrm{~Hz}, \mathrm{H}-6\right), 7.72-7.50(\mathrm{~m}, 6 \mathrm{H}, \mathrm{Bz}$ and $\mathrm{H}-5), 6.40$ (s, $\left.1 \mathrm{H}, \mathrm{H}-1^{\prime}\right), 4.88\left(\mathrm{~d}, 1 \mathrm{H}, J_{3^{\prime}, 4^{\prime}}=4.7 \mathrm{~Hz}, \mathrm{H}-3^{\prime}\right), 4.70$ (d, $\left.1 \mathrm{H}, \mathrm{H}-4^{\prime}\right), 4.51$, 4.38 (q, AB-system, $\left.2 \mathrm{H}, J=13.4 \mathrm{~Hz}, \mathrm{H}-5^{\prime}\right), 1.47,1.43\left(2 \mathrm{~s}, 6 \mathrm{H}, 2 \mathrm{CH}_{3}\right)$; ESI-MS $(m / z) 386.39\left[\mathrm{M}+\mathrm{H}^{+}\right]$; Anal. Calcd for $\mathrm{C}_{19} \mathrm{H}_{19} \mathrm{~N}_{3} \mathrm{O}_{6}$ : C 59.22, H 4.97, N 10.90. Found: C 59.38, H 5.05, N 10.88.

\subsection{Synthesis of 1-(2-deoxy-3,4-O-isopropylidene-2-methylene- $\alpha$-D-erythro-pentopyranosyl)nucleosides 12(a-d)}

\subsubsection{1-(2-Deoxy-3,4-O-isopropylidene-2-methylene- $\alpha$-D-erythro- pentopyranosyl)thymine (12a)}

To a stirred suspension of $\mathrm{Ph}_{3} \mathrm{PCH}_{3} \mathrm{Br}(3.94 \mathrm{~g}, 11.02 \mathrm{mmol})$ and $t$-amyl alcohol ( $1.32 \mathrm{~mL}, 12.02 \mathrm{mmol})$ in dry THF ( $34 \mathrm{~mL})$ was added $\mathrm{NaH}(0.46 \mathrm{~g}, 60 \%$ in oil, $19.23 \mathrm{mmol})$ at $0{ }^{\circ} \mathrm{C}$ under nitrogen and the reaction mixture was stirred for $2 \mathrm{~h}$ at ambient temperature. To this yellow phosphorous ylide was added a solution of 11a $(0.99 \mathrm{~g}$, $3.34 \mathrm{mmol})$ in dry THF $(5 \mathrm{~mL})$ dropwise, at $0{ }^{\circ} \mathrm{C}$ under nitrogen. After the mixture was stirred for $30 \mathrm{~min}$ at ambient temperature, the reaction mixture was quenched with saturated sodium bicarbonate and extracted with EtOAc. The organic layer was washed with water, dried with sodium sulfate and evaporated. The residue was purified by flash chromatography (EtOAc/hexane, 1:1) to give 12a $\left(0.57 \mathrm{~g}, 58 \%, R_{\mathrm{f}}=0.3\right)$, as a white solid, m.p. $110-112{ }^{\circ} \mathrm{C}$. $[\alpha]_{\mathrm{D}}^{22}$ -20.0 (c $\left.0.500, \mathrm{CHCl}_{3}\right)$; UV $\left(\mathrm{CHCl}_{3}\right): \lambda_{\max } 264 \mathrm{~nm}(\epsilon 9276) ;{ }^{1} \mathrm{H} \mathrm{NMR}$ $\left(\mathrm{CDCl}_{3}\right): \delta 8.27$ (br s, $\left.1 \mathrm{H}, \mathrm{NH}\right), 7.81(\mathrm{~s}, 1 \mathrm{H}, \mathrm{H}-6), 6.47\left(\mathrm{~s}, 1 \mathrm{H}, \mathrm{H}-1^{\prime}\right)$, 5.66, 5.50 (br s, $2 \mathrm{H}$, methylene), $4.86\left(\mathrm{~d}, 1 \mathrm{H}, J_{3^{\prime}} 4^{\prime}=7.4 \mathrm{~Hz}, \mathrm{H}-3^{\prime}\right), 4.35$ $\left(\mathrm{dd}, 1 \mathrm{H}, J_{4^{\prime}, 5 \mathrm{~b}^{\prime}}=1.7 \mathrm{~Hz}, \mathrm{H}-4^{\prime}\right), 3.98\left(\mathrm{~d}, 1 \mathrm{H}, J_{5 \mathrm{a}^{\prime}, 5 \mathrm{~b}^{\prime}}=13.5 \mathrm{~Hz}, \mathrm{H}-5 \mathrm{a}^{\prime}\right)$, 3.58 (dd, $\left.1 \mathrm{H}, \mathrm{H}-5 \mathrm{~b}^{\prime}\right), 1.92$ (s, 3H, 5- $\left.\mathrm{CH}_{3}\right), 1.61,1.44\left(2 \mathrm{~s}, 6 \mathrm{H}, 2 \mathrm{CH}_{3}\right)$; ESI-MS $(m / z) 295.32\left[\mathrm{M}+\mathrm{H}^{+}\right]$; Anal. Calcd for $\mathrm{C}_{14} \mathrm{H}_{18} \mathrm{~N}_{2} \mathrm{O}_{5}$ : C 57.13, H 6.16, N 9.52. Found: C 57.40, H 6.42, N 9.43.

\subsubsection{1-(2-Deoxy-3,4-O-isopropylidene-2-methylene- $\alpha-D$ -} erythro-pentopyranosyl)uracil (12b), 5-fluorouracil (12c), $\mathrm{N}^{4}$ benzoyl cytosine (12d)

Uracil, 5-fluorouracil and $N^{4}$-benzoyl cytosine derivatives $\mathbf{1 2 b}$, $\mathbf{1 2 c}$ and $12 \mathrm{~d}$ were synthesized by similar procedure as described for 12a.

12b: $\left(0.64 \mathrm{~g}, 65 \%, R_{\mathrm{f}}=0.6\right.$ in EtOAc), m.p. $213-215{ }^{\circ} \mathrm{C} .[\alpha]_{\mathrm{D}}^{22}$ -28.0 (c $\left.0.600, \mathrm{CHCl}_{3}\right)$; UV $\left(\mathrm{CHCl}_{3}\right): \lambda_{\max } 259 \mathrm{~nm}(\epsilon 5157) ;{ }^{1} \mathrm{H} \mathrm{NMR}$ $\left(\mathrm{CDCl}_{3}\right): \delta 8.51(\mathrm{br} \mathrm{s}, 1 \mathrm{H}, \mathrm{NH}), 7.92\left(\mathrm{~d}, 1 \mathrm{H}, J_{5,6}=8.2 \mathrm{~Hz}, \mathrm{H}-6\right), 6.46(\mathrm{~s}$, $1 \mathrm{H}, \mathrm{H}-1^{\prime}$ ), 5.72 (d, 1H, H-5), 5.67, 5.49 (br s, 2H, methylene), 4.85 (d, $\left.1 \mathrm{H}, J_{3^{\prime}, 4^{\prime}}=7.3 \mathrm{~Hz}, \mathrm{H}-3^{\prime}\right), 4.35\left(\mathrm{dd}, 1 \mathrm{H}, J_{4^{\prime}, 5 \mathrm{~b}^{\prime}}=2.3 \mathrm{~Hz}, \mathrm{H}-4^{\prime}\right), 3.97(\mathrm{~d}$, $\left.1 \mathrm{H}, J_{5 \mathrm{a}^{\prime}, 5 \mathrm{~b}^{\prime}}=13.4 \mathrm{~Hz}, \mathrm{H}-5 \mathrm{a}^{\prime}\right), 3.58\left(\mathrm{dd}, 1 \mathrm{H}, \mathrm{H}-5 \mathrm{~b}^{\prime}\right), 1.56,1.42(2 \mathrm{~s}, 6 \mathrm{H}$, $\left.2 \mathrm{CH}_{3}\right)$; ESI-MS $(\mathrm{m} / z) 281.29\left[\mathrm{M}+\mathrm{H}^{+}\right]$; Anal. Calcd for $\mathrm{C}_{13} \mathrm{H}_{16} \mathrm{~N}_{2} \mathrm{O}_{5}$ : C 55.71, H 5.75, N 9.99. Found: C 56.02, H 5.93, N 9.85.

12c: $\left(0.65 \mathrm{~g}, 58 \%, R_{\mathrm{f}}=0.71\right.$ in EtOAc/hexane, $\left.9: 1\right) \cdot[\alpha]_{\mathrm{D}}^{22}-20.0$ (c $\left.0.500, \mathrm{CHCl}_{3}\right) ; \mathrm{UV}\left(\mathrm{CHCl}_{3}\right): \lambda_{\max } 265 \mathrm{~nm}(\epsilon 8347) ;{ }^{1} \mathrm{H} \mathrm{NMR}\left(\mathrm{CDCl}_{3}\right)$ : $\delta 8.81$ (br s, $1 \mathrm{H}, \mathrm{NH}), 8.18$ (d, 1H, $\left.J_{\mathrm{F} 5,6}=6.5 \mathrm{~Hz}, \mathrm{H}-6\right), 6.49(\mathrm{~s}, 1 \mathrm{H}, \mathrm{H}-$ $1^{\prime}$ ), 5.71, 5.58 (br s, $2 \mathrm{H}$, methylene), $4.87\left(\mathrm{~d}, 1 \mathrm{H}, J_{3^{\prime}} 4^{\prime}=7.4 \mathrm{~Hz}, \mathrm{H}-3^{\prime}\right)$, $4.37\left(\mathrm{dd}, 1 \mathrm{H}, J_{4^{\prime}, 5 \mathrm{~b}^{\prime}}=1.9 \mathrm{~Hz}, \mathrm{H}-4^{\prime}\right), 3.98\left(\mathrm{~d}, 1 \mathrm{H}, J_{5 \mathrm{a}^{\prime}, 5 \mathrm{~b}^{\prime}}=13.4 \mathrm{~Hz}\right.$, H-5a' $), 3.56$ (dd, $\left.1 \mathrm{H}, \mathrm{H}-5 \mathrm{~b}^{\prime}\right), 1.64,1.45\left(2 \mathrm{~s}, 6 \mathrm{H}, 2 \mathrm{CH}_{3}\right)$; ESI-MS $(\mathrm{m} / \mathrm{z})$ 299.25 [M $\left.+\mathrm{H}^{+}\right]$; Anal. Calcd for $\mathrm{C}_{13} \mathrm{H}_{15} \mathrm{FN}_{2} \mathrm{O}_{5}$ : C 52.35, H 5.07, N 9.39. Found: C 52.11, H 5.21, N 9.55.

12d: $\left(0.63 \mathrm{~g}, 49 \%, R_{\mathrm{f}}=0.42\right.$ in EtOAc). $[\alpha]_{\mathrm{D}}^{22}-34.0$ (с 0.500 , $\left.\mathrm{CHCl}_{3}\right)$; UV $\left(\mathrm{CHCl}_{3}\right): \lambda_{\max } 261 \mathrm{~nm}(\epsilon 21256) ;{ }^{1} \mathrm{H} \mathrm{NMR}\left(\mathrm{CDCl}_{3}\right): \delta 7.92$ $\left(\mathrm{d}, 1 \mathrm{H}, J_{5,6}=7.9 \mathrm{~Hz}, \mathrm{H}-6\right), 7.91-7.63(\mathrm{~m}, 6 \mathrm{H}, \mathrm{Bz}$ and $\mathrm{H}-5), 6.67(\mathrm{~s}, 1 \mathrm{H}$, $\mathrm{H}-1^{\prime}$ ), 5.64, 5.58 (br s, 2H, methylene), 4.85 (d, $1 \mathrm{H}, J_{3^{\prime}, 4^{\prime}}=7.2 \mathrm{~Hz}, \mathrm{H}-$ $\left.3^{\prime}\right), 4.37\left(\mathrm{dd}, 1 \mathrm{H}, J_{4^{\prime}, 5 \mathrm{~b}^{\prime}}=2.3 \mathrm{~Hz}, \mathrm{H}-4^{\prime}\right), 4.03\left(\mathrm{~d}, 1 \mathrm{H}, J_{5 \mathrm{a}^{\prime}, 5 \mathrm{~b}^{\prime}}=13.4 \mathrm{~Hz}\right.$, H-5a'), 3.66 (dd, $\left.1 \mathrm{H}, \mathrm{H}-5 \mathrm{~b}^{\prime}\right), 1.59,1.43\left(2 \mathrm{~s}, 6 \mathrm{H}, 2 \mathrm{CH}_{3}\right)$; ESI-MS $(\mathrm{m} / z)$ $384.41\left[\mathrm{M}+\mathrm{H}^{+}\right]$; Anal. Calcd for $\mathrm{C}_{20} \mathrm{H}_{21} \mathrm{~N}_{3} \mathrm{O}_{5}$ : C 62.65, H 5.52, N 10.96. Found: C 62.72, H 5.63, N 10.89.

\subsection{Synthesis of 1-(2-deoxy-2-methylene- $\alpha$-D-erythro- pentopyranosyl)nucleosides $\mathbf{1 3}(\boldsymbol{a}-\mathbf{c})$}

\subsubsection{1-(2-Deoxy-2-methylene- $\alpha$-D-erythro-pentopyranosyl) thymine (13a)}

Compound 12a $(0.57 \mathrm{~g}, 1.94 \mathrm{mmol})$ was dissolved in a mixture of $\mathrm{CH}_{2} \mathrm{Cl}_{2}(6.9 \mathrm{~mL})$ and formic acid $(6.9 \mathrm{~mL}, 90 \%)$. The solution was stirred for $3 \mathrm{~h}$ at room temperature and then was concentrated under reduced pressure. The residue was purified by flash chromatography (EtOAc/hexane, 9:1) to give 13a $\left(0.43 \mathrm{~g}, 87 \%, R_{\mathrm{f}}=0.14\right)$ as a white foam. $[\alpha]_{\mathrm{D}}^{22}-2.0$ (c $\left.0.500, \mathrm{MeOH}\right) ; \mathrm{UV}(\mathrm{MeOH}): \lambda_{\max }$ $262 \mathrm{~nm}\left(\epsilon\right.$ 8524); ${ }^{1} \mathrm{H}$ NMR $\left(\mathrm{CDCl}_{3}\right): \delta 7.69(\mathrm{~s}, 1 \mathrm{H}, \mathrm{H}-6), 6.16(\mathrm{~s}, 1 \mathrm{H}, \mathrm{H}-$ $1^{\prime}$ ), 5.47, 4.83 (br s, $2 \mathrm{H}$, methylene), $4.41\left(\mathrm{~m}, 1 \mathrm{H}, \mathrm{H}-4^{\prime}\right), 4.06-4.04$ $\left(\mathrm{m}, 2 \mathrm{H}, J_{5 \mathrm{a}^{\prime}, 5 \mathrm{~b}^{\prime}}=12.5 \mathrm{~Hz}, \mathrm{H}-5 \mathrm{a}^{\prime}, \mathrm{H}-5 \mathrm{~b}^{\prime}\right), 3.92\left(\mathrm{~d}, 1 \mathrm{H}, J_{2^{\prime}, 3^{\prime}}=5.1 \mathrm{~Hz}, \mathrm{H}-\right.$ $\left.3^{\prime}\right), 1.91\left(\mathrm{~s}, 3 \mathrm{H}, 5-\mathrm{CH}_{3}\right) ;{ }^{13} \mathrm{C} \mathrm{NMR}\left(\mathrm{CDCl}_{3}\right): \delta 13.23,65.78,67.82,76.38$, 83.16, 112.11, 113.42, 139.43, 153.12, 154.01, 161.94; ESI-MS $(\mathrm{m} / \mathrm{z})$ 255.26 [M + $\left.\mathrm{H}^{+}\right]$; Anal. Calcd for $\mathrm{C}_{11} \mathrm{H}_{14} \mathrm{~N}_{2} \mathrm{O}_{5}$ : C 51.97, H 5.55, N 11.02. Found: C 52.23, H 5.76, N 10.88 .

\subsubsection{1-(2-Deoxy-2-methylene- $\alpha$-D-erythro-pentopyranosyl) uracil (13b), 5-fluorouracil (13c)}

Uracil and 5-fluorouracil derivatives $\mathbf{1 3 b}$ and $\mathbf{1 3 c}$ were synthesized by similar procedure as described for 13a.

13b: $\left(0.46 \mathrm{~g}, 85 \%, R_{\mathrm{f}}=0.15\right.$ in EtOAc/hexane, $\left.9: 1\right) \cdot[\alpha]_{\mathrm{D}}^{22}-8.0$ (c 0.300, $\mathrm{MeOH}) ; \mathrm{UV}(\mathrm{MeOH}): \lambda_{\max } 259 \mathrm{~nm}(\epsilon 8241) ;{ }^{1} \mathrm{H} \mathrm{NMR}\left(\mathrm{CDCl}_{3}\right): \delta 7.75$ (d, $\left.1 \mathrm{H}, J_{5,6}=8.1 \mathrm{~Hz}, \mathrm{H}-6\right), 6.14\left(\mathrm{~s}, 1 \mathrm{H}, \mathrm{H}-1^{\prime}\right), 5.73(\mathrm{~d}, 1 \mathrm{H}, \mathrm{H}-5), 5.43,4.81$ (br s, $2 \mathrm{H}$, methylene), $4.38\left(\mathrm{~m}, 1 \mathrm{H}, \mathrm{H}-4^{\prime}\right), 4.02\left(\mathrm{dd}, 1 \mathrm{H}, J_{4^{\prime}, 5 \mathrm{~b}^{\prime}}=2.3 \mathrm{~Hz}\right.$, $\left.J_{5 \mathrm{a}^{\prime}, 5 \mathrm{~b}^{\prime}}=12.6 \mathrm{~Hz}, \mathrm{H}-5 \mathrm{~b}^{\prime}\right), 3.91\left(\mathrm{~d}, 1 \mathrm{H}, \mathrm{H}-5 \mathrm{a}^{\prime}\right), 3.88\left(\mathrm{br} \mathrm{s}, 1 \mathrm{H}, \mathrm{H}-3^{\prime}\right) ;{ }^{13} \mathrm{CNMR}$ $\left(\mathrm{CDCl}_{3}\right): \delta 62.85,70.29,75.37,86.22,103.59,117.29,139.98,151.27$, 152.02, 162.90; ESI-MS $(\mathrm{m} / \mathrm{z}) 241.22\left[\mathrm{M}+\mathrm{H}^{+}\right]$; Anal. Calcd for $\mathrm{C}_{10} \mathrm{H}_{12} \mathrm{~N}_{2} \mathrm{O}_{5}$ : C 50.00, H 5.04, N 11.66. Found: C 50.36, H 5.22, N 11.43.

13c: $\left(0.5 \mathrm{~g}, 89 \%, R_{\mathrm{f}}=0.14\right.$ in EtOAc/hexane, 9:1), m.p. $182-184{ }^{\circ} \mathrm{C}$. $[\alpha]_{\mathrm{D}}^{22}-8.0$ (c 0.500, MeOH); UV (MeOH): $\lambda_{\max } 265 \mathrm{~nm}$ $(\epsilon 1407) ;{ }^{1} \mathrm{H} \mathrm{NMR}\left(\mathrm{CDCl}_{3}\right): \delta 8.04\left(\mathrm{~d}, 1 \mathrm{H}, J_{\mathrm{F} 5,6}=6.7 \mathrm{~Hz}, \mathrm{H}-6\right), 6.16(\mathrm{~s}$, $\left.1 \mathrm{H}, \mathrm{H}-1^{\prime}\right), 5.49,4.92$ (br s, 2H, methylene), 4.41 (m, 1H, H-4'), 4.05 $\left(\mathrm{dd}, 1 \mathrm{H}, J_{4^{\prime}, 5 \mathrm{~b}^{\prime}}=2.0 \mathrm{~Hz}, J_{5 \mathrm{a}^{\prime}, 5 \mathrm{~b}^{\prime}}=12.6 \mathrm{~Hz}, \mathrm{H}-5 \mathrm{~b}^{\prime}\right), 3.95\left(\mathrm{~d}, 1 \mathrm{H}, \mathrm{H}-5 \mathrm{a}^{\prime}\right)$, 3.91 (br s, $\left.1 \mathrm{H}, \mathrm{H}-3^{\prime}\right) ;{ }^{13} \mathrm{C}$ NMR $\left(\mathrm{CDCl}_{3}\right): \delta 66.03,67.98,75.89,84.02$, 113.58, 132.93, 141.39, 153.12, 153.97, 160.07; ESI-MS $(\mathrm{m} / \mathrm{z}) 259.22$ $\left[\mathrm{M}+\mathrm{H}^{+}\right]$; Anal. Calcd for $\mathrm{C}_{10} \mathrm{H}_{11} \mathrm{FN}_{2} \mathrm{O}_{5}$ : C 46.52, H 4.29, N 10.85 . Found: C 46.43, H 4.20, N 10.78.

\subsection{Synthesis of 1-(2,3,4-trideoxy-2-methylene- $\alpha$-pent-3- enopyranosyl)nucleosides $\mathbf{1 0}(\boldsymbol{a}-\boldsymbol{c})$}

\subsubsection{1-(2,3,4-Trideoxy-2-methylene- $\alpha$-pent-3-enopyranosyl) thymine (10a)}

$\mathrm{Ph}_{3} \mathrm{P}$ (1.33 g, $\left.5.07 \mathrm{mmol}\right)$, iodine (0.64 g, $\left.2.53 \mathrm{mmol}\right)$, and imidazole $(0.17 \mathrm{~g}, 2.53 \mathrm{mmol})$ were added to the suspension of $13 \mathrm{a}(0.43 \mathrm{~g}$, $1.69 \mathrm{mmol})$ in $47 \mathrm{~mL}$ of dry Tol/DMF (4:1). The reaction mixture was heated $\left(80^{\circ} \mathrm{C}\right.$, oil bath $)$ under nitrogen for $15 \mathrm{~min}$ and concentrated in vacuum. The residue was purified by flash chromatography (EtOAc/ hexane, 9:1) yielded $10 a(0.21 \mathrm{~g}, 57 \%)$, as a white foam. 
4.14.2. 1-(2,3,4-Trideoxy-2-methylene- $\alpha$-pent-3-enopyranosyl) uracil (10b), 5-fluorouracil (10c)

Uracil and 5-fluorouracil derivatives $10 \mathbf{b}$ and 10c were synthesized by similar procedure as described for 10a.

10b: $(0.21 \mathrm{~g}, 53 \%)$.

10c: $(0.23 \mathrm{~g}, 53 \%)$.

\subsection{Methods for measurement of biological activity}

\subsubsection{Cytostatic assays}

Murine leukemia L1210, murine mammary carcinoma FM3A, human T-lymphocyte CEM and human cervix carcinoma (HeLa) cells were suspended at 300,000-500,000 cells/mL of culture medium, and $100 \mu \mathrm{L}$ of a cell suspension was added to $100 \mu \mathrm{L}$ of an appropriate dilution of the test compounds in wells of 96-well microtiter plates. After incubation at $37^{\circ} \mathrm{C}$ for two (L1210, FM3A) or three (CEM, HeLa) days, the cell number was determined using a Coulter counter. The $\mathrm{IC}_{50}$ was defined as the compound concentration required to inhibit cell proliferation by $50 \%$.

The cytostatic activity $\left(\mathrm{IC}_{50}\right)$ of the 5 -FU derivatives and $5-\mathrm{FU}$, 5-Furd and 5-FdUrd was also examined in the presence of $20 \mu \mathrm{M}$ dThd, $20 \mu \mathrm{M}$ dUrd, $500 \mu \mathrm{M}$ Urd and $500 \mu \mathrm{M}$ uracil. The appropriate fixed concentration of the natural nucleosides/nucleobase were added to the serial concentrations of $9 c, 10 c$ and $13 c$ and the fluorinated control compounds before exposure to the tumor cells (either L1210 or HeLa).

\subsubsection{Antimetabolic assays}

Compounds 9c, 10c and 13c and 5-FU were evaluated for their capacity to inhibit the incorporation of $\left[\mathrm{CH}_{3}-{ }^{3} \mathrm{H}\right] \mathrm{dTh}$ and $\left[6-{ }^{3} \mathrm{H}\right]$ dUrd into DNA, or $\left[5-{ }^{3} \mathrm{H}\right]$ Urd into RNA. The assays were carried out in 96-well microtiter plates. To each well were added $10^{5} \mathrm{~L} 1210$ cells, $0.25 \mu \mathrm{Ci}$ of [methyl $\left.-{ }^{3} \mathrm{H}\right] \mathrm{dThd}, 1 \mu \mathrm{Ci}$ of $\left[6-{ }^{3} \mathrm{H}\right] \mathrm{dUrd}$ or $0.25 \mu \mathrm{Ci}$ $\left[5-{ }^{3} \mathrm{H}\right]$ Urd (all derived from Amersham, U.K.), and a given amount of the test compound was added to each well. The cells were allowed to proliferate for $20 \mathrm{~h}$ at $37{ }^{\circ} \mathrm{C}$ in a humidified, $\mathrm{CO}_{2-}$ controlled atmosphere. At the end of this incubation period, the contents of the wells $(200 \mu \mathrm{L})$ were transferred onto $25-\mathrm{mm}$ glass fiber filters (type A/E, Gelman Instrument Company, Ann Arbor, Mich.), mounted on a Millipore 3025 sampling manifold apparatus. The filters were washed twice with cold $\mathrm{NaCl} / \mathrm{Pi}$ (phosphate buffered saline), twice with cold $10 \%$ trichloroacetic acid, twice with cold $5 \%$ trichloroacetic acid, once with cold ethanol, and once with cold ether and assayed for radioactivity in the presence of a scintillant (Optiphase 'Hisafe' 2, Perking Elmer, Waltham, MA).

The activity of TS in intact L1210 cells was measured by evaluation of tritium release from $\left[5-{ }^{3} \mathrm{H}\right] \mathrm{dUMP}$ (formed in the cells from $\left[5-{ }^{3} \mathrm{H}\right] \mathrm{dUrd}$ or $\left.\left[5-{ }^{3} \mathrm{H}\right] \mathrm{dCyd}\right)$ in the reaction catalyzed by TS. Cell cultures ( $0.5 \mathrm{~mL}$ DMEM culture medium) were prepared containing $\sim 5 \times 10^{6}$ L1210 cells and appropriate amounts of the test compounds (9c, 10c and 13c, 5-FU and 5-FdUrd). After $15 \mathrm{~min}, 4$ or $24 \mathrm{~h}$ preincubation at $37{ }^{\circ} \mathrm{C}, 1 \mu \mathrm{Ci}$ of $\left[5-{ }^{3} \mathrm{H}\right] \mathrm{dUrd}$ (radiospecificity: $15.9 \mathrm{Ci} / \mathrm{mmol}$ ) (Moravek Biochemicals, Brea, CA) or $1 \mu \mathrm{Ci}$ of $\left[5-{ }^{3} \mathrm{H}\right]$ dCyd (radiospecificity: $22 \mathrm{Ci} / \mathrm{mmol}$ ) (Moravek Biochemicals) was added to the cell cultures. After $30 \mathrm{~min}$ incubation, $100 \mu \mathrm{L}$ of the cell suspensions were withdrawn and added to a cold suspension of $500 \mu \mathrm{L}$ activated charcoal (VWR, Haasrode, Belgium) $(100 \mathrm{mg} / \mathrm{mL}$ in TCA 5\%). After $10 \mathrm{~min}$, the suspension was centrifuged at $13,000 \mathrm{rpm}$ for $10 \mathrm{~min}$, after which the radioactivity in $400 \mu \mathrm{L}$ supernatant was counted in a liquid scintillator using OptiPhase HiSafe (Perkin Elmer, Waldham, MA).

\subsubsection{Thymidine and uridine phosphorylase assays}

The conversion of dThd to thymine, Urd to uracil and potentially 9c, 10c and 13c to 5-FU by human recombinant TP [47] and uridine phosphorylase type 1 [48] (kindly provided by Dr. T.P. Roosild, Las Vegas, Nevada, USA) was measured by high pressure liquid chromatography (HPLC) analysis. To determine the conversion activity, a high amount of recombinant enzyme was incubated with $100 \mu \mathrm{M}$ of dThd or 9c, 10c and $13 \mathrm{c}$ in TP-buffer $(10 \mathrm{mM}$ Tris.HCl, pH 7.6, $1 \mathrm{mM}$ EDTA, $2 \mathrm{mM} \mathrm{KH} \mathrm{PO}_{4} / \mathrm{K}_{2} \mathrm{HPO}_{4}$ and $150 \mathrm{mM} \mathrm{NaCl}$ ) or UP buffer (same as TP-buffer, but $300 \mathrm{mM} \mathrm{NaCl}$ instead of $150 \mathrm{mM}$ ). At 20, 40 and $60 \mathrm{~min}, 100 \mu \mathrm{L}$ aliquots of the reaction mixtures were withdrawn and heated at $95^{\circ} \mathrm{C}$ for 3 min to inactivate the enzyme. dThd and Urd were separated from thymine and uracil and 9c, 10c and 13c were separated from 5-FU on a reverse-phase RP-8 column (Merck, Darmstadt, Germany) and quantified by high pressure liquid chromatography (HPLC) analysis (Alliance 2690, Waters, Milford, MA). The separation was performed by a linear gradient from $98 \%$ buffer B $\left(50 \mathrm{mM} \mathrm{NaH} \mathrm{PO}_{4}\right.$ and $5 \mathrm{mM}$ heptane sulfonic acid, $\mathrm{pH} 3.2$ ), to $20 \%$ buffer $\mathrm{B}+80 \%$ acetonitrile ( $8 \mathrm{~min} 98 \%$ buffer $\mathrm{B}+2 \%$ acetonitrile; 5 min linear gradient of $98 \%$ buffer $\mathrm{B}+2 \%$ acetonitrile to $20 \%$ buffer B $+80 \%$ acetonitrile; 10 min $20 \%$ buffer $\mathrm{B}+80 \%$ acetonitrile, followed by equilibration at $98 \%$ buffer $\mathrm{B}+2 \%$ acetonitrile). Retention times for thymine and dThd were respectively 5.1 and $10.8 \mathrm{~min}$, for uracil and Urd respectively 2.1 and $2.4 \mathrm{~min}$ and for 9c, 10c, 13c and 5-FU respectively, 8.4, 11.1, 6.8 and $2.4 \mathrm{~min}$. UV/VIS-based detection was performed at $267 \mathrm{~nm}$.

\subsubsection{Antiviral assays}

The antiviral assays [except anti-human immunodeficiency virus (HIV) assays] were based on inhibition of virus-induced cytopathicity in HEL [herpes simplex virus type 1 (HSV-1), HSV-2 (G), vaccinia virus and vesicular stomatitis virus], Vero (parainfluenza-3, reovirus-1, Sindbis, Coxsackie B4, and Punta Toro virus), or HeLa (vesicular stomatitis virus, Coxsackie virus B4, and respiratory syncytial virus) cell cultures. Confluent cell cultures in microtiter 96-well plates were inoculated with 100 cell culture inhibitory dose- $50\left(\mathrm{CCID}_{50}\right)$ of virus $\left(1 \mathrm{CCID}_{50}\right.$ being the virus dose to infect $50 \%$ of the cell cultures). After a $1 \mathrm{~h}$ virus adsorption period, residual virus was removed, and the cell cultures were incubated in the presence of varying concentrations $(200,40,8, \ldots$ $\mu \mathrm{M}$ ) of the test compounds. Viral cytopathicity was recorded as soon as it reached completion in the control virus-infected cell cultures that were not treated with the test compounds. The methodology of the anti-HIV assays was as follows: human CEM $\left(\sim 3 \times 10^{5}\right.$ cells $\left./ \mathrm{cm}^{3}\right)$ cells were infected with 100 CCID $_{50}$ of HIV-1 $\left(\mathrm{III}_{\mathrm{B}}\right)$ or HIV-2(ROD)/mL and seeded in $200 \mu \mathrm{L}$ wells of a microtiter plate containing appropriate dilutions of the test compounds. After 4 days of incubation at $37{ }^{\circ} \mathrm{C}$, HIV-induced CEM giant cell formation was examined microscopically.

\section{Acknowledgments}

This work was supported in part by the Postgraduate Programmes "Biotechnology-Quality assessment in Nutrition and the Enviroment”, “Application of Molecular Biology-Molecular GeneticsMolecular Markers", Department of Biochemistry and Biotechnology, University of Thessaly. Financial support was also provided by the "Geconcerteerde Onderzoeksacties" (GOA no. 10/014) of the K.U.Leuven and the FWO (no. G-486-08). The authors are grateful to Dr. Angeliki Panagiotopoulou, technical scientist of the NMR Laboratory of NCSR "Demokritos", for obtaining the NMR spectra, and to Mrs. Lizette van Berckelaer, Leentje Persoons, Frieda De Meyer, Vickie Broeckx and Leen Ingels for dedicated technical help.

\section{References}

[1] A. Holý, Antiviral Res. 71 (2006) 248-253.

[2] R.C. Brandy, D.I. Bernstein, Antiviral Res. 61 (2004) 73-81. 
[3] D.C. Meadows, J. Gervay-Hague, Chem. Med. Chem. 1 (2006) 16-29.

[4] C. Mathé, G. Gosselin, Antiviral Res. 71 (2006) 276-281.

[5] R.F. Schinazi, B.I. Hernandez-Santiago, S.J. Hurwitz, Antiviral Res. 71 (2006) 322-334.

[6] D. Komiotis, S. Manta, E. Tsoukala, N. Tzioumaki, Curr. Med. Chem. Anti-Infect. Agents 7 (2008) 219-244.

[7] W.D. Meng, F.L. Qing, Curr. Top. Med. Chem. 6 (2006) 1499-1528.

[8] G.V. Papatheodoridis, E. Dimou, V. Papadimitropoulos, Am. J. Gastroenterol. 97 (2002) 1618-1628.

[9] I. Verheggen, A. Van Aerschot, L. Van Meervelt, J. Rozenski, L. Wiebe, R. Snoeck, G. Andrei, J. Balzarini, P. Claes, E. De Clercq, P. Herdewijn, J. Med. Chem. 38 (1995) 826-835.

[10] T. Ostrowski, B. Wroblowski, R. Busson, J. Rozenski, E. De Clercq, M.S. Bennet J.N. Champness, W.C. Summers, M.R. Sanderson, P. Herdewijn, J. Med. Chem. 41 (1998) 4343-4353.

[11] Y. Maurinsh, J. Schraml, H. De Winter, N. Blaton, O. Peeters, E. Lescrinier J. Rozenski, A. Van Aerschot, E. De Clercq, R. Busson, P. Herdewijn, J. Org. Chem. 62 (1997) 2861-2871.

[12] C. Spanou, S. Manta, D. Komiotis, A. Dervishi, D. Kouretas, Int. J. Mol. Sci. 8 (2007) 695-704.

[13] A. Haouz, V. Vanheusden, H. Munier-Lechman, M. Froeyen, P. Herdewijn, S. Van Galenbergh, M. Delarue, J. Biol. Chem. 278 (2003) 4963-4971.

[14] K. Vastmans, S. Pochet, A. Peys, L. Kerremans, A. Van Aerschot, C. Hendrix P. Marliere, P. Herdewijn, Biochemistry 39 (2000) 12757-12765.

[15] K. Vastmans, M. Froeyen, L. Kerremans, S. Pochet, P. Herdewijn, Nucleic Acids Res. 29 (2001) 3154-3163.

[16] P. Herdewijn, E. De Clercq, Bioorg. Med. Chem. Lett. 11 (2001) 1591-1597.

[17] M.J. Egron, F. Leclercq, K. Antonakis, I. Bennani-Baiti, C. Frayssinet, Carbohydr. Res. 248 (1993) 143-150.

[18] M. Alaoui, M.J. Egron, M. Bessodes, K. Antonakis, I. Chouroulinkov, Eur. J. Med. Chem. 22 (1987) 305-310.

[19] F. Leclercq, K. Antonakis, Carbohydr. Res. 263 (1994) 309-313.

[20] G.S. Bisacchi, S.T. Chao, C. Bachard, J.P. Daris, S. Innaimo, G.A. Jacobs, O. Kocy, P. Lapointe, A. Martel, Z. Merchant, W.A. Slusarchyk, J.E. Sundeen, M.G. Young, R. Colonno, R. Zahler, Bioorg. Med. Chem. Lett. 7 (1997) 127-132.

[21] S.J. Yoo, H.O. Kim, Y. Lim, J. Kim, L.S. Jeong, Bioorg. Med. Chem. 10 (2002) 215-226.

[22] P. Gunaga, M. Baba, L.S. Jeong, J. Org. Chem. 69 (2004) 3208-3211.

[23] F. Leclercq, K. Antonakis, Carbohydr. Res. 181 (1988) 217-222.

[24] S. Manta, G. Agelis, T. Botić, A. Cencič, D. Komiotis, Bioorg. Med. Chem. 15 (2007) 980-987.

[25] S. Manta, G. Agelis, T. Botić, A. Cencič, D. Komiotis, Eur. J. Med. Chem. 43 (2008) 420-428.
[26] S. Manta, E. Tsoukala, N. Tzioumaki, A. Goropevšek, R.T. Pamulapati, A. Cencič, J. Balzarini, D. Komiotis, Eur. J. Med. Chem. 44 (2009) 2696-2704

[27] S. Manta, E. Tsoukala, N. Tzioumaki, C. Kiritsis, J. Balzarini, D. Komiotis, Bioorg. Chem. 38 (2010) 48-55.

[28] S. Manta, N. Tzioumaki, E. Tsoukala, A. Panagiotopoulou, M. Pelecanou, J. Balzarini, D. Komiotis, Eur. J. Med. Chem. 44 (2009) 4764-4771.

[29] G. Agelis, N. Tzioumaki, T. Botić, A. Cencič, D. Komiotis, Bioorg. Med. Chem. 15 (2007) 5448-5456.

[30] G. Agelis, N. Tzioumaki, T. Tselios, T. Botić, A. Cencič, D. Komiotis, Eur. J. Med. Chem. 43 (2008) 1366-1375.

[31] N. Tzioumaki, E. Tsoukala, S. Manta, G. Agelis, J. Balzarini, D. Komiotis, Arch. Pharm. 342 (2009) 353-360.

[32] D.B. Longley, D.P. Harkin, P.G. Johnston, Nat. Rev. Canc. 3 (2003) 330-338.

[33] E. Tsoukala, G. Agelis, J. Dolinsek, T. Botić, A. Cencič, D. Komiotis, Bioorg. Med. Chem. 15 (2007) 3241-3247.

[34] V. Vanheusden, R. Busson, P. Herdewijn, S. Van Calenbergh, J. Org. Chem. 69 (2004) 4446-4453.

[35] J. Milecki, A. Földesi, A. Fischer, R.W. Adamiak, J. Chattopadhyaya, J. Labelled Compd. Rad. 44 (2001) 763-783.

[36] M. Bessodes, E. Abushanab, P.R. Panzica, J. Chem. Soc. Chem. Commun. (1981) 26-28.

[37] B.K. Chun, G.Y. Song, C.K. Chu, J. Org. Chem. 66 (2001) 4852-4858.

[38] M. Bessodes, D. Komiotis, K. Antonakis, Tetrahedron Lett. 27 (1986) 579-580

[39] J. Herscovici, K. Antonakis, J. Chem. Soc. Chem. Commun. 12 (1980) 561-564

[40] L.S. Jeong, S.J. Yoo, Bioorg. Med. Chem. Lett. 8 (1998) 847-852.

[41] R. Van Rijsbergen, M.J.O. Anteunis, A. De Bruyn, J. Carbohydr. Chem. 2 (1983) 395-404.

[42] M.J. Kim, L.S. Jeong, J.H. Kim, J.H. Shin, S.Y. Chung, S.K. Lee, M.W. Chun, Nucleosides, Nucleotides Nucleic Acids 23 (2004) 715-724.

[43] P.J. Garegg, B. Samuelsson, Synthesis (1979) 469-470.

[44] Z. Liu, B. Classon, B. Samuelsson, J. Org. Chem. 55 (1990) 4273-4275.

[45] P.J. Garegg, B. Samuelsson, Synthesis (1979) 813-814.

[46] A.F. Luzzio, E.M. Menes, J. Org. Chem. 59 (1994) 7267-7272.

[47] E. De Clercq, J. Balzarini, P.F. Torrence, M.P. Mertes, C.L. Schmidt, D. Shugar, P.J. Barr, A.S. Jones, G. Verhelst, R.T. Walker, Mol. Pharmacol. 19 (1981) $321-330$.

[48] J. Balzarini, E. De Clercq, Biochim. Biophys. Acta 785 (1984) 36-45.

[49] Y. Yamada, H. Yasui, A. Goto, T. Arai, T. Ura, T. Hamaguchi, K. Muro, Y. Shimada, K. Shirao, Int. J. Clin. Oncol. 8 (2003) 374-380.

[50] A. Bronckaers, L. Aguado, A. Negri, M.J. Camarasa, J. Balzarini, M.J. Pérez-Pérez, F. Gago, S. Liekens, Biochem. Pharmacol. 78 (2009) 231-240.

[51] T.P. Roosild, S. Castronovo, M. Fabbiani, G. Pizzorno, BMC Struct. Biol. 9(2009) 14.

[52] S. Liekens, A. Bronckaers, J. Balzarini, Lancet Oncol. 10 (2009) 628-635. 